\title{
Expert Consensus for Multimodality Imaging Evaluation of Adult Patients during and after Cancer Therapy: A Report from the American Society of Echocardiography and the European Association of Cardiovascular Imaging
}

Juan Carlos Plana, MD, FASE, Chair, Maurizio Galderisi, MD, FESC, Co-Chair, Ana Barac, MD, PhD,

Michael S. Ewer, MD, JD, Bonnie Ky, MD, FASE, Marielle Scherrer-Crosbie, MD, PhD, FASE, Javier Ganame, MD, PhD, FASE, Igal A. Sebag, MD, FASE, Deborah A. Agler, RCT, RDCS, FASE, Luigi P. Badano, MD, PhD, FESC, Jose Banchs, MD, FASE, Daniela Cardinale, MD, PhD, FESC, Joseph Carver, MD, Manuel Cerqueira, MD, Jeanne M. DeCara, MD, FASE, Thor Edvardsen, MD, PhD, FESC,

Scott D. Flamm, MD, MBA, Thomas Force, MD, Brian P. Griffin, MD, Guy Jerusalem, MD, PhD, Jennifer E. Liu, MD, FASE, Andreia Magalhães, MD, Thomas Marwick, MBBS, PhD, MPH, Liza Y. Sanchez, RCS, FASE, Rosa Sicari, MD, PhD, FESC, Hector R. Villarraga, MD, FASE, and Patrizio Lancellotti, MD, PhD, FESC, Cleveland, Ohio; Naples, Padua, Milan, and Pisa, Italy; Washington, District of Columbia; Houston, Texas; Philadelphia, Pennsylvania; Boston, Massachusetts; Hamilton, Ontario and Montreal, Quebec, Canada; Chicago, Illinois; Oslo, Norway; Liege, Belgium; New York, New York; Lisbon, Portugal; Hobart, Australia; Rochester, Minnesota

(J Am Soc Echocardiogr 2014;27:911-39.)

Keywords: Chemotherapy, Doxorubicin, Trastuzumab, Left ventricular dysfunction, Three-dimensional echocardiography, Early detection, Strain, Biomarkers

From the Cleveland Clinic, Cleveland, Ohio (J.C.P., D.A.A., M.C., S.D.F., and B.P.G.); Federico II University Hospital, Naples, Italy (M.G.); Medstar Washington Hospital Center, Washington, District of Columbia (A.B.); MD Anderson Cancer Center, University of Texas, Houston, Texas (M.S.E., J.B., and L.Y.S.); the University of Pennsylvania, Philadelphia, Pennsylvania (B.K.); Massachusetts General Hospital, Boston, Massachusetts (M.S.-C.); McMaster University, Hamilton, Ontario, Canada (J.G.); Jewish General Hospital and McGill University, Montreal, Quebec, Canada (I.A.S.); the University of Padua, Padua, Italy (L.P.B.); the European Institute of Oncology, Milan, Italy (D.C.); Abramson Cancer Center at the University of Pennsylvania, Philadelphia, Pennsylvania (J.C.); University of Chicago Medicine, Chicago, Illinois (J.M.D.C); Oslo University Hospital and the University of Oslo, Oslo, Norway (T.E.); Temple University, Philadelphia, Pennsylvania (T.F.); the University of Liege, Liege, Belgium (G.J. and P.L.); Memorial Sloan-Kettering Cancer Center, New York, New York (J.E.L.); Santa Marie University Hospital, Lisbon, Portugal (A.M.); Menzies Research Institute Tasmania, Hobart, Australia (T.M.); CNR Institute of Clinical Physiology, Pisa, Italy (R.S.); and the Mayo Clinic, Rochester, Minnesota (H.R.V.).

The following authors reported no actual or potential conflicts of interest in relation to this document: Juan Carlos Plana, MD, FASE, Maurizio Galderisi, MD, FESC, Marielle Scherrer-Crosbie, MD, PhD, FASE, Javier Ganame, MD, PhD, FASE, Deborah A. Agler, RCT, RDCS, FASE, Luigi P. Badano, MD, PhD, FESC, Jose Banchs, MD, FASE, Daniela Cardinale, MD, Joseph Carver, MD, Thor Edvardsen, MD, PhD, FESC, Brian Griffin, MD, Guy Jerusalem, MD, PhD, Jennifer E. Liu, MD, FASE, Andreia Magalhães, MD, Liza Y. Sanchez, RCS, FASE, Rosa Sicari, MD, PhD, FESC, Hector R. Villarraga, MD, FASE, and Patrizio Lancellotti, MD, PhD, FESC. The following authors reported relationships with one or more commercial interests: Ana Barac, MD, received research funding and lectures honoraria from Genentech and consultancy fees from Cell Therapeutics. Manuel Cerqueira, MD, received a grant from Perceptive Informatics, Inc; consults for GE Healthcare, FluoroPharma and Astellas; and serves on the speakers bureau for Astellas. Jeanne M. DeCara, MD, served as a consultant for Epsilon Imaging and Methylgene. Michael S. Ewer, MD, JD, consults or serves as advisory board member for Roche Laboratories, Cell Therapeutics, GlaxoSmithKline, and Boehringer Ingelheim. Scott D. Flamm, MD, MBA, serves on advisory boards for Philips Healthcare, Bayer Healthcare, and TeraRecon and received institutional research support from Siemens Healthcare. Thomas Force, MD consults for GlaxoSmithKline. Bonnie Ky, MD, FASE, received an investigator-initiated award from Pfizer, Inc. Thomas Marwick, MBBS, PhD, MPH, received research funding from the National Health and Medical Research Council in Australia and the Royal Hobart Hospital Foundation, an equipment grant from Philips Medical Systems and Siemens, and a project grant from GE Medical Systems. Igal A. Sebag, MD, FASE, serves on the speakers bureau for Lantheus.

\section{Attention ASE Members:}

The ASE has gone green! Visit www.aseuniversity.org to earn free continuing medical education credit through an online activity related to this article. Certificates are available for immediate access upon successful completion of the activity. Nonmembers will need to join the ASE to access this great member benefit!

Reprint requests: American Society of Echocardiography, 2100 Gateway Centre Boulevard, Suite 310, Morrisville, NC 27560 (E-mail: ase@asecho.org).

0894-7317/ $\$ 36.00$

Copyright 2014 by the American Society of Echocardiography.

http://dx.doi.org/10.1016/j.echo.2014.07.012 
ASE $=$ American Society of Echocardiography

BNP = Brain-type natriuretic peptide

CAD $=$ Coronary artery disease

CMR = Cardiac magnetic resonance

CTRCD = Cancer therapeutics-related cardiac dysfunction

DTI = Doppler tissue imaging

$\mathbf{E A C V I}=$ European

Association of Cardiovascular Imaging

$\mathbf{E A E}=$ European Association of Echocardiography

GLS = Global longitudinal strain

HF = Heart failure

LGE = Late gadolinium enhancement

$\mathbf{L V}=$ Left ventricular

LVEF = Left ventricular ejection fraction

MUGA = Multigated blood pool imaging

NT-proBNP = N-terminal pro-B-type natriuretic peptide

$\mathbf{R V}=$ Right ventricular

STE $=$ Speckle-tracking echocardiography

3D = Three-dimensional

3DE = Three-dimensional echocardiography

Tnl = Troponin I

2D = Two-dimensional

2DE = Two-dimensional echocardiography

VEGF = Vascular endothelia growth factor

1. Troponins 924

2. Other Biomarkers 926

C. An Integrated Approach of Imaging and Biomarkers 926

D. Implications of Early Detection on Therapeutic Approaches 926

IV. Other Imaging Modalities 927

A. Radionuclide Approaches for Monitoring Chemotherapy-Induced Cardiotoxicity 927

1. MUGA 927

Cardiac Dysfunction 912

A. Definition, Classification, and Mechanisms of

Toxicity 912

1. Definition of Cancer

Therapeutics-Related

Cardiac Dysfunction

(CTRCD) 912

2. Classification by

Mechanism of

Toxicity 913

a. Type I

CTRCD 913

b. Type II

CTRCD 913

II. Echocardiographic Evaluation tion in Cancer Patients 914

A. LV Systolic Function 914

B. LV Diastolic Function 915

C. RV Function 915

D. Valvular Heart Disease 916

E. Pericardial ease 917

F. 3DE 918

G. Contrast Echocardiography 919

H. Stress Echocardiography 919

I. Other 920

III. Detection of Subclinical LV Dysfunction 920

A. Detection of Subclinical LV Dysfunction Using Imaging 920

1. LVEF as a Tool to Detect Subclinical LV Dysfunction 920

2. Diastolic Dysfunction: Early Signs and Prognostic Value 920

3. Detection of Subclinical LV Dysfunction Using DTI Velocities 922

4. Early Detection of LV Dysfunction Using

Strain and Strain

Rate 922

B. Detection of Subclinical LV Dysfunction Using Biomarkers 924
2. MUGA Compared with Other Modalities 927

B. CMR for Monitoring CTRCD 928

1. CMR in the Assessment of Cardiac Structure and Function

928

2. CMR and Echocardiography 928

3. Beyond the LVEF: Advanced CMR Assessments 929 of Cardiac Structure and Func-
C. Specific Challenges 929

V. Integrated Approach 930

A. Baseline Assessment and Monitoring 930

1. Type I Agents 930

2. Type II Agents 930

B. Detection of Subclinical LV Dysfunction 931

Notice and Disclaimer 933

References 933

\section{CANCER THERAPEUTICS-RELATED CARDIAC DYSFUNCTION}

\section{A. Definition, Classification, and Mechanisms of Toxicity}

Cardiac dysfunction resulting from exposure to cancer therapeutics was first recognized in the 1960s, with the widespread introduction of anthracyclines into the oncologic therapeutic armamentarium. Heart failure (HF) associated with anthracyclines was then recognized as an important side effect. As a result, physicians learned to limit their doses to avoid cardiac dysfunction. ${ }^{2}$ Several strategies have been used over the past decades to detect it. Two of them evolved over time to be very useful: endomyocardial biopsies and monitoring of left ventricular (LV) ejection fraction (LVEF) by cardiac imaging. Examination of endomyocardial biopsies proved to be the most sensitive and specific parameter for the identification of anthracycline-induced LV dysfunction and became the gold standard in the 1970s. However, the interest in endomyocardial biopsy has diminished over time because of the reduction in the cumulative dosages used to treat malignancies, the invasive nature of the procedure, and the remarkable progress made in noninvasive cardiac imaging. The noninvasive evaluation of LVEF has gained importance, and notwithstanding the limitations of the techniques used for its calculation, has emerged as the most widely used strategy for monitoring the changes in cardiac function, both during and after the administration of potentially cardiotoxic cancer treatment. ${ }^{3-5}$

The timing of LV dysfunction can vary among agents. In the case of anthracyclines, the damage occurs immediately after the exposure ${ }^{6}$; for others, the time frame between drug administration and detectable cardiac dysfunction appears to be more variable. Nevertheless, the heart has significant cardiac reserve, and the expression of damage in the form of alterations in systolic or diastolic parameters may not be overt until a substantial amount of cardiac reserve has been exhausted. Thus, cardiac damage may not become apparent until years or even decades after receiving the cardiotoxic treatment This is particularly applicable to adult survivors of childhood cancers.

Not all cancer treatments affect the heart in the same way. Therefore these agents cannot be viewed as a single class of drugs.

\section{Definition of Cancer Therapeutics-Related Cardiac} Dysfunction (CTRCD). Different definitions of CTRCD have been used historically. ${ }^{7}$ It is the consensus of this committee to define CTRCD as a decrease in the LVEF of $>10$ percentage points, to a value $<53 \%$ (normal reference value for two-dimensional (2D) echocardiography (2DE) (see Section II). This decrease should be confirmed by repeated cardiac imaging. The repeat study should be
Executive Summary 932 
Table 1 Characteristics of type I and II CTRCD

\begin{tabular}{|c|c|c|}
\hline & Type I & Type II \\
\hline Characteristic agent & Doxorubicin & Trastuzumab \\
\hline $\begin{array}{l}\text { Clinical course and typical response to } \\
\text { antiremodeling therapy ( } \beta \text {-blockers, ACE } \\
\text { inhibitors) }\end{array}$ & $\begin{array}{l}\text { May stabilize, but underlying damage } \\
\text { appears to be permanent and irreversible; } \\
\text { recurrence in months or years may be } \\
\text { related to sequential cardiac stress }\end{array}$ & $\begin{array}{l}\text { High likelihood of recovery (to or near } \\
\text { baseline cardiac status) in 2-4 months } \\
\text { after interruption (reversible) }\end{array}$ \\
\hline Dose effects & Cumulative, dose related & Not dose related \\
\hline Effect of rechallenge & $\begin{array}{l}\text { High probability of recurrent dysfunction that } \\
\text { is progressive; may result in intractable } \\
\text { heart failure or death }\end{array}$ & $\begin{array}{l}\text { Increasing evidence for the relative safety of } \\
\text { rechallenge (additional data needed) }\end{array}$ \\
\hline Ultrastructure & $\begin{array}{l}\text { Vacuoles; myofibrillar disarray and dropout; } \\
\text { necrosis (changes resolve over time) }\end{array}$ & $\begin{array}{l}\text { No apparent ultra structural abnormalities } \\
\text { (though not thoroughly studied) }\end{array}$ \\
\hline
\end{tabular}

$A C E$, Angiotensin-converting enzyme.

performed 2 to 3 weeks after the baseline diagnostic study showing the initial decrease in LVEF. LVEF decrease may be further categorized as symptomatic or asymptomatic, or with regard to reversibility:

- Reversible: to within 5 percentage points of baseline

- Partially reversible: improved by $\geq 10$ percentage points from the nadir but remaining $>5$ percentage points below baseline

- Irreversible: improved by $<10$ percentage points from the nadir and remain ing $>5$ percentage points below baseline

- Indeterminate: patient not available for re-evaluation

In this expert consensus document, a classification of CTRCD on the basis of the mechanisms of toxicity of the agents is used (Table 1).

2. Classification by Mechanism of Toxicity. a. Type I CTRCD. Doxorubicin is believed to cause dose-dependent cardiac dysfunction through the generation of reactive oxygen species. Recently, investigators using an animal model proposed that doxorubicin-induced CTRCD is mediated by topoisomerase-II $\beta$ in cardiomyocytes through the formation of ternary complexes (topoisomerase-II $\beta$-anthracycline-deoxyribonucleic acid). These complexes induce deoxyribonucleic acid double-strand breaks and transcriptome changes responsible for defective mitochondrial biogenesis, and reactive oxygen species formation. ${ }^{8}$ The damage caused by the anthracyclines occurs in a cumulative dose-dependent fashion. The expression of damage is related to preexisting disease, the state of cardiac reserve at the time of administration, coexisting damage, and individual variability (including genetic variability). Electron microscopy of myocardial biopsies shows varying degrees of myocyte damage: vacuolar swelling progressing to myofibrillar disarray and ultimately cell death. Once myocytes undergo cell death, they have minimal potential for replacement via regeneration. In this regard, cardiac damage at the cellular level may be deemed irreversible, although cardiac function may be preserved and compensation optimized through antiremodeling pharmacologic therapy, and/or less frequently, mechanical intervention. Agents that are associated with type I CTRCD include all of the anthracyclines (doxorubicin, epirubicin, and idarubicin) as well as mitoxantrone. These agents are now considered to have increased potential for long-term cardiac dysfunction, increased morbidity, and mortality. ${ }^{10,11}$

b. Type I/ CTRCD. A number of agents do not directly cause cell damage in a cumulative dose-dependent fashion. There is considerable evidence for this: first, the typical anthracycline-induced cell damage by electron microscopy is not seen with these agents, and second, in many instances, these agents have been continued for decades, without the progressive cardiac dysfunction that would be expected with type I agents. Finally, functional recovery of myocardial function is frequently (albeit not invariably) seen after their interruption, assuming a type I agent was not given before or at the time of therapy. ${ }^{10}$ This document uses trastuzumab as the classical example of type II CTRCD and presents evidence and consensus recommendations for cardiac evaluation of patients receiving this targeted therapy, primarily indicated for HER2-positive breast cancer (summarized in Section $\mathrm{V}$ of this document). The role of cardiac assessment and imaging in patients receiving this regimen is further complicated by the fact that type I (doxorubicin) and type II agents (trastuzumab), are often given sequentially or concurrently. Such sequential or concurrent use may increase cell death indirectly by compromising the environment of marginally compensated cells, contributing to the concern that type II agents can still result in cell death at the time of administration. We recognize that in the setting of a variety of predisposing factors, varying cumulative dosages of recognized cardiotoxic agents, and use of other agents that are known to increase oxidative stress and compromise myocyte stability, the algorithm proposed in this document cannot be based on strong clinical data.

Since the approval of trastuzumab, numerous agents have entered the therapeutic armamentarium, including the small-molecule tyrosine kinase inhibitors. It is difficult to make broad generalizations about these agents, because they often have different kinase targets. However, it appears that the most problematic are the agents that target vascular endothelial growth factor (VEGF) and VEGF receptors. These agents typically are associated with severe systemic arterial hypertension and ischemic events. The development of CTRCD in these patients may be related to transient impairment of the contractile elements within the cell or to the increased afterload on a compromised ventricle. The most concerning of this group are the nonselective agents, including sunitinib and sorafenib, because these drugs can target up to 50 different kinases, in addition to the intended target. ${ }^{12}$ Because those "off-target" kinases play important roles in the heart and vasculature, the risk for toxicity is increased. As a result of the unspecific nature and predictability of myocardial damage, it is difficult to provide general recommendations regarding how to monitor patients receiving these agents. A number of attempts have been made to unify approaches to manage these patients, all stopping short of proposing guidelines; one attempt focused on arterial hypertension $^{13}$ and the other on CTRCD. ${ }^{14}$ Careful management of comorbidities was urged in these documents. 


\section{Key Points}

- Highly effective chemotherapeutic agents may cause CTRCD.

- CTRCD has been classified as follows:

1. Type I CTRCD is characterized by anthracyclines. It is dose dependent, leads to cell apoptosis, and is therefore irreversible at the cell level. Early detection and prompt treatment may prevent LV remodeling and the progression to the HF syndrome.

2. Type II CTRCD is characterized by trastuzumab. It is not dose dependent, does not lead to apoptosis by itself, and is often reversible.

\section{ECHOCARDIOGRAPHIC EVALUATION OF CARDIAC STRUCTURE AND FUNCTION IN CANCER PATIENTS}

Echocardiography is the cornerstone in the cardiac imaging evaluation of patients in preparation for, during, and after cancer therapy, because of its wide availability, easy repeatability, versatility, lack of radiation exposure, and safety in patients with concomitant renal disease. In addition to the evaluation of LV and right ventricular (RV) dimensions, systolic and diastolic function at rest and during stress, echocardiography also allows a comprehensive evaluation of cardiac valves, the aorta, and the pericardium. ${ }^{15}$ Table 2 summarizes the recommended cardio-oncology-echocardiogram protocol.

\section{A. LV Systolic Function}

Exposure to potentially cardiotoxic chemotherapeutic agents is a wellrecognized indication for baseline and longitudinal evaluation of LV function. ${ }^{16,17}$ The most commonly used parameter for monitoring LV function with echocardiography is LVEF. Accurate calculation of LVEF should be done with the best method available in a given echocardiography lab. Consistency with regard to the method used to determine LVEF should be maintained whenever possible during treatment and surveillance after treatment. Importantly, the digital images obtained to calculate LVEF on follow-up echocardiography should be visually compared with the previous ones to minimize reader variability. As previously reported, ${ }^{18,19}$ imaging at baseline has been particularly helpful in patients with a history or clinical findings suggestive of LV systolic dysfunction (known cardiac ischemic or nonischemic insult) and those at high risk for cardiac events on the basis of traditional risk factors (age, gender, hypertension, hyperlipidemia, and family history of premature coronary artery disease [CAD]). Other imaging modalities, such as multigated blood pool imaging (MUGA) and cardiac magnetic resonance (CMR) imaging, have been used in the evaluation of LVEF. CMR is considered the reference standard for the calculation of LV volumes and LVEF. However, echocardiography is suitable for serial evaluation of LV structure and function. The incorporation of modern techniques such as myocardial contrast echocardiography, three-dimensional (3D) echocardiography (3DE), Doppler tissue imaging (DTI), and speckle-tracking echocardiography (STE), offer a prudent compromise between cost-effectiveness and clinical predictive value (discussed in detail in Sections II and III of this document). According to joint recommendations from the American Society of Echocardiography (ASE), and the European Association of Echocardiography (EAE), the method of choice for LV volumes quantitation and LVEF calculation is the modified biplane Simpson's technique (method of disks) by 2DE (Figures $1 \mathrm{a}$ and $1 \mathrm{~b}$ ). ${ }^{20}$ Historically, fractional shortening using linear measurements from M-mode echocardiography or 2DE was used as a surrogate of LVEF in the evaluation of oncologic (especially pediatric) patients.
Table 2 Recommended cardio-oncology echocardiogram protocol

Standard transthoracic echocardiography

- In accordance with ASE/EAE guidelines and IAC-Echo

2D strain imaging acquisition

- Apical three-, four-, and two-chamber views

* Acquire $\geq 3$ cardiac cycles

- Images obtained simultaneously maintaining the same 2D frame rate and imaging depth

* Frame rate between 40 and 90 frames/sec or $\geq 40 \%$ of HR

- Aortic VTI (aortic ejection time)

2D strain imaging analysis

- Quantify segmental and global strain (GLS)

- Display the segmental strain curves from apical views in a quad format

- Display the global strain in a bull's-eye plot

2D strain imaging pitfalls

- Ectopy

- Breathing translation

3D imaging acquisition

- Apical four-chamber full volume to assess LV volumes and LVEF calculation

- Single and multiple beats optimizing spatial and temporal resolution

Reporting

- Timing of echocardiography with respect to the IV infusion (number of days before or after)

- Vital signs (BP, HR)

- 3D LVEF/2D biplane Simpson's method

- GLS (echocardiography machine, software, and version used)

- In the absence of GLS, measurement of medial and lateral $s^{\prime}$ and MAPSE

- RV: TAPSE, $s^{\prime}$, FAC

$B P$, Blood pressure; FAC, fractional area change; $H R$, heart rate $I A C$-Echo, Intersocietal Accreditation Commission Echocardiography; MAPSE, mitral annular plane systolic excursion; TAPSE, tricuspid annular plane systolic excursion; RV, right ventricle; VTI, velocity-time integral.

However, this approach should be discouraged, as it takes into consideration only two LV walls (the anterior septum and inferolateral wall) for the calculation of LVEF. The common occurrence of CAD in patients with cancer, along with the observation that CTRCD due to some chemotherapeutic agents may be regional, and not necessarily global, makes necessary a calculation of LVEF using a volumetric assessment. $^{21}$ The recommendations for chamber quantification from the ASE and EAE established LVEF $\geq 55 \%$ as a normal reference range. ${ }^{20}$ New data extracted from six databases, including Asklepios, FLEMENGHO, CARDIA5 and CARDIA25, Padua 3D Echo Normal, and the Normal Reference Ranges for Echocardiography (NORRE) study, indicate that the normal LVEF using the biplane method of disks is $63 \pm 5 \%$. LVEF in the range of 53\% to $73 \%$ should be classified as normal. ${ }^{22-26}$ A revision of the current guideline incorporating these new data is being completed as of this writing. Changes in LVEF indicative of LV damage can be more appropriately identified when comparisons are made between baseline and follow-up studies. In addition, the calculation of LVEF should be combined with assessment of the wall motion score index. $^{20}$ Resting wall motion score index based on a 16-segment model of the left ventricle has been demonstrated to be a more sensitive marker of anthracycline-induced CTRCD than relying on the LVEF alone. ${ }^{27}$ 

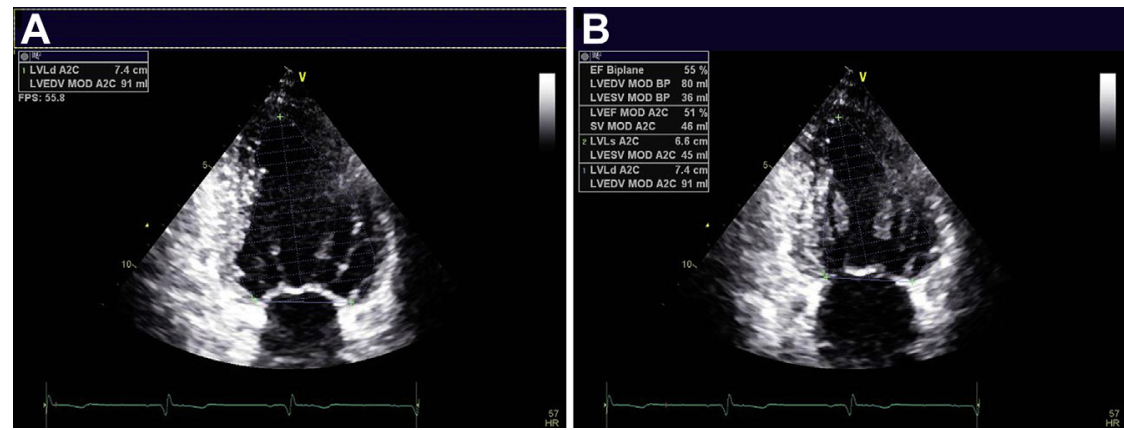

Figure 1 Calculation of LVEF using the biplane Simpson's method. (A) Apical two-chamber view obtained at end-diastole. (B) Apical two-chamber view obtained at end-systole.

Several studies have been published on cardiac monitoring to assess CTRCD, particularly with anthracyclines, the most frequent implicated agents. ${ }^{28-35}$ There has been controversy as to the definition of CTRCD by using changes in resting LVEF, occurring during or after chemotherapy. The use of different LVEF cutoffs and methods of measurement (Teichholz, Simpson's biplane, or area-length method) have compromised the ability to compare results from different studies and collect evidence-based data. ${ }^{36,37}$ Although monitoring guidelines have been proposed for several potentially cardiotoxic treatments, ${ }^{33,38-40}$ limited data are available to formulate evidence-based screening and follow-up recommendations for CTRCD. ${ }^{41}$

Although LVEF is a robust predictor of cardiac outcomes in the general population, it has low sensitivity for the detection of small changes in LV function. LVEF calculated by conventional 2DE often fails to detect small changes in LV contractility because of several factors. These factors include LV geometric assumptions, inadequate visualization of the true LV apex, lack of consideration of subtle regional wall motion abnormalities, and inherent variability of the measurement. ${ }^{42}$ It is also important to bear in mind the load dependency of this measurement. Changes in loading conditions are frequent during chemotherapy and may affect the LVEF value (volume expansion due to the intravenous administration of chemotherapy or volume contraction due to vomiting or diarrhea).

Otterstad et al. ${ }^{43}$ reported in 1997 that 2DE is capable of recognizing differences in sequential measurements of LVEF of $8.9 \%$. In a more recent study of cancer patients undergoing chemotherapy but free of HF symptoms, the upper limit of the 95\% confidence interval for longitudinal variability of 2D LVEF measurement was 9.8\% (range, 9.0\%-10.8\%). In this study, Thavendiranathan et al. ${ }^{44}$ followed the ASE recommendations for the biplane calculation of LVEF (using apical four- and two-chamber views), in contrast to the apical four- and three-chamber views used by Otterstad et al., and adjusted for intraobserver variability in their calculation of interobserver variability. They concluded that $2 \mathrm{DE}$ appears to be reliable in the detection of differences close to $10 \%$ in LVEF. Because this is the same magnitude of change used to adjudicate CTRCD, the sensitivity of $2 \mathrm{DE}$ has been questioned. Accordingly, strategies using newer echocardiographic technology, such as STE-derived strain imaging for the early detection of subclinical LV systolic dysfunction, have been actively investigated (see Section III). When this technology is not available, the quantitation of LV longitudinal function by simple ultrasound tools such as mitral annular plane systolic excursion by M-mode echocardiography, and/or the peak systolic velocity ( $\left.\mathrm{s}^{\prime}\right)$ of the mitral annulus by pulsed-wave DTI, could be useful adjunct information to LVEF in the evaluation of LV systolic function. ${ }^{45-49}$ Mitral annular plane systolic excursion is less dependent on image quality. Although there are no cutoff values that allow the prediction of CTRCD, a progressive decline should raise concern for subclinical LV dysfunction.

\section{Key Points}

- Echocardiography is the method of choice for the evaluation of patients before, during, and after cancer therapy. Accurate calculation of LVEF should be done with the best method available in the echocardiography laboratory (ideally 3DE).

- When using 2DE, the modified biplane Simpson's technique is the method of choice.

- LVEF should be combined with the calculation of wall motion score index.

- In the absence of global longitudinal strain (GLS) by STE, quantification of LV longitudinal function using mitral annular displacement by M-mode echocardiography and/or peak systolic velocity $\left(s^{\prime}\right)$ of the mitral annulus by pulsed-wave DTI is recommended.

- LVEF assessed by 2DE often fails to detect small changes in LV contractility.

\section{B. LV Diastolic Function}

A comprehensive assessment of LV diastolic function should be performed, including grading of diastolic function, and providing an estimate of LV filling pressure (by using the $\mathrm{E} / \mathrm{e}^{\prime}$ ratio) according to the joint ASE and EAE recommendations on LV diastolic function. ${ }^{50}$ Use of the $\mathrm{E} / \mathrm{e}^{\prime}$ ratio remains questionable in the oncologic setting, as $\mathrm{E}$ and $\mathrm{e}^{\prime}$ velocities fluctuation in these patients could be the consequence of changes in loading conditions as a result of side effects associated with the chemotherapy (nausea, vomiting, and diarrhea) more than the result of a real change in LV diastolic performance. Diastolic parameters have not yet demonstrated value in predicting subsequent CTRCD (please see full discussion in Section III.A)

\section{Key Point}

- Although diastolic parameters have not been found to be prognostic of CTRCD, a conventional assessment of LV diastolic function, including grading of diastolic function and noninvasive estimation of LV filling pressures, should be added to the assessment of LV systolic function, per ASE and EAE recommendations for the evaluation of LV diastolic function with echocardiography.

\section{RV Function}

RV abnormalities may occur in oncologic patients for a number of reasons: preexisting RV dysfunction, neoplastic involvement (primary or metastatic), or as a result of the cardiotoxic effects of chemotherapy. It may be implied that the right ventricle is affected by chemotherapy, as early studies of CTRCD often included RV biopsies. $^{51}$ However, the frequency of RV involvement or its 



Figure 2 (A) Tricuspid annular plane systolic excursion (TAPSE) obtained from an apical chamber view in patient receiving anthracycline based therapy. The TAPSE is normal, measuring $2.26 \mathrm{~cm}$ (abnormal $<1.6 \mathrm{~cm}$ ). (B) Pulse Doppler peak systolic velocity at the tricuspid valve annulus in a patient 6 months after completion of trastuzumab-based therapy. The measurement is normal at $18 \mathrm{~cm} / \mathrm{sec}$ (abnormal $<10 \mathrm{~cm} / \mathrm{sec}$ ).
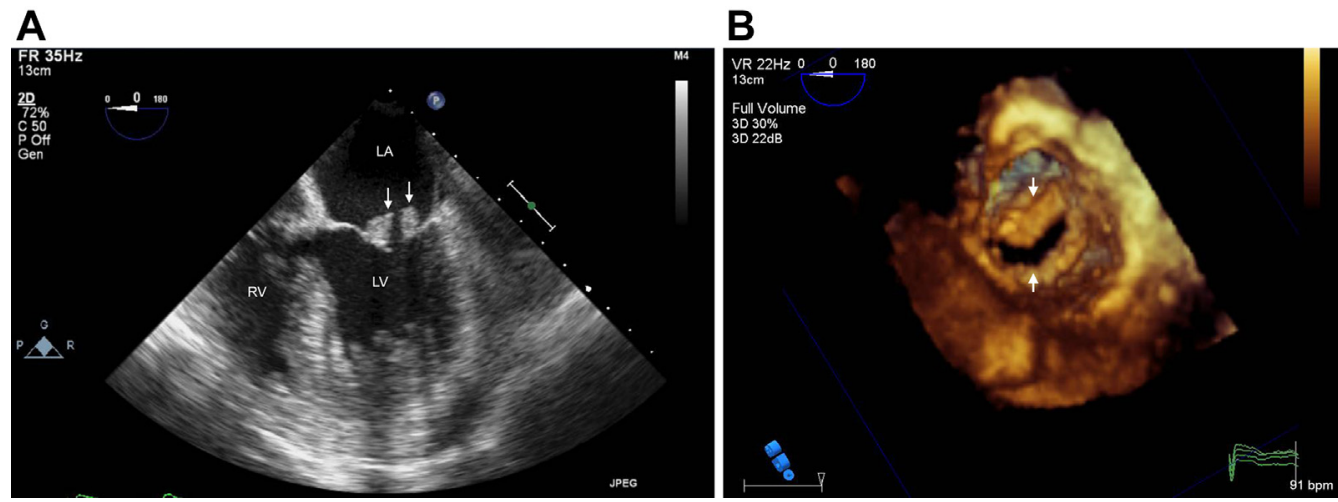

Figures 3 Transesophageal apical four-chamber and 3D reconstruction in an 86-year-old woman with marantic endocarditis, in the setting of metastatic pancreatic cancer. Please note the diffuse involvement of the edge of the anterior and posterior leaflets.

prognostic value has not been adequately studied. There is only one study reporting subclinical decrease in RV systolic and diastolic echocardiographic indices, although mostly in the normal range in 37 patients in a relatively short time interval after onset of chemotherapy with anthracyclines. ${ }^{52}$

Evaluation of the right ventricle should include qualitative and quantitative assessments of chamber size (at least RV basal diameter) and right atrial size (area), as well as quantitative assessment of RV longitudinal M-mode-derived tricuspid annular plane systolic excursion (Figure 2a) and pulsed DTI-derived systolic peak velocity of the tricuspid annulus $\left(\mathrm{s}^{\prime}\right)$ (Figure $2 \mathrm{~b}$ ) and RV radial function (fractional area shortening). ${ }^{53}$

It is recommended when technically possible to provide an estimate of RV systolic pressure. This is particularly important in patients treated with dasatinib, a tyrosine kinase inhibitor, as pulmonary arterial hypertension may be a specific complication. ${ }^{54}$

\section{Key Point}

- Although the prognostic value of RV dysfunction has not been demonstrated in patients undergoing chemotherapy, a quantitative assessment of RV chamber and function should be performed because of possible RV involvement.

\section{Valvular Heart Disease}

Chemotherapeutic agents do not appear to directly affect cardiac valves. However, valvular heart disease may manifest in oncologic patients for a number of reasons, including preexisting valve lesions, ${ }^{55-57}$ concomitant radiation therapy, ${ }^{58}$ severe infection as a complication of chemotherapy, or CTRCD.

Primary or secondary cardiac tumors may rarely affect valve function by their local effects. In patients with advanced malignant tumors, nonbacterial thrombotic, or marantic endocarditis (Figures $3 \mathrm{a}$ and $3 \mathrm{~b}$ ) may occur. ${ }^{59,60}$ This is more common with left-sided valves. Valve lesions may vary in size from microscopic to large bulky lesions, leading to impaired valve coaptation and regurgitation, which is occasionally severe. Significant valve stenosis is infrequent. However, it is thromboembolism from these lesions that is most consequential to the patient rather than hemodynamic impact.

Valve disease may occur because of concomitant or previous radiation therapy. ${ }^{61-63}$ The effect of radiotherapy on the valvular apparatus was described thoroughly in the recent joint ASE and European Association of Cardiovascular Imaging (EACVI) recommendations, ${ }^{58}$ and cardiac imaging evaluation of patients undergoing radiotherapy should be performed according to that document.

Chemotherapy may lead to pancytopenia and result in bacteremia and sepsis, which in turn may lead to increased risk for endocarditis, with vegetations and valve regurgitation. This is more likely in those with predisposing valve lesions (i.e., mitral valve prolapse ${ }^{55}$ and bicuspid aortic valve) or with indwelling central venous catheters placed for vascular access. ${ }^{64}$

Valve disease may occur as a consequence of CTRCD. This usually manifests as mitral regurgitation caused by annular dilation or apical tethering in the setting of LV dysfunction and secondary LV remodeling. Secondary tricuspid regurgitation may also occur because of RV dysfunction or pulmonary arterial hypertension in the setting of 


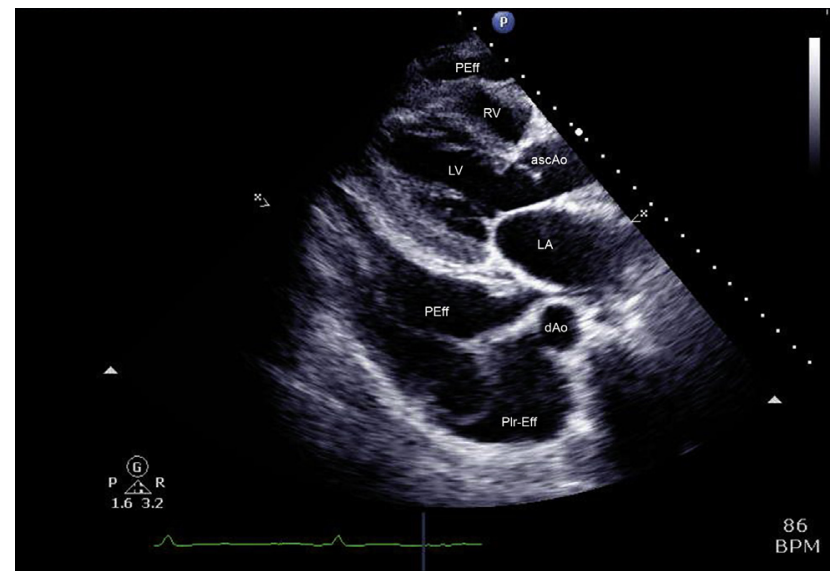

Figure 4 Parasternal long-axis view of a patient with metastatic lung cancer. Echo-lucent spaces are seen anterior (pericardial effusion [PEff]) and posterior to the descending aorta (pleural effusion [PIr-Eff]). Echo-lucent space is also seen anterior to the free wall of the right ventricle (pericardial effusion). Findings are consistent with a circumferential pericardial effusion.

CTRCD. Both secondary mitral and tricuspid regurgitation occur late in the course of CTRCD, after significant ventricular dysfunction and geometric remodeling have occurred.

Echocardiography is the technique of choice for the evaluation of valvular heart disease in patients with cancer. Assessment of the severity of valvular stenosis or regurgitation should be performed on the basis of the current ASE and EAE recommendations. ${ }^{65-68}$ Although a complete transthoracic echocardiographic Doppler evaluation is often sufficient to evaluate the valve pathology and the hemodynamic consequences of valve dysfunction, transesophageal echocardiography may be of incremental value in the setting of suspected endocarditis. ${ }^{69}$ Both computed tomographic scanning and CMR are not typically required in the routine evaluation of valve disease in oncologic patients, but may have a role in assessing tumor infiltration of valvular structures or when radiationinduced constriction or restrictive cardiomyopathy is suspected. ${ }^{70}$ CMR may be valuable in following ventricular volumes and function in patients with significant valve regurgitation.

Patients with significant baseline or changing valvular findings during chemotherapy require more frequent serial echocardiographic examinations. The indications for follow-up and interventions for specific valve lesions should be based on guidelines published by the American Heart Association and American College of Cardiology, and the European Society of Cardiology, ${ }^{71,72}$ though follow-up should be adjusted to the clinical situation and individual prognosis of each patient.

\section{Key Points}

- Cardiac valves should be carefully evaluated in patients undergoing chemotherapy.

- Patients with baseline or changing valvular findings during chemotherapy should undergo careful reevaluation of valve structure and function on serial echocardiography during and after the course of their treatment

\section{E. Pericardial Disease}

Pericardial disease in oncologic patients is relatively common. It may be secondary to cardiac metastasis, or may be a consequence of radiotherapy $^{73,74}$ and/or chemotherapy. ${ }^{75}$

Pericardial disease induced by chemotherapy usually manifests as pericarditis, with or without associated myocarditis. The pericarditis may be associated with pericardial effusion with varying degrees of hemodynamic impairment.

Several chemotherapy agents are associated with pericardial disease. Anthracyclines, ${ }^{75-78}$ cyclophosphamide, ${ }^{79-84}$ and cytarabine ${ }^{85-89}$ are associated with acute or subacute development of pericarditis and pericardial effusion, which may or not be accompanied by myocarditis. Imatinib mesylate ${ }^{90,91}$ and dasatinib, ${ }^{92,93}$ both tyrosinekinase inhibitors, are associated with the development of pleural and pericardial effusions, which may progress to cardiac tamponade. Interferon- $\alpha,{ }^{94-98}$ used in the treatment of melanoma, can cause pericarditis and pericardial effusion. Retinoic acid syndrome occurs in approximately $26 \%$ of patients treated with this drug and is characterized by fever, arterial hypotension, acute renal failure, and pleural and pericardial effusions. 99,100 The occurrence of pericardial and endomyocardial fibrosis years after administration of busulfan has also been described. ${ }^{101}$ Other agents associated with pericardial disease are methotrexate, ${ }^{102-105}$ arsenic trioxide, ${ }^{106,107}$ and, less frequently, 5-fluorouracil ${ }^{108}$ and docetaxel. ${ }^{109}$

Transthoracic echocardiography is the method of choice for the initial evaluation of patients with suspected pericardial disease. In most cases, it allows not only diagnosis but also guidance of pericardiocentesis. The echocardiographic findings in patients with pericarditis can be entirely normal or show evidence of a pericardial effusion. The pericardial effusion should be quantified and graded according to recognized methods, to allow comparison in subsequent evaluations (Figure 4). ${ }^{110}$ Evaluation of cardiac tamponade (particularly frequent in the case of malignant effusions) should be performed according to published guidelines. ${ }^{70,111-113}$

When pericardial thickening is evident, especially if there are clinical signs of RV failure and low cardiac output in the presence of normal ventricular dimension and function, evaluation of constrictive physiology should be made. Constrictive pericarditis is more often associated with radiation-induced cardiotoxicity, ${ }^{58,114,115}$ but there are reports of occurrence after high-dose chemotherapy administration. ${ }^{116}$ Echocardiographic signs of constriction should be explored according to published guidelines. ${ }^{70,110,117-119}$

Differentiating constrictive pericarditis from restrictive cardiomyopathy in oncologic patients may be a challenge because the two conditions can overlap. ${ }^{70}$

In some instances, the use of other imaging modalities, such as computed tomography or CMR, can be a useful complement to the echocardiographic evaluation. They should especially be considered in the evaluation of primary tumors of the heart, with or without compromise of the pericardium, or when the diagnosis of constrictive pericarditis remains uncertain after a careful echocardiographic evaluation. ${ }^{70}$ CMR is particularly useful in determining the presence of late gadolinium enhancement (LGE) for the identification of patients with transient constriction, who will benefit from aggressive antiinflammatory regimens rather than pericardiectomy.

\section{Key Points}

- Pericardial disease in oncologic patients can be associated with cardiac metastasis or be a consequence of chemotherapy and/or radiotherapy.

- Pericardial effusion should be quantified and graded according to standard methods.

- Echocardiographic and Doppler signs of cardiac tamponade should be investigated, particularly in patients with malignant effusions.

- CMR should be considered in evaluation of primary tumors of the heart with or without compromise of the pericardium or when the diagnosis of constrictive pericarditis remains uncertain after a careful echocardiographic evaluation 


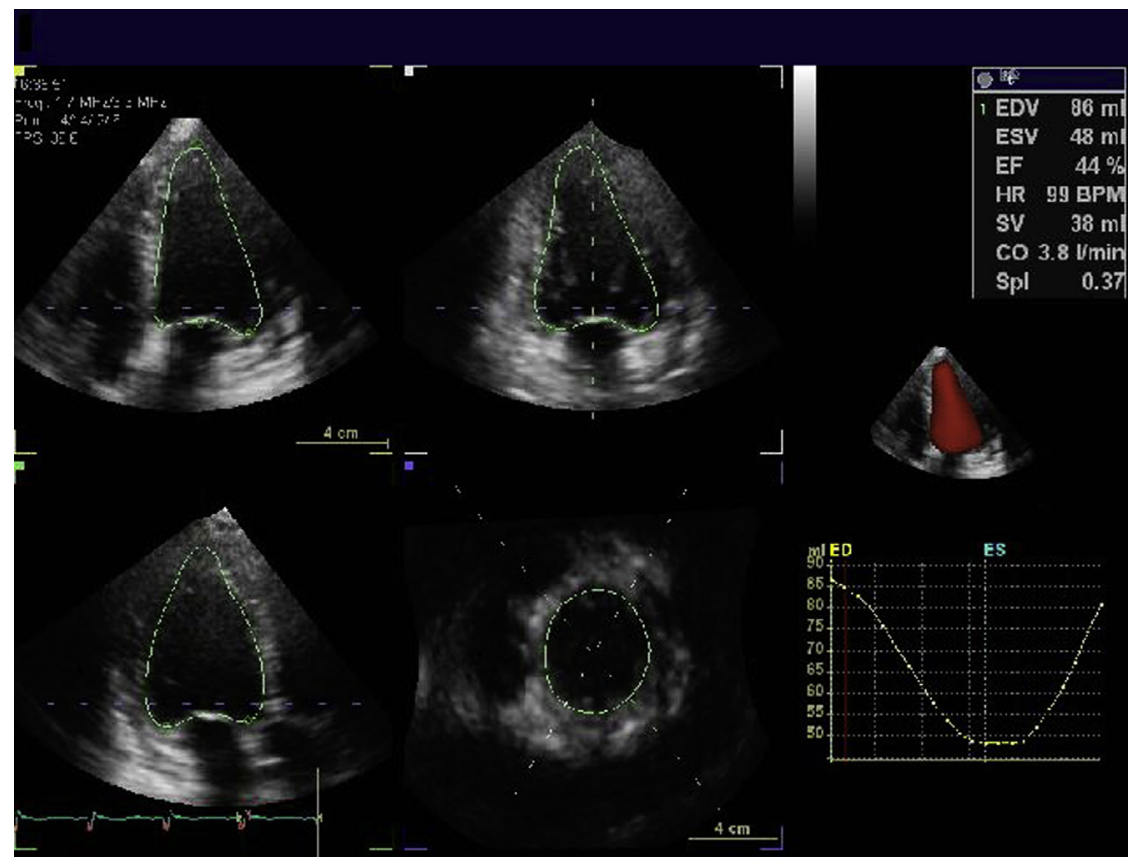

Figure 5 Semiautomated calculation of LVEF using real-time 3DE in a patient with trastuzumab-induced CTRCD. The LVEF is abnormal at $44 \%$ (normal $>53 \%$ ).

\section{F. 3DE}

Although 3DE is more accurate than 2DE for the measurement of LV volumes ${ }^{120}$ in normally shaped ventricles, the accuracy of 2D LVEF calculation should be conceptually similar to that of 3DE because the extent of volume underestimation by $2 \mathrm{DE}$ should be similar in both diastole and systole. However, improved accuracy of 3DE (sensitivity, 53\%; false-negative rate, 47\%) over 2DE (25\% and 75\%, respectively) in detecting LVEF $<50 \%$ on CMR has been observed in survivors of childhood cancer. ${ }^{121}$ This result may be explained by the fact that 3DE volume measurements are not conditioned by errors induced by geometric assumptions of LV shape, foreshortening of views, or uncontrolled orientation of apical two-chamber and fourchamber views that commonly affect the accuracy of 2DE (Figure 5).

Moreover, serial evaluation of patients at risk for CTRCD requires that the imaging technique should be repeatable and provide consistent results when quantitative analysis is performed on images acquired at different time points and also when images are acquired and/or analyzed by different observers. To address this issue, a recent study ${ }^{44}$ compared different echocardiographic techniques (2D biplane Simpson's method, 2D triplane, and 3DE with and without contrast) for the serial evaluation of LVEF in patients with cancer undergoing chemotherapy with stable LV function, to identify the technique with the lowest test-retest variability over 1 year of follow-up. Among 56 patients, noncontrast 3DE showed significantly lower temporal variability than all other techniques. Noncontrast 3D echocardiographic measurement of LVEF provided the desired level of longitudinal reproducibility of 5.6\% (95\% confidence interval, $5.0 \%-6.2 \%$ ), whereas 2D echocardiographic techniques showed higher temporal variability $(9.8 \%)$. Noncontrast 3DE also had the best intra- and interobserver and test-retest variability. Low testretest variability is as important as the actual LVEF measurement and warrants careful adherence to optimal lab techniques aimed at minimizing it. The superiority of 3DE over 2DE may be explained by the fact that the former is less affected by acquisition differences

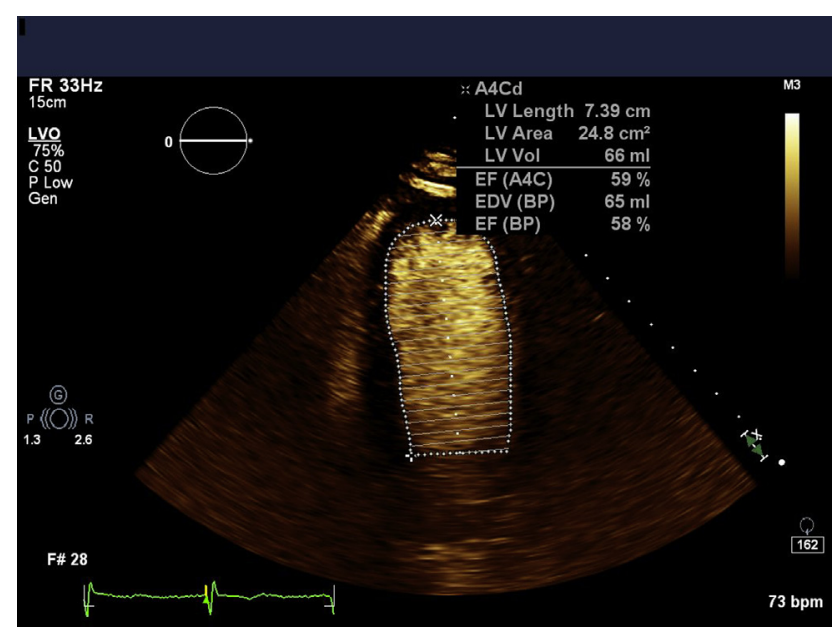

Figure 6 End-diastolic endocardial tracing obtained from the apical four-chamber view after the administration of contrast for the calculation of LVEF using the method of disks in a patient with inadequate 2D echocardiographic images.

from one scan to the next, as often seen with the latter, ${ }^{122,123}$ and by use of an automated or semiautomated method for identifying endocardium, compared with manual tracing of endocardial contour required by $2 \mathrm{DE}$. The improved reproducibility of semiautomated versus manual contouring has been previously reported both with $2 \mathrm{DE}$ and $3 \mathrm{DE} .{ }^{124,125}$ Three-dimensional echocardiography appears to be the technique of choice for monitoring the cardiac effects of chemotherapy. ${ }^{126}$ However, it is important to realize that this technology has several limitations as well. It is not widely available because of cost, and it relies heavily on high-quality images and operator expertise to achieve the superior performance mentioned above. A recent study by Tsang et al. ${ }^{127}$ demonstrated 
that a quality improvement session dedicated to formally standardize the analytic approach of the readers in the echocardiography laboratory can eliminate the systematic bias and improve the agreement among readers in the measurement of LV volumes. It is recommended to include in the echocardiographic report the calculation of LVEF by the biplane Simpson's method, allowing comparison with previous studies if this method was used. Where available, serial 3D echocardiographic calculation of LVEF should be encouraged for monitoring CTRCD. It is to be expected that during the years to come, less expensive, more automated, and user-friendly 3DE machines that rely less on operator expertise could allow a wider application of this technique.

\section{Key Points}

- Three-dimensional echocardiography is the preferred technique for monitoring LV function and detecting CTRCD in patients with cancer. Advantages include better accuracy in detecting LVEF below the lower limit of normal, better reproducibility, and lower temporal variability compared with $2 \mathrm{DE}$ in patients with cancer treated with chemotherapy.

- Costs, availability, high reliance on image quality, and need for training of operators currently limit the wide application of $3 \mathrm{DE}$ in the oncologic setting.

\section{G. Contrast Echocardiography}

Underestimation of volumes may occur when the endocardium is not adequately visualized. ${ }^{128}$ Endocardial border dropout can frequently occur in patients undergoing chemotherapy (in particular patients with breast cancer after mastectomy and chest irradiation). According to the ASE consensus statement on the clinical applications of ultrasonic contrast agents in echocardiography and EAE recommendations $^{129,130}$ on myocardial contrast echocardiography, a contrast agent should be used when two contiguous LV segments from any apical view are not seen on noncontrast images (Figure 6).

There is limited literature to support the use of contrast for 3D assessment of LV volumes in patients with cancer. ${ }^{122}$ A recent study performed in patients with cancer undergoing chemotherapy did not demonstrate any advantage of using contrast-enhanced 3DE for the measurement of LV volumes and LVEF (lower reproducibility and higher temporal variability were noted compared with 3DE alone). ${ }^{44}$ There are two potential explanations for the findings. First, blooming and attenuation artifacts may hinder the delineation of structures such as the mitral valve, with the resultant variability in contouring of the left ventricle. Second, most of the patients studied had adequate acoustic windows with harmonic imaging and therefore did not meet traditional criteria for contrast administration.

\section{Key Points}

- The use of myocardial contrast agents could be potentially useful in chemotherapy patients when endocardial dropout occurs.

- According to current recommendations, contrast should be used when two contiguous LV segments are not well visualized on noncontrast apical images.

- Contrast agents are not recommended in conjunction with 3DE in the longitudinal follow-up of patients with cancer.

\section{H. Stress Echocardiography}

Stress echocardiography, an established technique for the detection and prognostication of stable CAD as recommended by guidelines, may be useful in the evaluation of patients with intermediate or

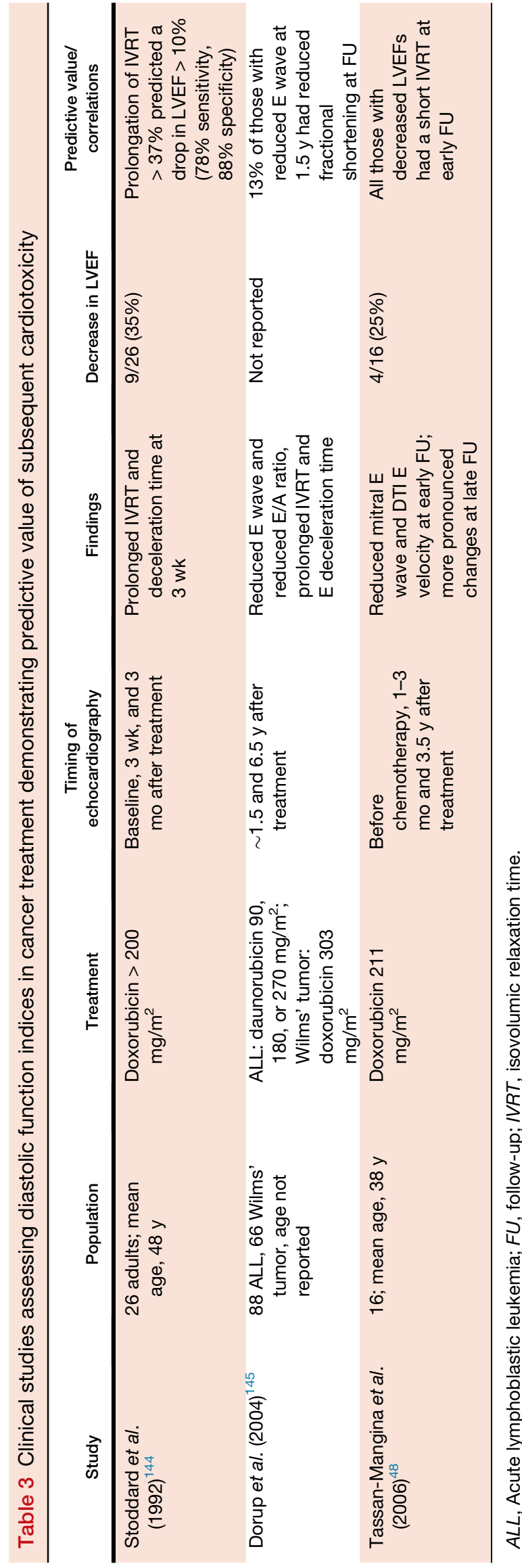



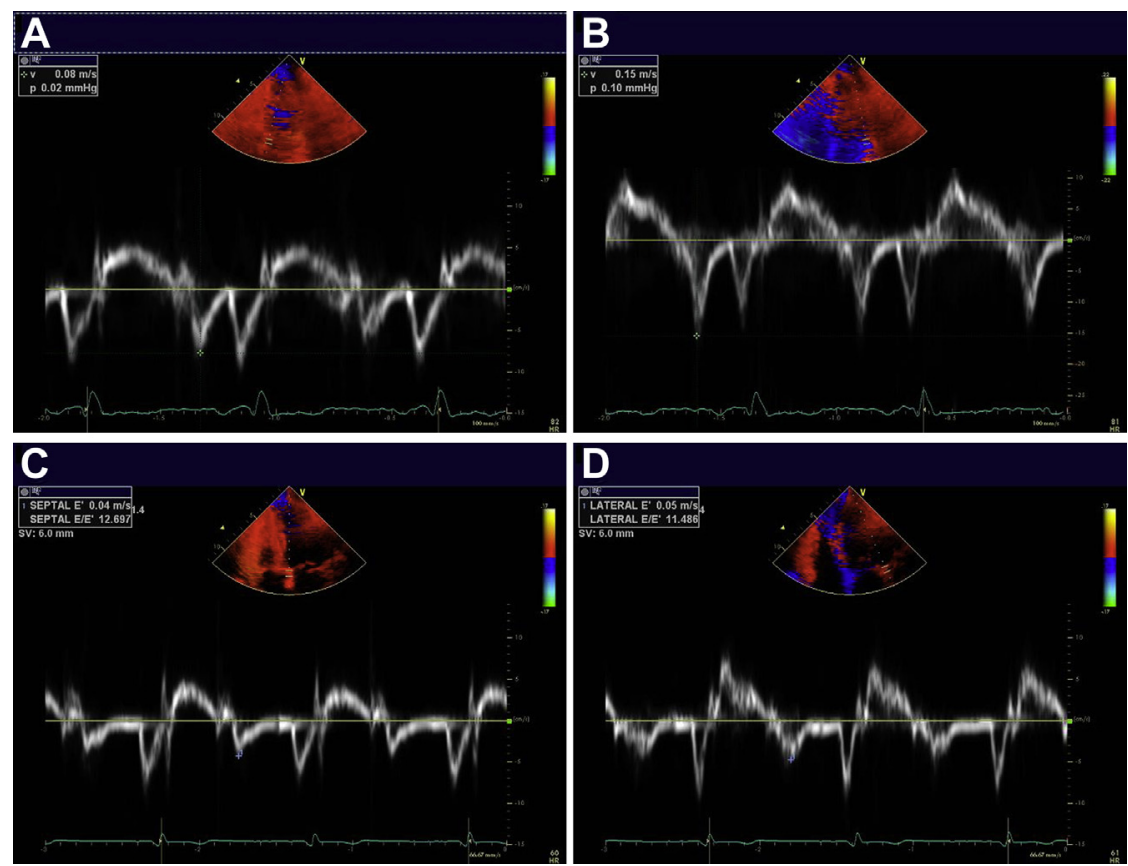

Figure 7 Reductions in pulsed DTI e' velocities in the setting of anthracycline-induced CTRCD. (A,B) Septal and lateral $\mathrm{e}^{\prime}$ velocities were 8 and $15 \mathrm{~cm} / \mathrm{sec}$, respectively, before the initiation of therapy. (C,D) Septal and lateral velocities decreased to 4 and $5 \mathrm{~cm} / \mathrm{sec}$, respectively, during anthracycline therapy.

high pretest probability for CAD (uninterpretable electrocardiogram or unable to exercise), ${ }^{131}$ who are undergoing regimens that may be associated with ischemia (fluorouracil, bevacizumab, sorafenib, and sunitinib). ${ }^{132}$

In addition, there are two specific areas in which stress echocardiography may be useful: (1) the evaluation of subclinical LV dysfunction and (2) the evaluation of contractile reserve in patients with CTRCD.

Although both exercise ${ }^{27}$ and dobutamine stress echocardiography ${ }^{27,112,133-140}$ have been applied to patients with cancer for the identification of anthracycline-induced CTRCD, the results of these studies appear to be inconclusive and contradictory. One of these studies prospectively assessed LV contractile reserve by low-dose dobutamine stress echocardiography in 49 women with breast cancer before each chemotherapy cycle and 1, 4, and 7 months after stopping the treatment. A 5-unit fall in LV contractile reserve was found to be predictive of subsequent LVEF reduction $<50 \%$. $^{140}$ Dobutamine could potentially allow the earlier identification of disease by recognizing a compromise in cardiac reserve.

In case of the development of CTRCD, the transient recovery of LV function during stress echo may also predict a better outcome. ${ }^{141}$

\section{Key Points}

- Stress echocardiography may be helpful in the evaluation of patients with intermediate or high pretest probability for CAD (uninterpretable electrocardiogram or unable to exercise) who will receive regimens that may cause ischemia (fluorouracil, bevacizumab, sorafenib, and sunitinib).

- Stress echocardiography may be of help in the determination of contractile reserve of patients with evidence of CTRCD.

\section{Other}

In the presence of implanted ports, tunneled catheters, or peripherally inserted central lines, it is recommended to report the location of the tip with respect to the superior vena cava-right atrium junction, as well as the presence of thrombus or vegetations.

\section{DETECTION OF SUBCLINICAL LV DYSFUNCTION}

\section{A. Detection of Subclinical LV Dysfunction Using Imaging}

\section{LVEF as a Tool to Detect Subclinical LV}

Dysfunction. Although the decrease in LVEF during treatment has been associated with symptomatic $\mathrm{HF}^{31,34,35}$ the ability of serial LVEF assessment during and after treatment to identify CTRCD and prevent subsequent HF remains controversial. $2,5,30$ Recently, the value of baseline LVEF and LVEF measured after anthracyclines in the prediction of subsequent HF was underlined in a large study of women with breast cancer treated with anthracyclines, with or without trastuzumab. In this study, a reduced LVEF (including LVEFs of 50\%-54\%) at baseline or after anthracyclines was associated with higher rates of cardiac events on follow-up, ${ }^{142}$ although the percentage of patients with LVEFs $<55 \%$ after anthracyclines in the study was quite low (10\%-12\%). Unfortunately, detecting a decreased LVEF after anthracyclines may be too late for treatment, ${ }^{143}$ suggesting that more sensitive parameters of LV dysfunction would be helpful.

\section{Diastolic Dysfunction: Early Signs and Prognostic}

Value. In a small prospective study, a prolongation in the isovolumic relaxation time preceded and predicted a drop in LVEF of $>10 \%$, occurring up to 3 months later. ${ }^{144}$ Larger studies, however, although confirming early changes of LV diastolic parameters after treatment, have not reproduced its predictive value. ${ }^{145}$

Significant increases in the myocardial performance index occur early after anthracycline administration and were reported in two studies to predict later decreases in LVEF. ${ }^{146,147}$ The prognostic 


\begin{tabular}{|c|c|c|c|c|c|c|c|c|c|c|c|c|}
\hline Study & $\begin{array}{l}\text { Echocar- } \\
\text { diographic } \\
\text { method }\end{array}$ & Cancer type & $\mathrm{n}$ & Age, yrs & $\begin{array}{c}\text { Female, } \\
\%\end{array}$ & Treatment & $\begin{array}{c}\text { Echocardiography } \\
\text { timing }\end{array}$ & Pre-echo & Post-echo & $\begin{array}{c}\text { Cardiotoxicity } \\
\text { Rate (\%) }\end{array}$ & $\begin{array}{l}\text { Thresholds } \\
\text { for Toxicity } \\
\text { Prediction }\end{array}$ & Vendor, Reproducibility \\
\hline $\begin{array}{l}\text { Mornos } \\
\text { et al. } \\
(2013)^{234}\end{array}$ & STE & $\begin{array}{l}\text { Breast } \\
\text { lymphoma, } \\
\text { ALL, AML, } \\
\text { osteosarcoma }\end{array}$ & $\begin{array}{l}74 \& 37 \\
\text { controls }\end{array}$ & $51 \pm 11$ & 58 & Anthracyclines & $\begin{array}{l}\text { Pre, post, and } \\
6,12,24 \text { and } \\
52 \text { weeks }\end{array}$ & $\begin{array}{l}\text { GLS }-21.2 \pm 2.5 \% \\
\text { GRS } 47.8 \pm 5.3 \%\end{array}$ & $\begin{array}{l}\text { GLS }-19.0 \pm 2.4 \% \\
\text { GRS } 41.1 \pm 5.4 \% \\
(6 \text { weeks })\end{array}$ & 13 & $\begin{array}{l}\Delta \text { GLS } 2.8 \%(13.1 \% \\
\text { relative), } \\
\text { sensitivity } 79 \% \\
\text { and specificity } \\
73 \% \text { at } 6 \text { weeks } \\
\text { for toxicity at } 24 \\
-52 \text { weeks }\end{array}$ & $\begin{array}{l}\text { GE, intraobserver } \\
\text { ICC for GLS } 0.95 \text {, } \\
\text { interobserver } 0.91\end{array}$ \\
\hline $\begin{array}{l}\text { Negishi } \\
\text { et al. } \\
(2013)^{155}\end{array}$ & STE & Breast & 81 & $50 \pm 11$ & 100 & $\begin{array}{l}\text { Trastuzumab, } \\
\text { doxorubicin } 46 \% \\
\text { RT } 62 \%\end{array}$ & $\begin{array}{l}\text { Pre-trastuzumab, } \\
\text { and } 6 \text { and } \\
12 \text { months later }\end{array}$ & $\begin{array}{c}\text { GLS }-20.7 \pm 2.6 \% \\
\text { GLSR }-1.17 \pm \\
0.24 / \mathrm{s} \text { GLSR-E } \\
1.36 \pm 0.28 / \mathrm{s}\end{array}$ & $\begin{array}{l}\text { GLS }-18.3 \pm 2.1 \% \\
\text { GLSR }-1.00 \pm \\
0.15 / \mathrm{s} \text { GLSR-E } \\
1.20 \pm 0.28 / \mathrm{s} \text { (at } 6 \\
\text { months in patients } \\
\text { who later had } \\
\text { toxicity) }\end{array}$ & 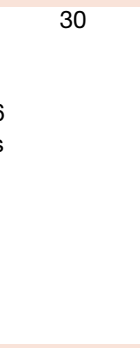 & $\begin{array}{l}\text { GLS change } \geq 11 \% \\
\text { between pre- } \\
\text { treatment and } 6 \\
\text { months, sensitivity } \\
65 \%, \text { spec } 95 \% \text { or } \\
\text { absolute GLS } \\
>-20.5 \text { at } 6 \\
\text { months, sensitivity } \\
96 \%, \text { spec } 66 \% \\
\text { for toxicity at } 12 \\
\text { months }\end{array}$ & 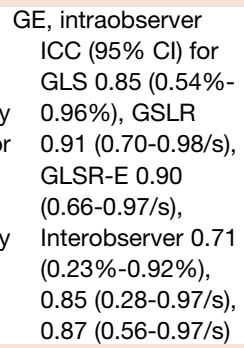 \\
\hline $\begin{array}{l}\text { Baratta } \\
\text { et al. } \\
(2013)^{235}\end{array}$ & STE & Breast & 36 & $47 \pm 16$ & 58 & $\begin{array}{l}\text { Doxorubicin } 58 \% \\
\quad \text { trastuzumab } 22 \%\end{array}$ & $\begin{array}{l}\text { Pre- and } 2,3,4 \\
\text { and } 6 \text { months } \\
\text { after start } \\
\text { of therapy }\end{array}$ & $\begin{array}{r}\text { GLS }-20.3 \pm 2.7 \% \\
\text { GRS } 53.1 \pm 4 \%\end{array}$ & $\begin{array}{c}\text { GLS }-18.9 \pm 2.5 \% \text { ( } 3 \\
\text { months) GRS } 50 \\
\pm 3.9 \% \text { (4 months) }\end{array}$ & 19.4 & $\begin{array}{l}\text { GLS fall } \geq 15 \% \text { at } 3 \\
\text { months, sensitivity } \\
86 \%, \text { spec } 86 \% \text {. } \\
\text { GRS fall } \geq 10 \% \text { at } \\
4 \text { months, } \\
\text { sensitivity } 86 \% \\
\text { spec } 69 \%\end{array}$ & $\begin{array}{l}\text { GE, mean (SD) } \\
\text { y absolute } \\
\text { difference inter/ } \\
\text { intraobserver GLS } \\
0.6(1.4 \%) / 0.2(1 / \\
1 \%), \text { GRS } 3.4 \\
(7.1 \%) / 3.2(6.6 \%)\end{array}$ \\
\hline $\begin{array}{l}\text { Sawaya } \\
\text { et al. } \\
(2012)^{160}\end{array}$ & STE & Breast & 81 & $50 \pm 10$ & 100 & $\begin{array}{l}\text { Doxorubicin, } \\
\text { epirubicin, } \\
\text { trastuzumab, RT } \\
60 \%\end{array}$ & $\begin{array}{l}\text { Pre-anthracycline } \\
\text { and at } 3,6,9, \\
12 \text {, and } 15 \text { months }\end{array}$ & $\begin{array}{l}\text { GLS }-21 \pm 2 \% \\
\text { GRS } 53 \pm 15 \% \\
\text { GCS }-18 \pm 4 \%\end{array}$ & $\begin{array}{c}\text { GLS }-19 \pm 2 \% \text { GRS } \\
50 \pm 17 \% \text { GCS } \\
-16 \pm 4 \% \text { at } 3 \\
\text { months }\end{array}$ & 32 & $\begin{array}{l}\text { Absolute GLS < } \\
-19 \% \text { at } 3 \text { months, } \\
\text { sensitivity } 74 \%, \\
\text { spec } 73 \% \text { for } \\
\text { subsequent } \\
\text { toxicity }\end{array}$ & $\begin{array}{l}\text { GE, same variability } \\
\text { as in previous } \\
\text { study (153) }\end{array}$ \\
\hline $\begin{array}{l}\text { Sawaya } \\
\text { et al. } \\
(2011)^{153}\end{array}$ & STE & Breast & 43 & $49 \pm 10$ & 100 & $\begin{array}{l}\text { Doxorubicin, } \\
\text { epirubicin, } \\
\text { trastuzumab, RT } \\
11.6 \%\end{array}$ & $\begin{array}{l}\text { Pre-anthracycline } \\
\text { and at } 3 \text { and } \\
6 \text { months }\end{array}$ & $\begin{array}{c}\text { GLS }-20.5 \pm 2.2 \% \\
\text { GCS } 18 \pm 4 \%\end{array}$ & $\begin{array}{c}\text { GLS }-19.3 \pm 2.4 \% \\
\text { GCS } 15 \pm 4 \%\end{array}$ & 21 & $\begin{array}{l}\text { GLS fall }>10 \% \text { at } 3 \\
\text { months, sensitivity } \\
78 \%, \text { spec } 79 \% \\
\text { for toxicity at } 6 \\
\text { months }\end{array}$ & 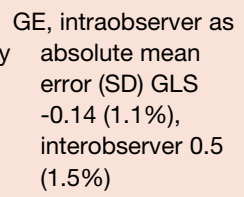 \\
\hline $\begin{array}{l}\text { Fallah-Rad } \\
\text { et al. } \\
\quad(2011)^{156}\end{array}$ & STE & Breast & 42 & $47 \pm 9$ & 100 & $\begin{array}{l}\text { Epirubicin, } \\
\text { doxorubicin, } \\
\text { trastuzumab, RT } \\
98 \%\end{array}$ & $\begin{array}{l}\text { Pre-anthracycline, } \\
\text { Pre-trastuzumab } \\
\text { and at } 3,6,9, \\
\text { and } 12 \text { months }\end{array}$ & $\begin{array}{l}\text { GLS }-19.8 \pm 1.8 \% \\
\text { GLS } 41.4 \pm \\
15.2 \%\end{array}$ & $\begin{array}{c}\text { GLS }-16.4 \pm 1.1 \% \\
\text { GRS } 34.5 \pm \\
15.2 \% \text { (3 months } \\
\text { into trastuzumab) }\end{array}$ & 24 & $\begin{array}{l}\text { Absolute GLS fall of } \\
2.0 \% \text {, sensitivity } \\
79 \% \text {, spec } 82 \% \text {. } \\
\text { Absolute GRS fall } \\
\text { of } 0.8 \% \text {, sensitivity } \\
86 \%, \text { spec } 81 \% \\
\text { for subsequent } \\
\text { toxicity }\end{array}$ & $\begin{array}{l}\text { GE, intraobserver as } \\
\text { ICC (COV) GLS } \\
0.94(3.5 \%), \text { GRS } \\
0.91(3.2 \%) . \\
\text { y } \\
\text { Interobserver } 0.90 \\
(5.2 \%), 0.82 \\
(5.4 \%)\end{array}$ \\
\hline \multirow[t]{2}{*}{$\begin{array}{l}\text { Hare } \\
\text { et al. } \\
\quad(2009)^{162}\end{array}$} & $\begin{array}{l}\text { TDI and } \\
\text { STE }\end{array}$ & Breast & 35 & $51 \pm 8$ & 100 & $\begin{array}{l}\text { Doxorubicin, } \\
\text { epirubicin, } \\
\text { trastuzumab, RT } \\
77 \%\end{array}$ & $\begin{array}{l}\text { Pre- and/or } \\
\text { post- } \\
\text { anthracycline } \\
\text { and at 3-month }\end{array}$ & $\begin{array}{c}\text { STE GLSR }-1.30 \pm \\
0.21 / \mathrm{s} \text { STE RSR } \\
2.02 \pm 0.61 / \mathrm{s}\end{array}$ & $\begin{array}{l}\text { STE GLSR }-1.24 \pm \\
0.18 / \mathrm{s} \text { (by } 3 \\
\text { months) STE RSR } \\
1.75 \pm 0.41 / \mathrm{s} \text { (by }\end{array}$ & 14 & $\begin{array}{l}\text { A >1 SD drop in } \\
\text { GLSR (toxicity at } \\
\text { mean follow-up of } \\
22 \pm 6 \text { months) }\end{array}$ & $\begin{array}{l}\text { GE, intra/ } \\
\text { interobserver as } \\
\text { ICC for 2D GLS } \\
0.94 / 0.91, \text { GLSR }\end{array}$ \\
\hline & & & & & & & & & & & & (Continued) \\
\hline
\end{tabular}




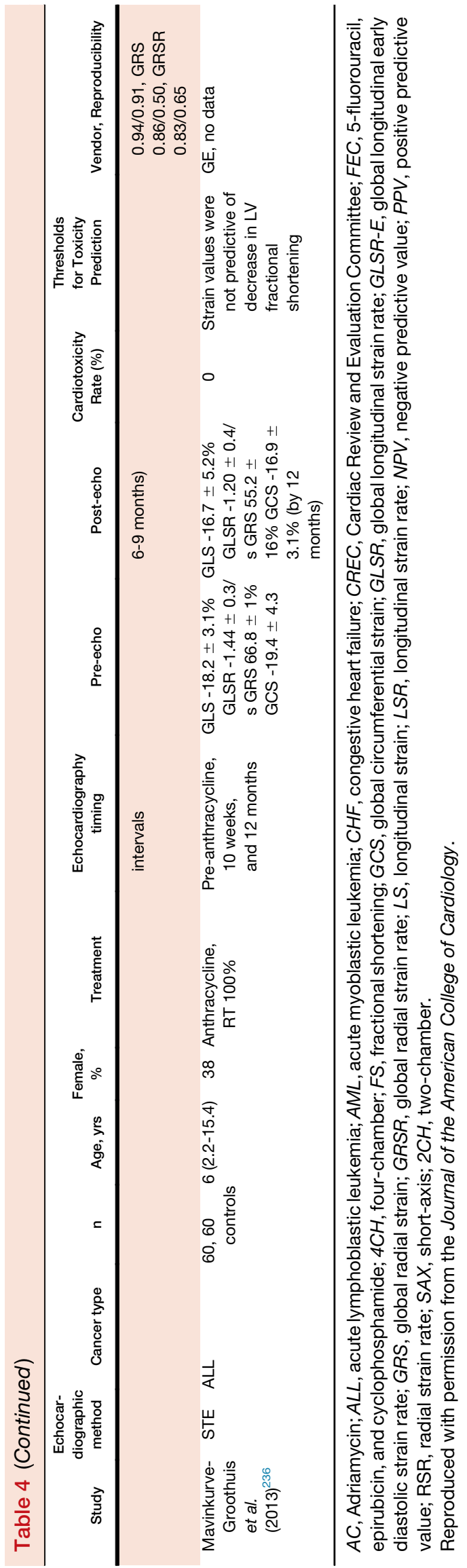

value of myocardial performance index could not be replicated in subsequent studies. ${ }^{148}$

Two studies have reported LV diastolic abnormalities late after anthracycline administration; these abnormalities were associated with wall motion abnormalities despite a preserved LVEF. ${ }^{149}$ Another study reported that a reduced transmitral E/A ratio was associated with a reduction in longitudinal strain by STE in patients with normal LVEFs late after treatment. ${ }^{150}$ It is unclear, however, if these findings have any clinical significance.

As a result, it can be concluded that the use of Doppler-derived diastolic indices is not useful in the early detection of CTRCD because of their inability to predict subsequent HF (Table 3 ).

\section{Detection of Subclinical LV Dysfunction Using DTI}

Velocities. Several investigators have demonstrated an early reduction in $\mathrm{e}^{\prime}$ velocity of the mitral annulus in patients receiving anthracyclines (Figures $7 \mathrm{c}$ and $7 \mathrm{~d}$ ), ${ }^{48,150-152}$ which remained reduced during treatment ${ }^{153}$ and several years thereafter. ${ }^{150}$ The reductions in $\mathrm{e}^{\prime}$ velocity appear heterogeneous, ${ }^{150,151,154}$ suggesting differences in regional wall stress, apoptosis, or fibrosis.

In a study by Negishi et al., ${ }^{155}$ a $10 \%$ reduction in e' velocity was observed in patients who developed CTRCD. Nevertheless, the reduction was not statistically significant $(P=.09)$ or predictive of subsequent reduction in $\operatorname{LVEF}(P=0.14)$.

A reduction in DTI-derived systolic velocity $\left(s^{\prime}\right)$ was reported in animal models of doxorubicin-induced cardiac injury ${ }^{6}$ and in the chronic follow-up of patients treated with anthracyclines. ${ }^{150} \mathrm{~A}$ marked early decrease in $s^{\prime}$, and its value as a potential predictor of changes of LV systolic function after chemotherapy, was reported in a study of 42 patients with breast cancer treated with trastuzumab in the adjuvant setting. ${ }^{156}$ It is to be noted, however, that the rate of symptomatic HF in this study was of $24 \%$ at 6 months of treatment, an unusually high rate in chemotherapy-treated populations. Whether these results can be generalized to patients with a lower incidence of HF is unknown.

\section{Key Point}

- A decreased LVEF at baseline or after anthracyclines is associated with higher rates of cardiac events on follow-up.

- Although it has been suggested that alterations in LV diastolic function (as evaluated by Doppler indices of mitral inflow and $\mathrm{e}^{\prime}$ by pulsed DTI) precede alterations in systolic function, the evidence does not support the role of these indices for the prediction of later CTRCD.

\section{Early Detection of LV Dysfunction Using Strain and Strain}

Rate. A recent systematic review shows that as of 2014, 21 peerreviewed studies have reported the sensitivity of measuring deformation indices (strain, strain rate, and twist) in the detection of subclinical LV dysfunction in patients treated for cancer (Table 4 summarizes these studies). ${ }^{157}$ The studies evaluated patients treated with anthracyclines alone, or in association with other therapies, either during treatment or late after completion of the therapy (survivor studies).

The decrease in myocardial systolic function induced by anthracyclines appears to be extremely rapid, as early as 2 hours after the first anthracycline dose. ${ }^{47}$ As in most of the other studies, the decrease in deformation indices preceded the decrease in LVEF and persisted during the subsequent cancer treatment. Early decreases in radial and longitudinal strain and strain rate were noted using DTI ${ }^{158}$ and STE ${ }^{153,156,159-161}$ and have been confirmed in patients treated with anthracyclines (in some studies in association with taxanes and 

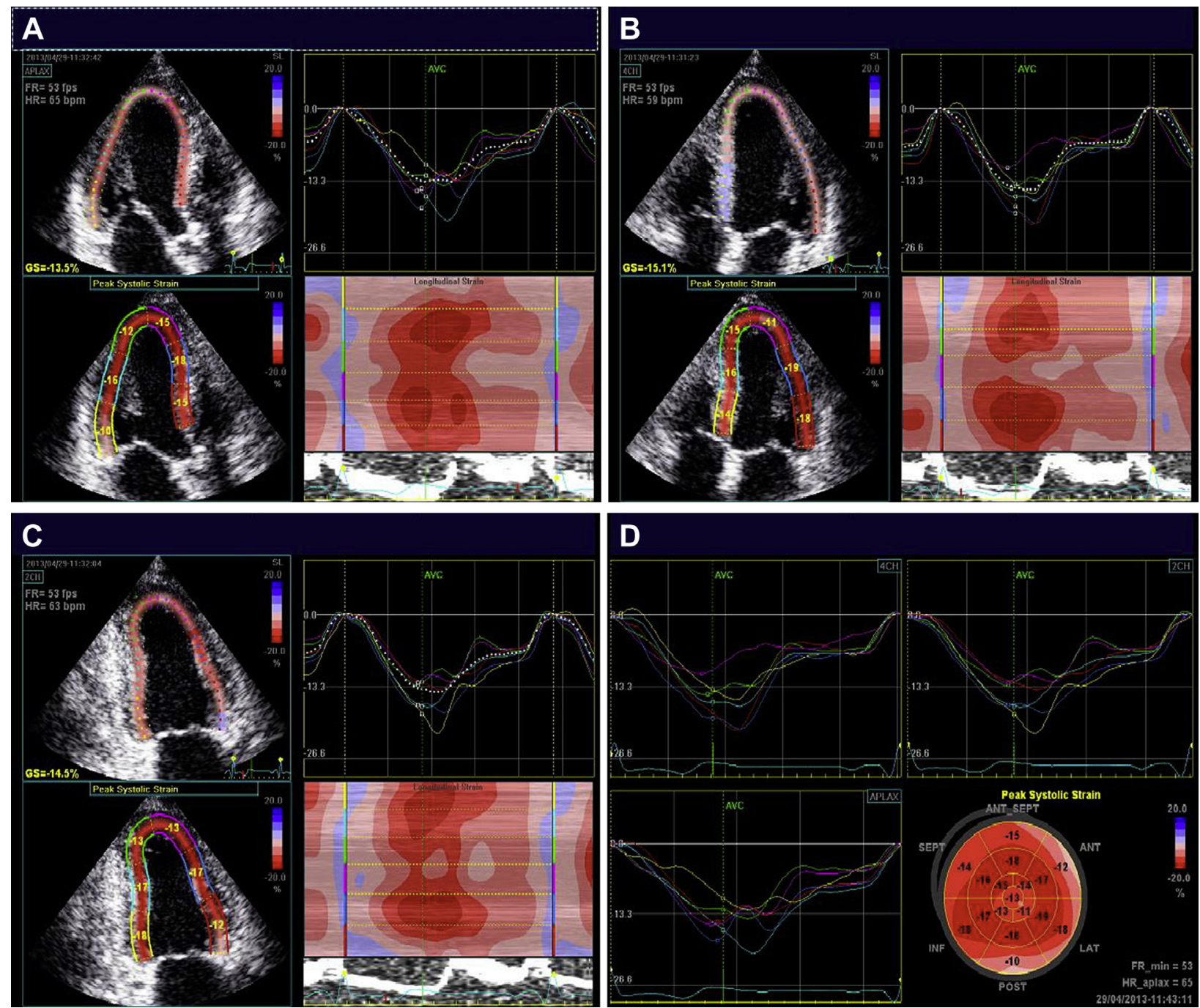

Figure 8 Speckle-tracking echocardiographic images illustrating GLS obtained from the apical long-axis view (A), four-chamberview (B), and two-chamber-view (C) and strain curves and bull's-eye plot in a patient with breast cancer who developed CTRCD after receiving doxorubicin followed by trastuzumab. Each segment has a numeric and color-coded strain value. The cardiac dysfunction appears to be regional, with some segments more involved than others.

trastuzumab), with or without later decreases in LVEF. In one small study, radial indices decreased earlier than longitudinal indices after three cycles of anthracyclines. ${ }^{158}$ Decreases in global $^{160}$ and regional $^{161}$ circumferential strain have also been reported early after anthracycline treatment. The magnitude of the decrease in longitudinal strain appears to average between $10 \%$ and $20 \%$ over the length of the treatment, depending on the population, the analysis, and the treatment studied.

The regionality of the impairment of LV systolic function was assessed in 19 children at the midpoint and at the end of their anthracycline treatment. The investigators reported mainly a septal and apical pattern, which was partially improved at the end of the treatment. ${ }^{159}$ There does not appear to be preferential impairment of one particular layer (subendocardial, midmyocardial, or subepicardial) by anthracyclines, as both longitudinal and radial (and, when studied, circumferential) strain was altered. This result is concordant with experimental models of doxorubicin-induced CTRCD, in which cardiomyocyte apoptosis is present throughout the myocardial layers.
Interestingly, Hare et al. ${ }^{162}$ did not report any change in longitudinal or radial global systolic strain (but a slight decrease in longitudinal and radial strain rate) in patients treated by anthracyclines and trastuzumab. Strain rate measurements may be more sensitive than strain to subtle changes in cardiac function. However, use of strain rate appears to be more challenging in clinical practice.

The prognostic value of early measurement of systolic deformation indices in the prediction of subsequent LV systolic function has been evaluated in several studies, both in animals ${ }^{6}$ and humans. ${ }^{153,156,159,160}$ In 81 patients with breast cancer treated with anthracyclines followed by taxanes and trastuzumab who were followed for 15 months with quarterly echocardiography, the average of the basal and midventricular peak systolic longitudinal strain measured in apical four- and two-chamber views using STE after the completion of anthracyclines predicted subsequent CTRCD. CTRCD was defined in this study as a decrease in LVEF of $>10 \%$ to $<55 \%$ during the remainder of the treatment (12 months there after). Longitudinal strain calculated with EchoPAC software (GE Healthcare, Milwaukee, Wisconsin) was $>-19 \%$ in all patients who 
later developed HF (Figures 8a-8d). Although reductions were seen in all three layers, neither radial nor circumferential strain was predictive of subsequent CTRCD. ${ }^{160}$ A predictive value of regional strain was also reported in smaller studies with shorter follow-up periods. ${ }^{153,156,159}$ Importantly, although the decrease in longitudinal strain and LVEF appears to at least partially persist throughout the duration of the treatment, ${ }^{160}$ it is unknown what their evolution will be in subsequent years, and whether early deformation measurements will predict persistent decreases in LVEF or symptomatic HF.

Negishi et al. ${ }^{155}$ recently published a study looking for the optimal myocardial deformation index to predict CTRCD at 12 months in 81 women with breast cancer treated with trastuzumab, with or without anthracyclines. The strongest predictor of CTRCD was $\Delta$ GLS measured at the 6-month visit. An $11 \%$ reduction $(95 \%$ confidence interval, 8.3\%-14.6\%) was the optimal cutoff, with sensitivity of $65 \%$ and specificity of $94 \%$. Of note, $\Delta$ GLS was superior to changes in the count of abnormal segments, $s^{\prime}$ and $\mathrm{e}^{\prime}$ velocities. They concluded that in patients with baseline strain measurements, the 95\% confidence interval suggests that reductions of GLS of $<8 \%$ compared with baseline appear not to be clinically meaningful, whereas those $>15 \%$ are very likely to be of clinical significance (see Figures $9 \mathrm{a}$ and $9 \mathrm{~b}$ for example of calculation). They confirmed the findings of Sawaya et al., ${ }^{160}$ this time using the conventional calculation of GLS averaging the 18 segments from the three apical views. They showed that in patients without baseline strain measurements, the proposed cutoff of $-19 \%$ conforms to the confidence interval around $-20.5 \%$ found in their study. Nevertheless the area under the curve for absolute strain value is less, making the change in strain the preferable approach.

Finally, four studies evaluated the deformation parameters in long-term cancer survivors (range, 2-30 years after treatment). ${ }^{150,154,163,164}$ In two of the studies with longer follow-up and/or higher doses of anthracyclines, the LVEF (or fractional shortening) was slightly decreased. ${ }^{163,164}$ In contrast, all four studies detected decreases in longitudinal and radial (and circumferential when studied) parameters compared with age-matched control patients, underlining the sensitivity of these parameters in the detection of subclinical LV dysfunction. STE appears therefore as the imaging technique of choice for detection of subclinical LV dysfunction. Normal values for GLS depend on the measurement position in the myocardium, the vendor, and the version of the analysis software, resulting in considerable heterogeneity in the published literature. Two recently published large studies evaluating the normal ranges of LV 2D strain have shown an effect of gender in LV myocardial deformation. ${ }^{165,166}$ The study of Kocabay et al. ${ }^{165}$ reported a mean normal GLS of $-20.7 \pm 2$ for men and $-22.1 \pm 1.8$ for women These values are almost identical to the ones reported by the Japanese Ultrasound Speckle Tracking of the Left Ventricle (JUSTICE) study ${ }^{166}$ for the same vendor. There is also concern that strain values may decrease with age. ${ }^{166,167}$ As a result, it is not possible to recommend universal normal values or lower limits of normal. We refer the reader to Table 5, which summarizes the findings of the Japanese Ultrasound Speckle Tracking of the Left Ventricle study, providing mean values for GLS according to vendor, gender, and age. Cheng et al. ${ }^{168}$ recently evaluated the reproducibility of 2D STE in the Offspring Cohort of the Framingham Heart Study. The interobserver intraclass correlation coefficient was $\geq 0.84$ for all global strain measurements, with an average coefficient of variation for GLS of $\leq 4 \%$. The intraobserver intraclass correlation coefficient was $\geq 0.91$ among time points spanning a total 8-month period, with an average of $\leq 6 \%$ for GLS. The authors concluded that $2 \mathrm{D}$
STE is reproducible when performed by trained operators. However, the technique has important limitations (Table 6). There are no data currently available as to the reproducibility of GLS at nonacademic centers or community hospitals. The presence of a learning curve for sonographers and interpreting physicians makes dedicated training and monitoring of quality (i.e., intra- and interobserver and test-retest variability) essential. When setting a strain program, it is recommended to initially designate one physician and, where available, one technician to perform, interpret, and compare studies over time. As experience is gained with the technique, the effort may be expanded to include other physicians, technicians, and trainees. Nevertheless, the most important limitation is intervendor variability. ${ }^{166,169}$ Different echocardigoraphy machines or software packages can in fact produce different results, in particular for circumferential and radial strain, making problematic intraindividual comparisons over time. Recognizing the critical need for standardization in strain imaging, the EACVI and ASE invited technical representatives from all interested vendors to participate in a concerted effort to reduce intervendor variability in strain measurement. ${ }^{170}$ Until that is achieved, it is recommended to use the same vendor's machine and software version to compare individual patients with cancer when using 2D STE for the serial evaluation of systolic function.

Individual echocardiographic laboratories following patients with cancer should strive to incorporate strain assessment in their echocardiography laboratory protocols.

\section{Key Points}

- Myocardial deformation (strain) can be measured using DTI or 2D STE. The latter is favored because of a lack of angle dependency.

- GLS is the optimal parameter of deformation for the early detection of subclinical LV dysfunction.

- Ideally, the measurements during chemotherapy should be compared with the baseline value. In patients with available baseline strain measurements, a relative percentage reduction of GLS of $<8 \%$ from baseline appears not to be meaningful, and those $>15 \%$ from baseline are very likely to be abnormal.

- When applying STE for the longitudinal follow-up of patients with cancer, the same vendor-specific ultrasound machine should be used.

\section{B. Detection of Subclinical LV Dysfunction Using Biomarkers}

Biomarkers have the potential to fulfill a critical unmet need as a robust diagnostic tool for the early identification, assessment, and monitoring of CTRCD. A biomarker approach is minimally invasive and can be readily repeated without significant risk. Despite intrinsic assay variability, standardized assays typically have acceptable coefficients of variation of $<10 \%$, potentially minimizing intra- and interobserver variability. ${ }^{171}$

1. Troponins. Cardiac troponins are the gold-standard biomarkers for the diagnosis of myocardial injury. ${ }^{172,173}$ Troponin I (TnI) is a sensitive and specific marker for myocardial injury in adults treated with anthracycline chemotherapy, and studies suggest that an elevation of troponin identifies patients at risk for the subsequent development of CTRCD.

The largest of these studies was performed in 703 patients with cancer, in whom TnI was determined with each cycle of high-dose chemotherapy and 1 month after chemotherapy. ${ }^{174}$ Patients were classified into three subgroups on the basis of the combined presence of any detectable TnI either within 72 hours (early) or 1 month after the last administration of chemotherapy (late). In 495 patients, both early 

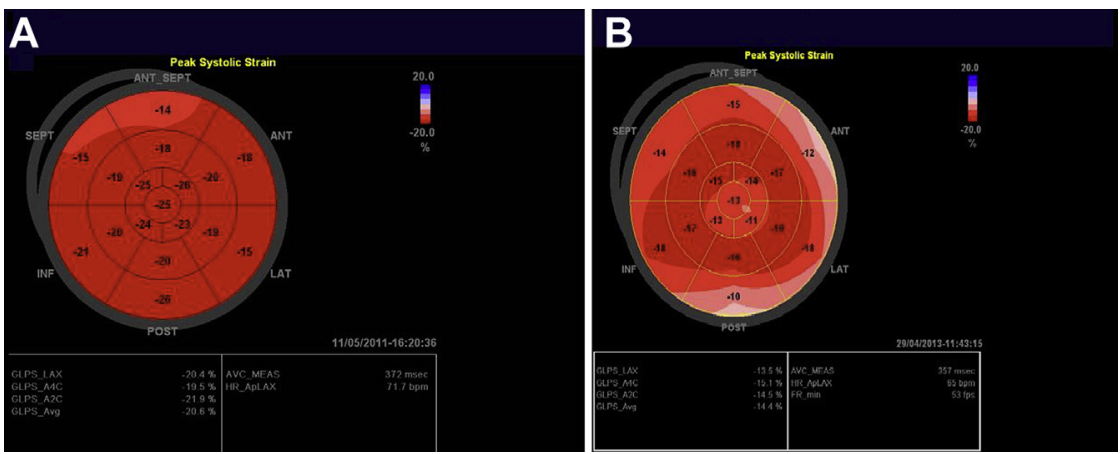

Figure 9 Bull's-eye plot showing GLS of the patient shown in Figure 8. (A) GLS and regional longitudinal strain at baseline. (B) GLS and regional longitudinal strain 3 months during trastuzumab-based therapy after anthracyclines. GLS has decreased from -20.6\% to $-14.4 \%$ (30\% decrease). The decrease in GLS is therefore considered of clinical significance (>15\% vs baseline).

Table 5 Effect of vendor age and gender on GLS

\begin{tabular}{|c|c|c|c|c|c|c|c|}
\hline \multirow[b]{2}{*}{ Vendor } & \multicolumn{6}{|c|}{ Age group (y) } & \multirow[b]{2}{*}{$P$} \\
\hline & $0-19$ & $20-29$ & $30-39$ & $40-49$ & $50-59$ & $\geq 60$ & \\
\hline \multicolumn{8}{|l|}{ V1 } \\
\hline Overall & $-22.1 \pm 2.4$ & $-21.2 \pm 1.9$ & $-21.1 \pm 2.1$ & $-21.4 \pm 2.0$ & $-21.0 \pm 2.2$ & $-20.3 \pm 1.9$ & .0218 \\
\hline Male & $-21.7 \pm 3.1$ & $-20.9 \pm 1.9$ & $-20.6 \pm 1.9$ & $-20.9 \pm 1.8$ & $-21.0 \pm 1.9$ & $-19.7 \pm 1.4$ & .1982 \\
\hline Female & $-22.4 \pm 1.6$ & $-22.3 \pm 1.6$ & $-22.8 \pm 1.8$ & $-22.6 \pm 2.1$ & $-23.3 \pm 1.9$ & $-20.9 \pm 2.1$ & .0348 \\
\hline$P$ (male vs female) & .4292 & .0316 & $<.0001$ & .0178 & .0029 & .1381 & \\
\hline \multicolumn{8}{|l|}{ V2 } \\
\hline Overall & $-19.9 \pm 2.5$ & $-19.0 \pm 2.1$ & $-19.5 \pm 2.2$ & $-18.2 \pm 2.5$ & $-17.6 \pm 2.5$ & $-16.7 \pm 2.1$ & $<.0001$ \\
\hline Male & $-19.4 \pm 2.7$ & $-18.8 \pm 2.0$ & $-19.1 \pm 2.3$ & $-17.9 \pm 2.8$ & $-16.9 \pm 2.3$ & $-15.8 \pm 1.4$ & .0019 \\
\hline Female & $-20.5 \pm 2.2$ & $-20.6 \pm 2.3$ & $-20.2 \pm 2.0$ & $-19.3 \pm 0.9$ & $-20.4 \pm 1.5$ & $-17.3 \pm 2.3$ & .0002 \\
\hline$P$ (male vs female) & .1349 & .0248 & .1083 & .4316 & .0294 & .0928 & \\
\hline \multicolumn{8}{|l|}{ V3 } \\
\hline Overall & $-21.4 \pm 1.7$ & $-20.2 \pm 2.1$ & $-20.4 \pm 2.3$ & $-19.4 \pm 2.2$ & $-18.5 \pm 2.6$ & $-17.8 \pm 2.8$ & $<.0001$ \\
\hline Male & $-21.6 \pm 2.0$ & $-20.2 \pm 2.0$ & $-20.4 \pm 2.2$ & $-19.8 \pm 2.3$ & $-18.7 \pm 2.6$ & $-16.3 \pm 3.1$ & $<.0001$ \\
\hline Female & $-21.2 \pm 1.5$ & $-20.2 \pm 2.4$ & $-20.4 \pm 2.8$ & $-18.7 \pm 1.8$ & $-18.3 \pm 2.8$ & $-18.6 \pm 2.3$ & .0141 \\
\hline$P$ (male vs female) & .6076 & .9787 & .9201 & .1415 & .7374 & .0668 & \\
\hline
\end{tabular}

V1, Vivid 7 or Vivid E9 (GE Healthcare); V2, iE33 (Philips Medical Systems); V3, Artida or Aplio (Toshiba Medical Systems).

Reproduced with permisssion from Circulation Journal. ${ }^{166}$

(within 72 hours) and late TnI values were $<0.08 \mathrm{ng} / \mathrm{mL}$; in 145 , there was only an early increase; and in 63 patients, both values increased These troponin release patterns identified patients at different levels of risk for CTRCD, with the majority of events occurring in TnIpositive patients. Furthermore, a persistent TnI increase was associated with an increase in the severity of CTRCD and a higher incidence or cardiac events compared with transient increases. The correlation between TnI positivity and LVEF maximal reduction ranged from 0.78 to 0.92 , with positive and negative predictive values of $84 \%$ and $99 \%$, respectively. The advantage of this high negative predictive value is the identification of patients at low risk for CTRCD. However, a persistent Tnl increase was associated with an increased severity of CTRCD and a higher incidence of cardiac events compared with transient increases. Additional smaller studies have also demonstrated correlations between troponin elevations and subsequent LVEF decline. ${ }^{175-177}$

Troponins may be also be used to identify early cardiac injury in patients undergoing treatment with newer targeted anticancer drugs. The largest of these studies, performed in 251 patients with breast cancer treated with trastuzumab, demonstrated that TnI positivity was associated with an increased incidence of cardiac events and lower likelihood of recovery. ${ }^{178}$ Other investigators have also studied the changes in $\mathrm{TnI}$ in patients with breast cancer receiving doxorubicin followed by trastuzumab therapy. ${ }^{160}$ In women who developed cardiotoxicity at the completion of anthracyclines, the mean ultrasensitive TnI concentration was $32 \mathrm{pg} / \mathrm{mL}$ (range, 10-56 pg/mL), compared with $17 \mathrm{pg} / \mathrm{ml}$ (range, 5-35 pg/ml) in women who did not. Furthermore, a value $>30 \mathrm{pg} / \mathrm{mL}$ was associated with specificity of $73 \%$ and negative predictive value of $77 \%$ for subsequent CTRCD. In contrast, Morris et al. ${ }^{179}$ demonstrated that TnI increases in patients receiving both trastuzumab and the tyrosine kinase inhibitor lapatinib were common, occurring in $67 \%$ of individuals; these elevations were not associated with subsequent CTRCD as detected by serial MUGA scans.

Schmidinger et al. ${ }^{180}$ also reported an increase in troponin T in 10\% of patients with metastatic renal cancer treated with sunitinib or sorafenib. Here, troponin $\mathrm{T}$ was used as a surrogate marker for 
Table 6 Strengths and limitations of GLS

GLS

\begin{tabular}{ll}
\hline Strengths & Superiority in the prediction of all-cause mortality \\
in the general population compared with LVEF & - Improved risk stratification in patients with $\mathrm{HF}^{238}$ \\
- & Ability to recognize early LV dysfunction in pa- \\
& tients undergoing cardiotoxic therapy and prog- \\
& nosticate subsequent CTRCD \\
- & Reproducibo \\
& tors \\
- & Heavy dependence on the quality of the 2D \\
& echocardiographic images \\
- Imfluenced by loading conditions & - Lack of long-term randomized clinical trials \\
& evaluating the ability of GLS to predict persistent \\
& decreases in LVEF or symptomatic HF \\
- & Lack of data as to the reproducibility of GLS in \\
& nonacademic centers or community hospitals \\
- & Vendor and software specific \\
\hline
\end{tabular}

subclinical dysfunction. These data suggest that troponins may be a useful tool for assessing CTRCD in patients treated with both conventional and newer anticancer therapies.

The role of $\mathrm{TnI}$ has been evaluated in patients with solid metastatic tumors treated with new anti-VEGF monoclonal inhibitors and tyrosine kinase inhibitors. ${ }^{181}$ Eleven percent of patients showed increases in TnI during treatment. Normalization of TnI values was obtained with $\beta$-blockers and aspirin, allowing patients to be rechallenged with the study drug. No patient experienced any subsequent increase in TnI or cardiac events during the subsequent observation period (mean follow-up period, 3 months).

Currently, there are a number of barriers to the widespread application of troponin as a clinical biomarker in CTRCD. First, the determination of the optimal timing of troponin assessment remains in question, as it is unclear if a single measurement with each cycle of chemotherapy has sufficient predictive value to be of utility or if multiple measurements are needed. Moreover, defining the cutoff point for positivity that maximizes the positive and negative predictive value, determining the optimal assay platform, and minimizing the coefficient of variation at the lower detection limit remain important goals.

2. Other Biomarkers. Natriuretic peptides, such as brain-type natriuretic peptide (BNP) and N-terminal pro-BNP (NT-proBNP), have also been measured in adults undergoing chemotherapy, with elevations typically reflective of abnormal filling pressures, but conclusions regarding their utility are conflicting and less consistent.

In a study using point-of-care testing, serial assessment of natriuretic peptides in 109 patients undergoing anthracycline-based therapy showed that a BNP elevation of $>200 \mathrm{pg} / \mathrm{mL}$ conferred a significantly increased risk for subsequent CTRCD, as observed in 11 patients. ${ }^{182}$ In smaller retrospective studies, patients with persistent BNP elevations 72 hours after high-dose chemotherapy had worsening of LV diastolic and systolic function indices from baseline to 12 months, with the mean LVEF decreasing from $62.8 \pm 3.4 \%$ to $45.6 \pm 11.5 \%{ }^{183}$

In contrast, a study of 100 patients demonstrated transient increases in NT-proBNP in 13 patients treated with anthracycline chemotherapy but no association with LV systolic or diastolic function. ${ }^{184}$ Other small studies have also demonstrated a lack of association $^{113,160,185,186}$ or only cross-sectional associations between BNP and LV diastolic function. ${ }^{187}$
A larger scale study, the Effectiveness of Using Biomarkers to Detect and Identify Cardiotoxicity and Describe Treatment trial, ${ }^{188}$ is currently under way, aiming to comprehensively determine the role of point-of-care biomarker testing in predicting cardiotoxicity in patients being treated with anthracyclines.

\section{Key Points}

- Elevated troponins in patients receiving cardiotoxic chemotherapy may be a sensitive measurement for the early detection of toxicity.

- In contrast to troponins, serum concentrations of natriuretic peptides, although likely reflective of elevated filling pressures, may be less consistent in the early identification of CTRCD.

\section{An Integrated Approach of Imaging and Biomarkers}

An integrated approach combining echocardiographic data and biomarkers may be of utility and provide incremental value in predicting subsequent CTRCD. It may also provide a strategy for more aggressive surveillance if used in parallel or reduction in the frequency of imaging when used in series (i.e., alternating imaging with biomarkers). Sawaya et al. ${ }^{160}$ published findings in the anthracycline and trastuzumab breast cancer population suggesting that the assessment of ultrasensitive troponin levels at the same time as STE-derived strain imaging obtained after anthracycline exposure has improved specificity of 93\%, in comparison with either parameter alone (73\%). An elevation in ultrasensitive TnI or a decrease in GLS of $>-19 \%$ was associated with sensitivity of $87 \%$ compared with $48 \%$ or $74 \%$ for each parameter alone. Some centers use an integrated approach with the use of echocardiography at standardized, clinical preselected intervals (e.g., every 3 months during trastuzumab therapy) with biomarker assessment before each cycle of trastuzumab (e.g., every 3 weeks) in patients at high risk for CTRCD. However, there is a critical need for additional research to further strengthen the validity of this approach.

\section{Key Point}

- An integrated approach may provide incremental value in predicting subsequent CTRCD.

\section{Implications of Early Detection on Therapeutic Approaches}

Although combination regimens for HF therapy have been reported to be effective, HF due to CTRCD is often resistant to therapy if diagnosed late in its course. Therefore, efforts have been directed at HF prevention. The possible approaches to HF prevention are prophylaxis in all patients or early identification and treatment.

Recognition of the availability of prophylaxis against subclinical LV dysfunction is an important step in developing a screening strategy; there would be no purpose in screening if there were no therapeutic implications. Pretreatment with a variety of agents (i.e., iron chelators, angiotensin-converting enzyme inhibitors, $\beta$-blockers, or statins) may be helpful in reducing the risk for cardiotoxicity. ${ }^{189}$ The most effective agents appear to be dexrazoxane ${ }^{190,191}$ and statin therapy. ${ }^{192,193}$ The use of vasoactive medications may be limited by the risk for side effects (especially dizziness and hypotension) ${ }^{194}$ and is supported by limited evidence for angiotensin-converting enzyme inhibitors, angiotensin-receptor blockers, and $\beta$-blockers. ${ }^{195-199}$ Given the frequency of asymptomatic LV dysfunction and the potential side effects associated with the proposed regimens, early identification and treatment may be the optimal path. 
Treatment of subclinical LV dysfunction is based on a strategy of early detection of myocardial disease with either biomarkers or imaging. The attraction of this approach is that there is potential benefit for any patient, and those without dysfunction are not burdened by the treatment. The disadvantages are that screening has to be sufficiently accurate to identify as closely as possible all at-risk patients and that some patients may have progressed to sufficient damage that treatment may provide only a partial response.

TnI release after high-dose chemotherapy in patients treated by anthracyclines was investigated by Cardinale and Sandri. ${ }^{171}$ This team demonstrated the usefulness of enalapril in this population, ${ }^{178}$ when given before ${ }^{178}$ or early after ${ }^{143}$ the LVEF decrease. The initial study in 114 cancer survivors with TnI release demonstrated significant reductions in LVEF but increases in LV volumes only in untreated patients. ${ }^{178}$ The study, however, lacked placebo administration, was unblinded, and lacked clinical end points. A further study demonstrated the role and limitations of an LVEF decrease initiating cardiac treatment in chemotherapy patients. ${ }^{143}$ In 201 consecutive patients with LV dysfunction (LVEF $<45 \%$ ) due to anthracycline cardiomyopathy, ${ }^{143}$ enalapril (and, if possible, carvedilol) were initiated promptly after the detection of reduced LVEF. On the basis of sequential LVEF measurements over the subsequent $36 \pm 27$ months, $42 \%$ of patients were considered responders, $13 \%$ were partial responders, and $45 \%$ were deemed nonresponders. Cardiac events were fewer in responders than partial responders and nonresponders. The response rate progressively decreased with increasing time delay between the end of chemotherapy to the start of HF; no complete recovery of LVEF was observed after 6 months.

Similar positive findings have been obtained with $\beta$-blockers in patients with subclinical LV dysfunction after trastuzumab. ${ }^{200}$ Of 42 patients with GLS decreases of $\geq-11 \%$, the 19 who were treated showed subsequent significant LVEF increases after 6 months (from $52.6 \pm 5.6 \%$ to $57.4 \pm 6.0 \%)$ but patients not taking $\beta$-blockers showed no change (from $56.7 \pm 5.9 \%$ to $56.0 \pm 5.2 \%, P=.001$ between groups). Additionally, data from a small number of recent studies indicate that $\beta$-blockers have a role as novel therapeutic agents in reducing tumor metastasis, tumor recurrence, and breast cancerspecific mortality. ${ }^{201}$

\section{Key Point}

- Small studies have suggested that a variety of agents (such as dexrazoxane, $\beta$-blockers, angiotensin-receptor blockers, and statins) may be helpful in the prevention or early treatment of CTRCD, but no definitive recommendations can be set with the current available data.

\section{OTHER IMAGING MODALITIES}

\section{A. Radionuclide Approaches for Monitoring Chemotherapy-Induced Cardiotoxicity}

1. MUGA. Measurement of LV function using either first-pass or equilibrium radionuclide angiography (also known as MUGA) was first used in the late 1970 s to identify patients receiving anthracyclines who had declines in LVEF before the development of clinical HF symptoms. ${ }^{202}$ When anthracyclines were stopped with a clinically asymptomatic decline in LVEF, there was no further deterioration in function, and in some patients, there was even recovery, especially when aggressively treated with optimal HF medications. Thus, monitoring by MUGA to detect an asymptomatic decline in LVEF was preferable to waiting for the development of symptoms of congestive HF symptoms, by which time CTRCD was irreversible. Serial imaging by MUGA had been reported to allow safe use of anthracyclines even when baseline LVEF was abnormal. ${ }^{203}$ On the basis of these results, the following recommendations for the use of MUGA to monitor anthracycline-induced cardiotoxicity were proposed ${ }^{33}$ :

1. LVEF $>50 \%$ at baseline

a. Measurement at 250 to $300 \mathrm{mg} / \mathrm{m}^{2}$

b. Measurement at $450 \mathrm{mg} / \mathrm{m}^{2}$

c. Measurement before each dose above $450 \mathrm{mg} / \mathrm{m}^{2}$

d. Discontinue therapy if LVEF decreases by $\geq 10 \%$ from baseline and $\mathrm{LVEF} \leq 50 \%$

2. $\mathrm{LVEF}<50 \%$ at baseline

a. Do not treat if LVEF is $<30 \%$

b. Serial measurement before each dose

c. Discontinue therapy if LVEF decreases by $\geq 10 \%$ from baseline or LVEF $\leq 30 \%$

These early reports suggested that clinical symptoms of CTRCD develop after irreversible damage has occurred and that asymptomatic declines in LVEF may represent an early sign of permanent damage. Efforts were made for earlier detection using stress testing and detection of fibrosis that preceded decline in LV systolic function. The use of exercise stress to measure LV functional reserve, with normal defined as an increase of $\geq 5$ LVEF units, was shown to have a higher sensitivity for early detection of CTRCD. ${ }^{202,204}$ Because of relatively low specificity, limited exercise capacity in most patients with cancer, and the requirement for using supine bicycle exercise, this technique is seldom used today. As mentioned with echocardiography, the significant variability in measurements of LV diastolic function by MUGA limits its clinical application. ${ }^{205}$

2. MUGA Compared with Other Modalities. As a $3 \mathrm{D}$ imaging technique, MUGA has consistently outperformed standard 2DE with respect to accuracy and reproducibility of LVEF measurements. ${ }^{206,207}$ In several studies, the values obtained by MUGA showed much higher correlations with those obtained with other 3D imaging tools, such as CMR and novel 3D echocardiographic techniques, but individual LV volumes and LVEF values still differed significantly across the techniques. ${ }^{206,208}$ Together, these findings point out that the LVEF results obtained by different techniques are not interchangeable and suggest that choosing a single technique may provide the best option for serial monitoring of LVEF in patients at risk.

The MUGA technique for monitoring anthracycline-induced CTRCD has been standardized, shown to be highly reproducible, and widely available and effectively applied in academic centers, community hospitals, and physicians' offices. ${ }^{33}$ On the basis of these findings, MUGA has been widely used in general clinical practice as well as in the efficacy trials for development of new chemotherapy agents for all tumor types. ${ }^{209}$ Advantages of MUGA in evaluation of patients during or after cancer therapy include the following:

1. Its widespread use in clinical practice with extensive long-term follow up: In the 1980s, there were extensive publications establishing the efficacy of MUGA for all types of adult and pediatric tumors treated with anthracyclines. On the basis of this body of evidence, MUGA was used widely in clinical trials and carried over into clinical practice.

2. Few technical limitations: ${ }^{99 \mathrm{~m}} \mathrm{Tc}$ red blood cell labeling and planar imaging can be done in all patients without limitations due to obesity, poor acoustic windows, or the presence of cardiac devices such as pacemakers or defibrillators. The technique is widely available, and cost is comparable with that of alternative modalities. 


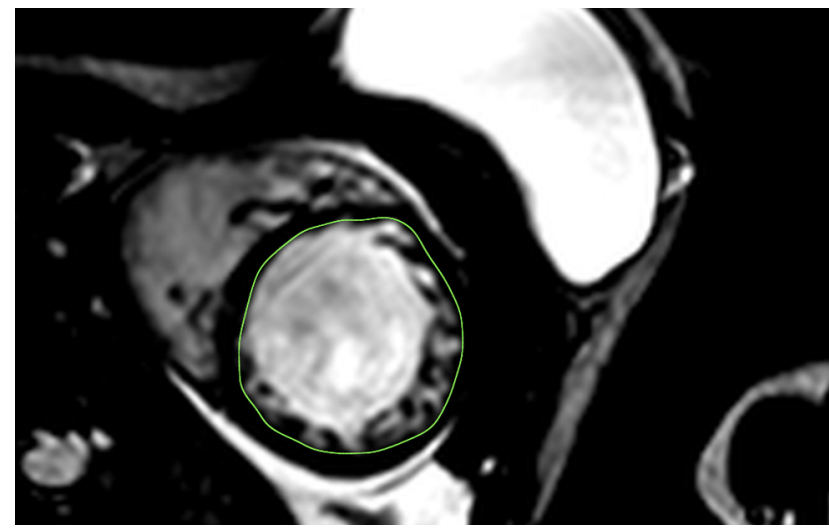

Figure 10 Short-axis, end-diastolic CMR cine image demonstrating quantitative approach to left ventricular volume measurement. Endocardial contour (green) is traced in a series of images encompassing the entire ventricle during cardiac cycle. A left breast implant is seen anterior to the chest wall in a patient with a history of left mastectomy and reconstruction.

3. High reproducibility and low variability make it desirable for serial testing Compared with qualitative estimates of LVEF by 2DE, serial measurements of MUGA have lower intra- and interobserver variability and a smaller coefficient of variability. ${ }^{210}$ This makes measurements highly reproducible, which is critical for serial testing and detecting early deterioration in LVEF.

The main disadvantage of MUGA is radiation exposure. The use of 20 to $30 \mathrm{mCi}$ of ${ }^{99 \mathrm{~m}} \mathrm{Tc}$ pertechnetate exposes patients to approximately 5 to $10 \mathrm{mSv}$ of radiation. Although linkage of such low levels of radiation to increased cancer risk has not been shown, it is good medical practice to keep radiation exposure "as low as reasonably achievable" and assess the risk versus the benefit of MUGA for individual patients. ${ }^{131}$ In addition, current gamma cameras may be suboptimal for performing critical measurements of LV volumes and LVEF. Early MUGA studies in the 1970s and 1980s were performed using single-headed, small-field-of-view gamma cameras that allowed optimal positioning of the patient to obtain the best separation between the two ventricles and apply a caudal tilt to avoid overlap with the left atrium. Current gamma cameras are predominately large-field-of-view or two-head systems that do not allow optimal patient positioning. Therefore, the high reproducibility of measurements of LVEF reported in the past may not apply to today's systems. Also, MUGA does not provide comprehensive information about RV function, left and right atrial size, or the presence or absence of valvular or pericardial disease, and it is frequently used as an adjunct and a complementary technique to echocardiography.

\section{B. CMR for Monitoring CTRCD}

CMR imaging has been an important tool to image the cardiovascular system since the early 1980s and particularly so over the past decade, with advances in both hardware and software contributing to its increased utility and acceptance. ${ }^{211}$ CMR is considered the reference standard in assessing LV and RV volumes and function and has demonstrated at least equivalence, if not superiority, for the detection of myocardial ischemia compared with cardiac nuclear imaging. ${ }^{212}$ With the advent of LGE, CMR is now considered the gold standard for myocardial viability imaging accompanied by positron emission tomography. ${ }^{213}$ However, only recently have multiple investigators begun to exploit the unique capabilities of CMR in detecting both the acute and chronic complications of cardiotoxic chemotherapeutic agents on cardiac function and to compare CMR's assessment efficacy relative to alternative imaging modalities. ${ }^{214,215}$ These initial reports suggest an important and rapidly evolving role for CMR in patients with cancer.

\section{CMR in the Assessment of Cardiac Structure and}

Function. CMR is a well-established clinical tool for the structural assessment of congenital and acquired cardiac anomalies and is often preferred to echocardiography and nuclear imaging for its wide field of view, flexible scanning planes, and lack of ionizing radiation. ${ }^{216}$ For LV and RV functional determination, CMR offers the advantages of true $3 \mathrm{D}$ volumetric coverage, high contrast-to-noise ratios providing excellent discrimination of endocardial and epicardial borders, and lack of reliance on assumed geometric models that may hinder accurate calculation of LV volumes, mass, and function by alternative modalities (Figure 10). These features provide a framework for more accurate functional assessment. In a recent study of 91 patients with reduced LVEFs after anthracycline therapy, CMR imaging demonstrated an inverse relationship between anthracycline dose and LV mass, thus illustrating a potential for additive diagnostic and prognostic information provided by CMR in patients with CTRCD CMR-determined parameters were also predictive of future cardiovascular events; both reduced LV mass and greater anthracycline dose were associated with increased rates of major adverse cardiovas cular events in patients followed for a median of 88 months. ${ }^{214}$

2. CMR and Echocardiography. The best-documented CMR technique for the assessment of LV volumes, LV mass, and LVEF uses a set of contiguous short-axis slices covering the entire left ventricle from the atrioventricular plane to the apex, acquired from a cine sequence. The short-axis slices can also be used for the assess ment of RV volumes and ejection fraction. Cine steady-state free precession is the technique currently used to measure these parameters. $^{217}$ Measurements of LVEF and volumes by CMR have been shown to be highly accurate and reproducible ${ }^{218}$ and have been demonstrated to be more reproducible than LV volumes and mass by echocardiography. ${ }^{111,219,220}$ Therefore, one obvious advantage of using CMR is in clinical research studies using LV volumes as outcome parameters. ${ }^{221,222}$

In most studies, CMR and echocardiographic measurements show high correlation. The absolute values, however, may differ. $^{223,224}$ LVEF by CMR, echocardiography, and radionuclide ventriculography were not interchangeable in a study of 52 patients with HF. ${ }^{219}$ Recently, Armstrong et al., ${ }^{221}$ in a cohort of long-term survivors of chemotherapy, demonstrated similar mean LVEF values by CMR and 3DE, whereas 2DE values were higher by approximately $5 \%$. This largest study with direct comparison of 2DE and 3DE with CMR showed that $3 \mathrm{DE}$ was superior to $2 \mathrm{DE}$, but both $3 \mathrm{DE}$ and 2DE were suboptimal at identifying patients with LVEFs below a threshold value of $50 \%$ defined by CMR. These data suggest that CMR may be the preferred technique for LVEF determination when echocardiography reaches a threshold value of LV dysfunction. It is the recommendation of this committee to consider the use of CMR in situations in which discontinuation of chemotherapeutic regimens secondary to CTRCD is being entertained or when, because of technical limitations or the quality of echocardiographic images, the estimation of the LVEF is thought to be controversial or unreliable. CMR may provide an important advantage in 


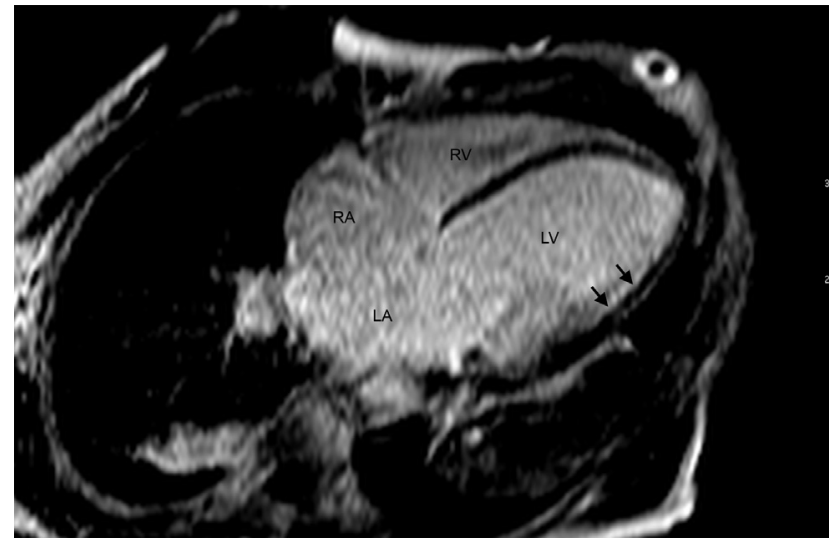

Figure 11 CMR image using LGE in four-chamber projection in a patient with a history of anthracycline-induced cardiomyopathy. The left ventricle is dilated with wall thinning. There is no evidence of LGE.

patients in whom extracardiac masses represent a concern. ${ }^{225}$ Measurements from CMR, echocardiography and nuclear techniques cannot be regarded as identical or be directly compared from one modality to another. Ideally, a single technique should be chosen for baseline assessment and follow-up studies during and after cancer treatment.

Disadvantages of CMR include its lesser flexibility and availability and higher operational cost compared with echocardiography. ${ }^{221}$ In addition, issues with claustrophobia and hazards associated with ferromagnetic devices need to be considered. Contraindications for CMR imaging that may be particularly relevant in some patients with cancer include the presence of ferromagnetic components within some breast tissue expanders (i.e., Contour Profile Tissue Expander [Mentor, Santa Barbara, CA], which contains a magnetic injection dome) used for breast reconstruction after mastectomy.

3. Beyond the LVEF: Advanced CMR Assessments. Contrastenhanced CMR offers a unique capability to assess myocardial tissue characteristics compared with other imaging techniques. This technique has demonstrated excellent ability to outline myocardial fibrosis and is commonly used in detection of myocardial scar and workup of cardiomyopathies. ${ }^{226}$ All CMR contrast agents are gadolinium based, and at the present time, contrast-enhanced CMR of the heart represents an off-label use for all US Food and Drug Administration-approved agents. Their main limitation is a potential to cause nephrogenic systemic fibrosis, an exceedingly rare but serious condition. ${ }^{227}$ The risk for nephrogenic systemic fibrosis increases in patients with renal insufficiency, and contrast CMR use should be limited to patients without significant kidney dysfunction. Gadolinium accumulates in the normal myocardium a few seconds after contrast injection. LGE can be observed 10 to 20 min after contrast injection and represents myocardial fibrosis. Lack of LGE is the most common finding in patients who develop anthracyclineinduced CTRCD (Figure 11). ${ }^{121,214}$ LGE has been the most frequently used technique to exclude other causes of cardiomyopathy, such as myocardial infarction, cardiac sarcoidosis, or amyloid heart disease. The recent findings from a single center of the presence of lateral wall LGE in patients who received HER2 therapies ${ }^{156}$ have not been reproduced. CMR may also have added value in the evaluation of cardiac metastasis or invasion tumor to the heart.

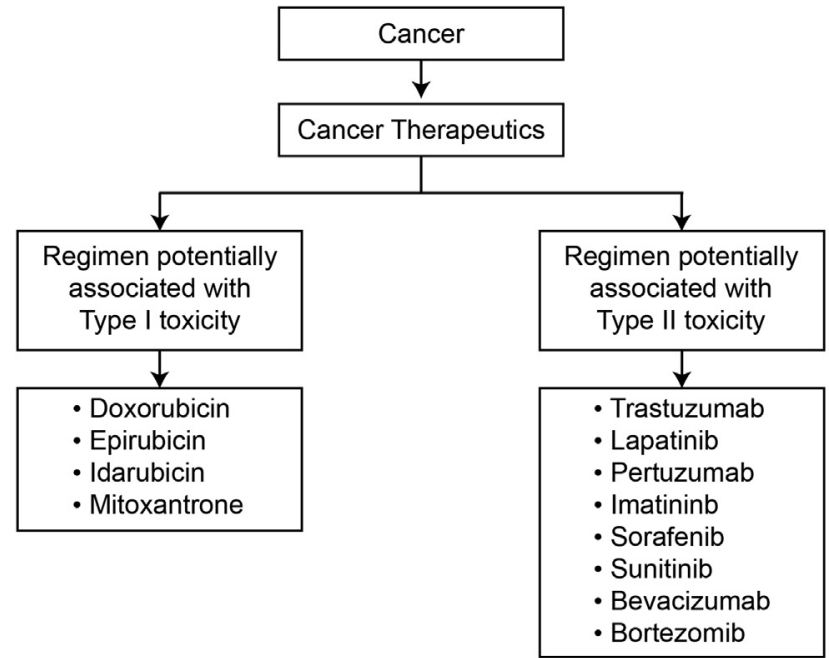

Figure 12 Cancer therapeutics regimens associated with type I and type II CTRCD.

More recently, gadolinium-based contrast has also been used in T1 mapping, a novel, quantitative CMR technique that identifies subtle myocardial abnormalities such as diffuse fibrosis, not visible on LGE imaging. $^{228,229}$ One recent study in a small cohort of 13 patients after anthracycline therapy and with normal LV function demonstrated no correlation between anthracycline dose and myocardial fibrosis, though there was a relationship with increased LV volume. ${ }^{230}$ Using this technique, Neilan et al. ${ }^{231}$ recently reported increased extracellular volume as a surrogate of myocardial fibrosis in 42 patients treated with anthracyclines, compared with age- and gender-matched controls. A positive association was found between the extracellular volume and the left atrial volume, and a negative association was found between the extracellular volume and LV diastolic function. Although this technique suggests promise for future diagnosis and possibly prediction of risk for cardiomyopathies, its current use is limited to research studies.

\section{Specific Challenges}

Patients with breast cancer (the majority of patients to whom this document applies) present specific challenges in their cardiac imaging. The feasibility of 2DE, 3DE, and strain imaging may be limited by the inability to obtain images of diagnostic quality because of mastectomy, radiation, or the presence of breast implants. It is important to adequately document these limitations in the report and to refrain from reporting findings if uncomfortable with the technical quality of the study. In these specific situations, the use of echocardiographic contrast (please see Section II.G) may be useful for an accurate calculation of ejection fraction. If with the administration of contrast the calculation of LVEF is still not feasible using the biplane method of disks, CMR is recommended. It is important to inquire about the presence of ferromagnetic components, if the patient has breast tissue expanders.

\section{Key Points}

- The calculation of LVEF by MUGA is highly reproducible. The main limita tions are radiation exposure and the lack of ability to report on pericardial and valvular heart disease and RV function. 


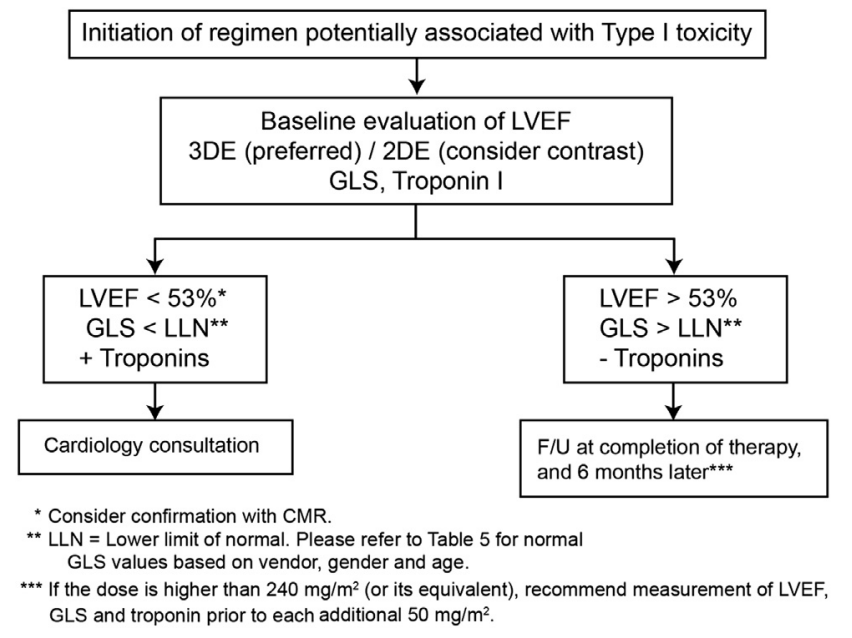

Figure 13 Initiation of a regimen potentially associated with type I toxicity. A baseline evaluation including measurements of LVEF, GLS, and troponin is recommended. If any are abnormal, a cardiology consultation is recommended. Follow-up is recommended at the completion of therapy and 6 months later for doses $<240 \mathrm{mg} / \mathrm{m}^{2}$ or its equivalent. Once this dose is exceeded, measurements of LVEF, GLS, and troponin are recommended before each additional $50 \mathrm{mg} / \mathrm{m}^{2}$.

- The newer and most commonly used dual-head gamma cameras were not used in the initial reproducibility studies, and their interstudy reproducibility is not well known.

- CMR is the reference standard in the evaluation of LV and RV volumes and LVEF. Its main limitation is its limited availability. It may be particularly useful in situations in which discontinuation of chemotherapy is being entertained and/or when there is concern regarding echocardiographic or equilibrium radionuclide angiographic calculation of LVEF.

- Standard precautions for CMR safety need to be followed, including consideration of electromagnetic interference. This may be particularly relevant in patients with breast cancer, in whom tissue expanders placed for breast reconstruction may represent a hazard.

- It is important to realize that the different techniques use different normal reference values. Thus, the same technique should be performed for baseline assessment and follow-up studies during and after cancer treatment.

\section{INTEGRATED APPROACH}

This section represents the consensus of the current clinical practices of the academic institutions represented by the authors of this report. We recognize the limited scientific data available and the lack of class A evidence (derived from randomized clinical trials) supporting the algorithms. The algorithms represent our current knowledge of the field. As new data becomes available, we anticipate that updates will be required.

\section{A. Baseline Assessment and Monitoring}

- Cooperation between cardiologists and oncologists is absolutely essential.

- It would be ideal to perform a baseline cardiac assessment in every patient scheduled to receive a potentially cardiotoxic agent. However, this is often not possible.

- If not possible in all patients, it is recommended to perform a baseline cardiac assessment in those considered to be at high risk for development of CTRCD, such as those patients with established or risk factors for cardiovascular disease, those with LV dysfunction, those $>65$ years of age, and those

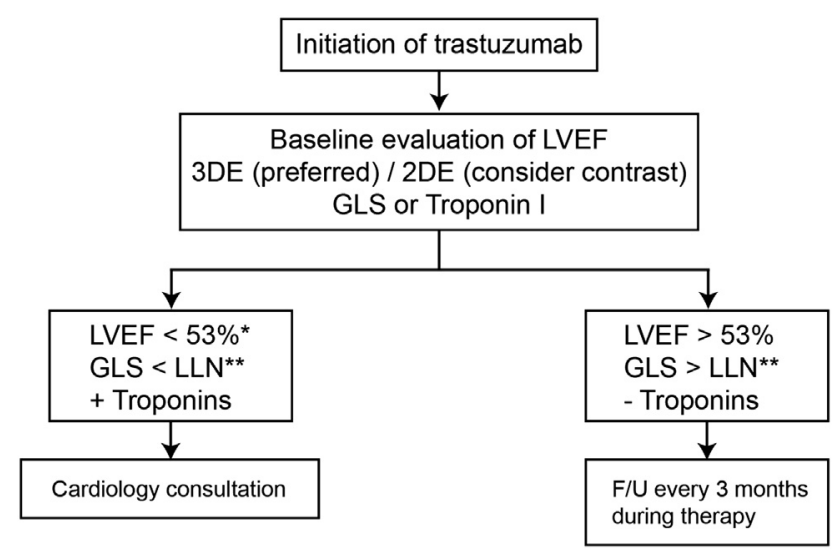

* Consider confirmation with CMR.

** LLN = Lower limit of normal. Please refer to Table 5 for normal GLS values based on vendor, gender and age.

Figure 14 Initiation of trastuzumab. A baseline evaluation including measurements of LVEF, GLS, and troponin is recommended. If any are abnormal, a cardiology consultation is recommended. Measurements of LVEF, GLS, and troponins are recommended every 3 months.

scheduled to receive high doses of type I agents $\left(>350 \mathrm{mg} / \mathrm{m}^{2}\right)$ or combination chemotherapy with both type I and type II agents (Figure 12).

- The baseline cardiac assessment, in addition to a thorough medical history and physical examination, should include electrocardiography to evaluate the cardiac rhythm and detect signs of resting ischemia and a cardiac imaging test (usually echocardiography) for the evaluation of cardiac structure and function (see Table 2 for cardio-oncology echocardiogram protocol).

- A baseline assessment of GLS and/or troponin is desirable. Although GLS has negative values in normal individuals, for the sake of simplicity in this section, we will refer to it as an absolute value (without the negative sign).

- A pretreatment assessment may help cardiologists advise oncologists as to known or anticipated risks.

- If the LVEF is $<53 \%,{ }^{22-26}$ GLS is below the limit of normal (Table 5), and/or troponins are elevated, a cardiology consultation should be considered, with discussion between the cardiologist and oncologist of the risk/benefit ratio, and cancer treatment at the discretion of the oncologist (Figures 13-15).

- If the quality of the echocardiogram is suboptimal, CMR is recommended.

- Follow-up assessment is recommended on the basis of the specific type of anticancer agent received (Figure 13).

\section{Type I Agents.}

- Historically, there has been concern for cumulative doses of anthracyclines exceeding $400 \mathrm{mg} / \mathrm{m}^{2}$, because of an associated $5 \%$ risk for HF. However the risk for doxorubicin-related CTRCD is really a continuum that spans from $0.2 \%$ to $100 \%$, for cumulative doses of 150 to $850 \mathrm{mg} / \mathrm{m}^{2}$, respectively. In the study by Swain et al., ${ }^{30}$ the earliest step-up in cardiac events occurred from 250 to $350 \mathrm{mg} / \mathrm{m}^{2}(9 \%-18 \%){ }^{232}$ New data evaluating patients who have received low doses of anthracyclines $\left(<375 \mathrm{mg} / \mathrm{m}^{2}\right)$ revealed a rate of subclinical LV dysfunction (LVEF $<50 \%$ ) of $26 \%$ at 6 months of follow-up after therapy. ${ }^{233}$ As a result, this committee recommends follow-up at the completion of therapy for regimens including doses $<240 \mathrm{mg} / \mathrm{m}^{2}$. After exceeding the dose of $240 \mathrm{mg} / \mathrm{m}^{2}$, an evaluation before each additional cycle is considered prudent (Figures 13 and 15).

\section{Type II Agents.}

- Patients receiving trastuzumab should undergo follow-up echocardiography every 3 months during therapy (Figures 14 and 15). 


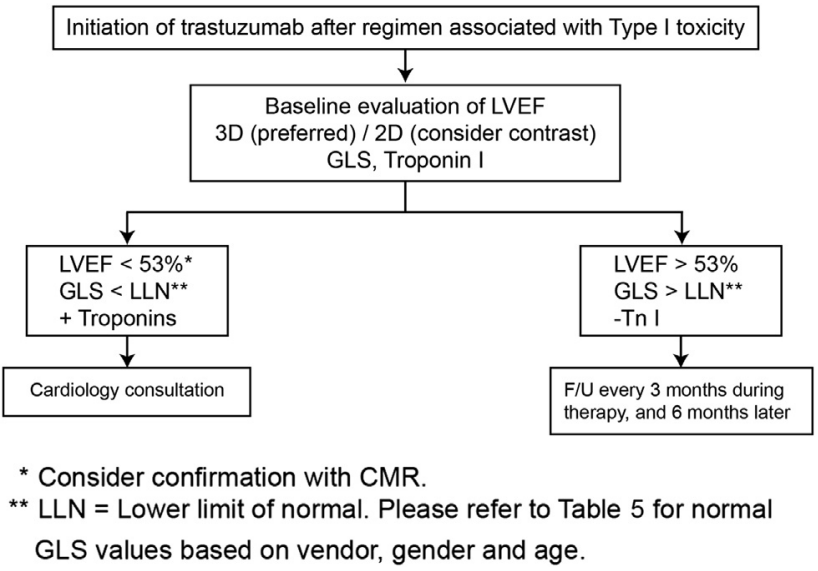

Figure 15 Initiation of trastuzumab after regimen associated with type I toxicity. A baseline evaluation including measurements of LVEF, GLS, and troponin is recommended. If any are abnormal, a cardiology consultation is recommended. Measurements of LVEF, GLS, and troponin are recommended every 3 months during therapy and 6 months later.

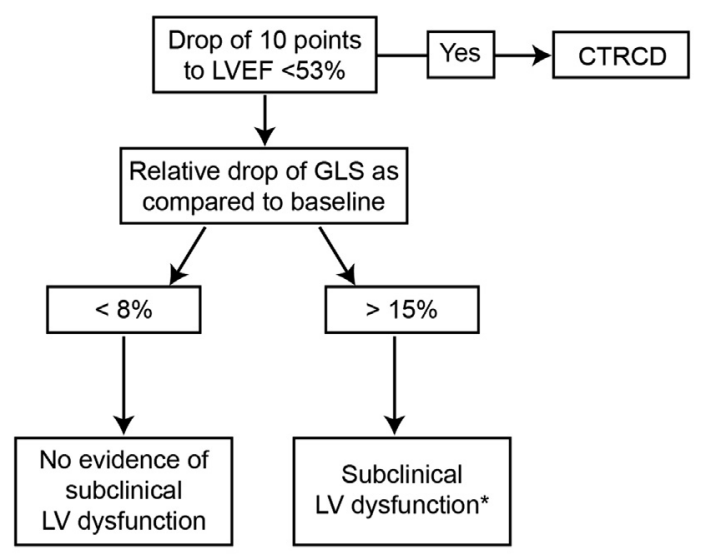

\section{* The data supporting the initiation of cardioprotection for the treatment of subclinical LV dysfunction is limited.}

Figure 16 Early detection of subclinical LV dysfunction using GLS. In the absence of adjudication of CTRCD, it is recommended to use GLS for the identification of subclinical LV dysfunction. If baseline strain is available, a relative percentage decrease of $>15 \%$ compared with baseline is likely to be of clinical significance, whereas a decrease of $<8 \%$ is not.

- The potential hemodynamic burden of other tyrosine kinase inhibitors (sunitinib, sorafenib) should be considered in patients with known CAD and should be assessed according to perceived individual risk with appropriate close monitoring and treatment of blood pressure and symptoms in patients at high cardiovascular risk. In the absence of data, we recommend a baseline echocardiographic evaluation, with follow-up at 1 month and every 3 months while on therapy with VEGF or VEGF receptor inhibitors.

\section{B. Detection of Subclinical LV Dysfunction}

- During chemotherapy, patients are longitudinally followed for evidence of CTRCD or subclinical LV dysfunction (abnormal GLS [Figure 16] or

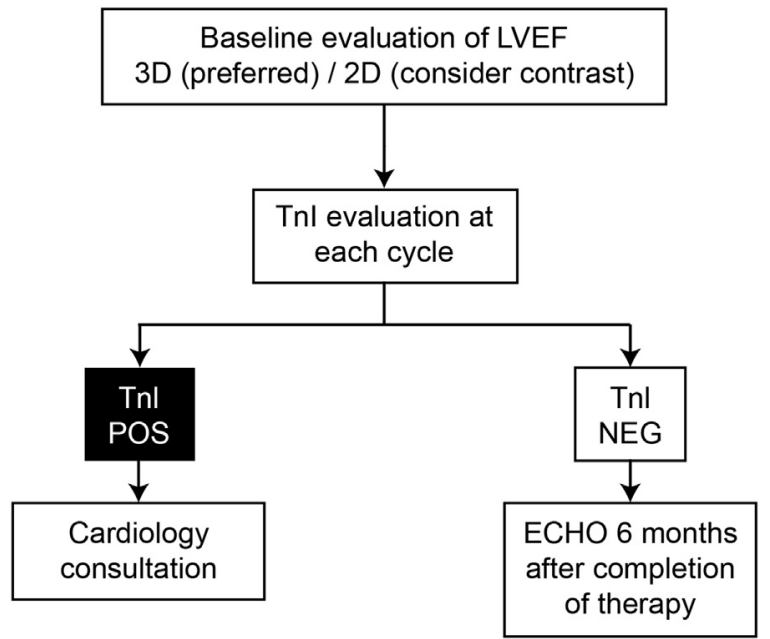

Figure 17 Early detection of subclinical LV dysfunction using biomarkers.

elevated troponins [Figure 17]). With these changes, a cardiology consultation should be considered, with discussion between the cardiologist and oncologist as to whether to continue the agent, alter the regimen, and/or consider the initiation of cardioprotective agents.

- The ideal strategy for the detection of subclinical LV dysfunction is to compare the measurements of GLS obtained during chemotherapy with the one obtained at baseline, allowing the patient to serve as his or her own control. A relative percentage reduction in GLS of $>15 \%$ is very likely to be abnormal, whereas a change of $<8 \%$ appears not to be of clinical significance (Figures $9 \mathrm{a}$ and $9 \mathrm{~b}$ ). The abnormal GLS value should be confirmed by a repeat study. The repeat study should be performed 2 to 3 weeks after the initial abnormal study.

- When comparing LVEF and GLS values, it is essential to keep in mind the load dependency of these measurements. This committee recommends reporting the timing of the echocardiographic examination with respect to the intravenous infusion of chemotherapeutic agents (number of days before or after treatment) as well as the vital signs measured during the test (blood pressure and heart rate), recognizing that changes in loading conditions are frequent and may affect the GLS value (volume expansion due to the intravenous administration of chemotherapeutic agents or volume contraction due to vomiting or diarrhea)

- Troponin levels are measured before and/or 24 hours after each chemotherapy cycle. Patients with troponin elevations during therapy (as defined by the cutoffs specific to the assay platform used in the individual labs) are at a higher risk for subsequent cardiovascular events. As such, it is suggested to obtain a cardiology consultation.

- Troponin levels have added prognostic value to GLS. If both are abnormal, the specificity for the prediction of CTRCD increases from $73 \%$ to $93 \%$. If both are normal, the negative predictive value increases to $91 \%$. ${ }^{160}$

- An elevation in NT-proBNP raises concern for increased LV filling pressures in the setting of CTRCD. The negative predictive value of NT-proBNP may be useful, but the variability over time has limited its utility. Further studies in this area are needed.

- It is the recommendation of this committee to consider the use of CMR in situations in which discontinuation of chemotherapeutic regimens second ary to CTRCD is being entertained or when, because of technical limitations or the quality of echocardiographic images, the estimation of the LVEF is thought to be controversial or unreliable.

- Although small studies suggest the role of the initiation of cardioprotective regimens in the setting of subclinical $\mathrm{LV}$ dysfunction, there is a lack of conclusive data (randomized clinical trials) supporting this strategy.

- If the agent is continued despite LV functional changes, reassessment should be undertaken by imaging, ideally with GLS and/or troponins before each additional cycle, with the understanding that the risk for cardiac events 
increases with further exposure. Patients' understanding of the risk-benefit analysis should be adequately documented.

- In the absence of factors that can modify the risk of the patient (concomitant risk factors or radiotherapy), if the GLS has been stable during chemotherapy and is normal at 6 months of follow-up after the completion of therapy with a type I agent, or the troponins have remained negative throughout therapy, additional imaging surveillance for CTRCD is not warranted.

- In the absence of CTRCD or subclinical LV dysfunction caused by chemotherapy, patients who have received concomitant radiation need to be followed according to published ASE and EACVI expert consensus. ${ }^{58}$

- After the completion of therapy, and particularly in patients who were not followed using a strategy of early detection of subclinical LV dysfunction, this committee suggests a yearly clinical cardiovascular assessment by a health care provider, looking for early signs and symptoms of cardiovascular disease, with further cardiac imaging ordered at the discretion of the provider

\section{EXECUTIVE SUMMARY}

\section{Chemotherapy related cardiac dysfunction}

- Highly effective chemotherapeutic agents may cause CTRCD.

- CTRCD is defined as a decrease in the LVEF of greater than 10 percentage points, to a value $<53 \%$ (normal reference value for $2 \mathrm{DE}$ ). This decrease should be confirmed by repeated cardiac imaging. The repeat study should be performed 2 to 3 weeks following the baseline diagnostic study showing the initial decrease in LVEF. Left ventricular ejection fraction decrease may be further categorized as symptomatic or asymptomatic, or with regard to reversibility: reversible (to within 5 percentage points of baseline); partially reversible (improved by at least 10 percentage points, but remaining more than 5 percentage points below baseline); irreversible (remaining within 10 percentage points of the nadir); or indeterminate (patient not available for re-evaluation).

- CTRCD has been classified as:

1. CTRCD Type I, characterized by anthracyclines. It is dose-dependent, leads to cell apoptosis, and is therefore irreversible at the cell level. Early detection and prompt treatment may prevent left ventricular remodel ing and the progression to the heart failure syndrome.

2. CTRCD Type II, characterized by trastuzumab. It is not dose-depen dent, does not lead to apoptosis by itself, and is often reversible.

\section{Echocardiographic evaluation of cardiac structure and function in the cancer patient}

\subsection{LV systolic function.}

- Echocardiography is the method of choice for the evaluation of patients before, during and after cancer therapy.

- Accurate calculation of LVEF should be done with the best method available in the echocardiography laboratory (ideally $3 \mathrm{DE}$ ).

- When using 2DE, the modified biplane Simpson technique is the method of choice.

- LVEF should be combined with the calculation of wall motion score index.

- In the absence of GLS by STE, quantification of LV longitudinal function us ing mitral-annulus displacement by M-mode echocardiography, and/or peak systolic velocity $\left(s^{\prime}\right)$ of the mitral annulus by pulsed-wave DTI is recommended.

- LVEF assessed by 2DE, often fails to detect small changes in LV contractility.

\subsection{Diastolic function.}

- Although diastolic parameters have not been found to be prognostic of CTRCD, a conventional assessment of LV diastolic function, including grading of diastolic function and noninvasive estimation of LV filling pressures, should be added to the assessment of LV systolic function, per ASE/EAE recommendations for the evaluation of LV diastolic function with echocardiography.

\section{3. $R V$ function.}

- Although prognostic value of RV dysfunction has not been demonstrated in patients undergoing chemotherapy, a quantitative assessment of RV chamber and function should be performed due to possible RV involvement.

\subsection{Valvular disease.}

- Cardiac valves should be carefully evaluated in patients undergoing chemotherapy.

- Patients with baseline or changing valvular findings during chemotherapy should have careful re-evaluation of valve structure and function on serial echocardiograms during and after the course of their treatment.

\subsection{Pericardial disease.}

- Pericardial disease in oncologic patients can be associated with cardiac metastasis or be a consequence of chemotherapy/radiotherapy.

- Pericardial effusion should be quantified and graded according to standard methods.

- Echocardiographic and Doppler signs of cardiac tamponade should be investigated, particularly in patients with malignant effusions.

- CMR should be considered in evaluation of primary tumors of the heart with or without compromise of the pericardium, or when the diagnosis of constrictive pericarditis remains uncertain after a careful echocardiographic evaluation

\subsection{DE.}

- $3 \mathrm{DE}$ is the preferred echo technique for monitoring LV function and detection of CTRCD in cancer patients. Advantages include better accuracy in detecting LVEF below the lower limit of normal, better reproducibility, and lower temporal variability, as compared with $2 \mathrm{DE}$ in cancer patients treated with chemotherapy.

- Costs, availability, high reliance on image quality, and need of training for operators currently limit wide application of 3DE in the oncologic setting.

\subsection{Contrast echocardiography.}

- The use of myocardial contrast agents could be potentially useful in chemotherapy patients when endocardial drop out occurs

- According to current recommendations, contrast should be used when 2 contiguous LV segments are not well visualized on noncontrast apical images.

- Contrast agents are not recommended in conjunction with 3DE in the longitudinal follow-up of cancer patients.

\subsection{Stress echocardiography.}

- Stress echocardiography may be helpful in the evaluation of patients with intermediate or high pretest probability for CAD, (echocardiogram uninterpretable or unable to exercise) who will receive regimens that may cause ischemia (fluorouacil, bevacizumab, sorafenib, and sunitinib).

- Stress echocardiography may be of help in the determination of contractile reserve of patients with evidence of CTRCD.

\section{Detection of sub clinical LV dysfunction}

- A decreased LVEF at baseline or after anthracyclines is associated with higher rates of cardiac events on follow-up.

- Although it has been suggested that alterations in LV diastolic function (as evaluated by Doppler indices of mitral inflow and e' by pulsed Doppler tissue imaging) precede alterations in systolic function, the evidence does not support the role of these indices for the prediction of later CTRCD.

- Myocardial deformation (strain) can be measured using Doppler tissue im aging or 2D STE. The latter is favored due to lack of angle dependency.

- Global longitudinal strain is the optimal parameter of deformation for the early detection of subclinical LV dysfunction.

- Ideally, the measurements during chemotherapy should be compared with the baseline value. In patients with available baseline strain measurements, a relative percentage reduction of global longitudinal strain $<8 \%$ from 
baseline appear not to be meaningful, and those $>15 \%$ from baseline are very likely to be abnormal.

- When applying STE for the longitudinal follow-up of cancer patients, the same vendor-specific ultrasound machine should be used.

- The elevation of troponins in patients receiving cardiotoxic chemotherapy may be a sensitive measurement for the early detection of toxicity.

- In contrast to troponins, serum concentrations of natriuretic peptides, although likely reflective of elevated filling pressures, may be less consistent in the early identification of CTRCD.

- An integrated approach may provide incremental value in predicting subsequent CTRCD.

- Small studies have suggested that a variety of agents (such as dexrazoxane, beta-blockers, angiotensin-receptor blockers, and statins) may be helpful in the prevention or early treatment of CTRCD, but no definitive recommendations can be set with the current available data.

\section{Other imaging modalities}

- The calculation of LVEF by MUGA is highly reproducible. The main limitations are radiation exposure and the lack of ability to report on pericardial and valvular heart disease and RV function.

- The newer and most commonly used dual head gamma cameras were not used in the initial reproducibility studies and their inter-study reproducibility is not well known.

- CMR is the reference standard in the evaluation of LV and RV volumes and LVEF. Its main limitation is its limited availability. It may be particularly useful in situations where discontinuation of chemotherapy is being entertained, and/or when there is concern regarding echocardiographic or equilibrium radionuclide angiocardiography calculation of LVEF.

- Standard precautions for CMR safety need to be followed including consideration of electromagnetic interference. This may be particularly relevant in patients with breast cancer in whom tissue expanders placed for breast reconstruction may represent a hazard.

- It is important to realize that the different techniques use different normal reference values. Thus, the same technique should be performed for baseline assessment and follow-up studies during and after cancer treatment.

\section{NOTICE AND DISCLAIMER}

This report is made available by the ASE and EACVI as a courtesy reference source for members. This report contains recommendations only and should not be used as the sole basis to make medical practice decisions or for disciplinary action against any employee. The statements and recommendations contained in this report are based primarily on the opinions of experts rather than on scientifically verified data. The ASE and EACVI make no express or implied warranties regarding the completeness or accuracy of the information in this report, including the warranty of merchantability or fitness for a particular purpose. In no event shall the ASE and EACVI be liable to you, your patients, or any other third parties for any decision made or action taken by you or such other parties in reliance on this information. Nor does your use of this information constitute the offering of medical advice by the ASE and EACVI or create any physician-patient relationship between the ASE and EACVI and your patients or anyone else.

\section{REFERENCES}

1. Tan C, Tasaka H, Yu KP, Murphy ML, Karnofsky DA. Daunomycin, an antitumor antibiotic, in the treatment of neoplastic disease. Clinical evaluation with special reference to childhood leukemia. Cancer 1967;20 333-53.
2. Alexander J, Dainiak N, Berger HJ, Goldman L, Johnstone D, Reduto L, et al. Serial assessment of doxorubicin cardiotoxicity with quantitative radionuclide angiocardiography. N Engl J Med 1979;300:278-83.

3. Lenzhofer R, Dudczak R, Gumhold G, Graninger W, Moser K, Spitzy KH Noninvasive methods for the early detection of doxorubicin-induced cardiomyopathy. J Cancer Res Clin Oncol 1983;106:136-42.

4. Ramos A, Meyer RA, Korfhagen J, Wong KY, Kaplan S. Echocardiographic evaluation of adriamycin cardiotoxicity in children. Cancer Treat Rep 1976;60:1281-4.

5. Ewer MS, Ali MK, Mackay B, Wallace S, Valdivieso M, Legha SS, et al. A comparison of cardiac biopsy grades and ejection fraction estimations in patients receiving Adriamycin. J Clin Oncol 1984;2:112-7.

6. Neilan TG, Jassal DS, Perez-Sanz TM, Raher MI, Pradhan AD, Buys ES, et al. Tissue Doppler imaging predicts left ventricular dysfunction and mortality in a murine model of cardiac injury. Eur Heart J 2006;27: 1868-75.

7. Khouri MG, Douglas PS, Mackey JR, Martin M, Scott JM, ScherrerCrosbie M, et al. Cancer therapy-induced cardiac toxicity in early breast cancer: addressing the unresolved issues. Circulation 2012;126:2749-63.

8. Zhang S, Liu X, Bawa-Khalfe T, Lu LS, Lyu YL, Liu LF, et al. Identification of the molecular basis of doxorubicin-induced cardiotoxicity. Nat Med 2012;18:1639-42.

9. Friedman MA, Bozdech MJ, Billingham ME, Rider AK. Doxorubicin car diotoxicity. Serial endomyocardial biopsies and systolic time intervals JAMA 1978;240:1603-6.

10. Ewer MS, Lippman SM. Type II chemotherapy-related cardiac dysfunction: time to recognize a new entity. J Clin Oncol 2005;23:2900-2.

11. Felker GM, Thompson RE, Hare JM, Hruban RH, Clemetson DE, Howard DL, et al. Underlying causes and long-term survival in patients with initially unexplained cardiomyopathy. N Engl J Med 2000;342: 1077-84.

12. Lal H, Kolaja KL, Force T. Cancer genetics and the cardiotoxicity of the therapeutics. J Am Coll Cardiol 2013;61:267-74.

13. Ewer M, Suter D, Lenihan DJ, Niculescu L, Breazna A, Motzer RJ, et al Sunitinib-related hypertension is a randomized placebo-controlled trial of GIST patients. J Clin Oncol 2010;28. abstract 10059-abstract 10059.

14. Ewer MS, Perez EA, Baselga J, Bell R, Brutsaert D, Marty M, et al. P176 Cardiac safety guidelines for the adjuvant use of trastuzumab (Hercep tin $^{\circledR}$ ) in HER2-positive early breast cancer. The Breast 2007; 16:S63.

15. Daher IN, Kim C, Saleh RR, Plana JC, Yusuf SW, Banchs J. Prevalence of abnormal echocardiographic findings in cancer patients: a retrospective evaluation of echocardiography for identifying cardiac abnormalities in cancer patients. Echocardiography 2011;28:1061-7.

16. Cheitlin MD, Armstrong WF, Aurigemma GP, Beller GA, Bierman FZ, Davis JL, et al. ACC/AHA/ASE 2003 Guideline Update for the Clinical Application of Echocardiography: summary article. A report of the American College of Cardiology/American Heart Association Task Force on Practice Guidelines (ACC/AHA/ASE Committee to Update the 1997 Guidelines for the Clinical Application of Echocardiography). J Am Soc Echocardiogr 2003;16:1091-110.

17. American College of Cardiology Foundation Appropriate Use Criteria Task Force, American Society of Echocardiography, American Heart Association, American Society of Nuclear Cardiology, Heart Failure Society of America, Heart Rhythm Society, et al. ACCF/ASE/AHA/ASNC/ HFSA/HRS/SCAI/SCCM/SCCT/SCMR 2011 Appropriate Use Criteria for Echocardiography. A Report of the American College of Cardiology Foundation Appropriate Use Criteria Task Force, American Society of Echocardiography, American Heart Association, American Society of Nuclear Cardiology, Heart Failure Society of America, Heart Rhythm Society, Society for Cardiovascular Angiography and Interventions, Society of Critical Care Medicine, Society of Cardiovascular Computed Tomography, Society for Cardiovascular Magnetic Resonance American College of Chest Physicians. J Am Soc Echocardiogr 2011;24:229-67.

18. Steingart RM, Bakris GL, Chen HX, Chen MH, Force T, Ivy SP, et al Management of cardiac toxicity in patients receiving vascular endothelial growth factor signaling pathway inhibitors. Am Heart J 2012; 163:156-63. 
19. Eschenhagen T, Force T, Ewer MS, de Keulenaer GW, Suter TM, Anker SD, et al. Cardiovascular side effects of cancer therapies: a position statement from the Heart Failure Association of the European Society of Cardiology. Eur J Heart Fail 2011;13:1-10.

20. Lang RM, Bierig M, Devereux RB, Flachskampf FA, Foster E, Pellikka PA, et al. Recommendations for chamber quantification: a report from the American Society of Echocardiography's Guidelines and Standards Committee and the Chamber Quantification Writing Group, developed in conjunction with the European Association of Echocardiography, a branch of the European Society of Cardiology. J Am Soc Echocardiogr 2005; 18:1440-63.

21. Isner JM, Ferrans VJ, Cohen SR, Witkind BG, Virmani R, Gottdiener JS, et al. Clinical and morphologic cardiac findings after anthracycline chemotherapy. Analysis of 64 patients studied at necropsy. Am J Cardiol 1983;51:1167-74.

22. Muraru D, Badano LP, Peluso D, Dal Bianco L, Casablanca S, Kocabay G, et al. Comprehensive analysis of left ventricular geometry and function by three-dimensional echocardiography in healthy adults. I Am Soc Echocardiogr 2013;26:618-28.

23. Rietzschel ER, De Buyzere ML, Bekaert S, Segers P, De Bacquer D, Cooman L, et al. Rationale, design, methods and baseline characteristics of the Asklepios Study. Eur J Cardiovasc Prev Rehabil 2007;14:179-91.

24. Kuznetsova T, Herbots L, Lopez B, Jin Y, Richart T, Thijs L, et al. Prevalence of left ventricular diastolic dysfunction in a general population. Circ Heart Fail 2009;2:105-12.

25. Friedman GD, Cutter GR, Donahue RP, Hughes GH, Hulley SB, Jacobs DR Jr, et al. CARDIA: study design, recruitment, and some char acteristics of the examined subjects. J Clin Epidemiol 1988;41:1105-16.

26. Lancellotti P, Badano LP, Lang RM, Akhaladze N, Athanassopoulos GD, Barone D, et al. Normal Reference Ranges for Echocardiography: rationale, study design, and methodology (NORRE Study). Eur Heart J Cardiovasc Imaging 2013;14:303-8.

27. Bountioukos M, Doorduijn JK, Roelandt JR, Vourvouri EC, Bax JJ, Schinkel AF, et al. Repetitive dobutamine stress echocardiography for the prediction of anthracycline cardiotoxicity. Eur J Echocardiogr 2003; 4:300-5.

28. Ryberg M, Nielsen D, Skovsgaard T, Hansen J, Jensen BV Dombernowsky P. Epirubicin cardiotoxicity: an analysis of 469 patients with metastatic breast cancer. J Clin Oncol 1998;16:3502-8.

29. Nielsen D, Jensen JB, Dombernowsky P, Munck O, Fogh J, Brynjolf I, et al. Epirubicin cardiotoxicity: a study of 135 patients with advanced breast cancer. J Clin Oncol 1990;8:1806-10.

30. Swain SM, Whaley FS, Ewer MS. Congestive heart failure in patients treated with doxorubicin: a retrospective analysis of three trials. Cancer 2003;97:2869-79.

31. Mitani I, Jain D, Joska TM, Burtness B, Zaret BL. Doxorubicin cardiotoxicity: prevention of congestive heart failure with serial cardiac function monitoring with equilibrium radionuclide angiocardiography in the current era. J Nucl Cardiol 2003; 10:132-9.

32. Nousiainen T, Jantunen E, Vanninen E, Hartikainen J. Early decline in left ventricular ejection fraction predicts doxorubicin cardiotoxicity in lymphoma patients. Br J Cancer 2002;86:1697-700.

33. Schwartz RG, McKenzie WB, Alexander I, Sager P, D'Souza A, Manatunga A, et al. Congestive heart failure and left ventricular dysfunc tion complicating doxorubicin therapy. Seven-year experience using serial radionuclide angiocardiography. Am J Med 1987;82:1109-18.

34. Jensen BV, Skovsgaard T, Nielsen SL. Functional monitoring of anthracycline cardiotoxicity: a prospective, blinded, long-term observational study of outcome in 120 patients. Ann Oncol 2002;13:699-709.

35. Steinherz LJ, Steinherz PG, Tan CT, Heller G, Murphy ML. Cardiac toxicity 4 to 20 years after completing anthracycline therapy. JAMA 1991;266:1672-7.

36. Moja L, Tagliabue L, Balduzzi S, Parmelli E, Pistotti V, Guarneri V, et al. Trastuzumab containing regimens for early breast cancer. Cochrane Database Syst Rev 2012;4:CD006243.
37. Seidman A, Hudis C, Pierri MK, Shak S, Paton V, Ashby M, et al. Cardiac dysfunction in the trastuzumab clinical trials experience. J Clin Oncol 2002;20:1215-21.

38. Youssef $G$, Links $M$. The prevention and management of cardiovascular complications of chemotherapy in patients with cancer. Am J Cardiovasc Drugs 2005;5:233-43.

39. Keefe DL. Trastuzumab-associated cardiotoxicity. Cancer 2002;95: 1592-600.

40. Schuchter LM, Hensley ML, Meropol NJ, Winer EP. American Society of Clinical Oncology Chemotherapy and Radiotherapy Expert Panel. 2002 update of recommendations for the use of chemotherapy and radiotherapy protectants: clinical practice guidelines of the American Society of Clinical Oncology. J Clin Oncol 2002;20:2895-903.

41. Carver JR, Shapiro CL, Ng A, Jacobs L, Schwartz C, Virgo KS, et al. American Society of Clinical Oncology clinical evidence review on the ongoing care of adult cancer survivors: cardiac and pulmonary late effects. J Clin Oncol 2007; 25:3991-4008.

42. Jacobs LD, Salgo IS, Goonewardena S, Weinert L, Coon P, Bardo D, et al. Rapid online quantification of left ventricular volume from real-time three-dimensional echocardiographic data. Eur Heart J 2006;27:460-8.

43. Otterstad JE, Froeland G, St John Sutton M, Holme I. Accuracy and reproducibility of biplane two-dimensional echocardiographic measurements of left ventricular dimensions and function. Eur Heart J 1997;18: 507-13.

44. Thavendiranathan P, Grant AD, Negishi T, Plana JC, Popovic ZB, Marwick TH. Reproducibility of echocardiographic techniques for sequential assessment of left ventricular ejection fraction and volumes: application to patients undergoing cancer chemotherapy. J Am Coll Cardiol 2013;61:77-84.

45. Ewer MS, Ewer SM. Long-term cardiac safety of dose-dense anthracycline therapy cannot be predicted from early ejection fraction data. ] Clin Oncol 2009;27:6073-5.

46. Karakurt C, Kocak G, Ozgen U. Evaluation of the left ventricular function with tissue tracking and tissue Doppler echocardiography in pediatric malignancy survivors after anthracycline therapy. Echocardiography 2008;25:880-7.

47. Ganame J, Claus P, Eyskens B, Uyttebroeck A, Renard M, D'hooge J, et al. Acute cardiac functional and morphological changes after Anthracycline infusions in children. Am J Cardiol 2007;99:974-7.

48. Tassan-Mangina S, Codorean D, Metivier M, Costa B, Himberlin C, Jouannaud C, et al. Tissue Doppler imaging and conventional echocardiography after anthracycline treatment in adults: early and late alterations of left ventricular function during a prospective study. Eur J Echocardiogr 2006;7:141-6.

49. Kapusta L, Thijssen JM, Groot-Loonen I, Antonius T, Mulder J, Daniels $\mathrm{O}$. Tissue Doppler imaging in detection of myocardial dysfunc tion in survivors of childhood cancer treated with anthracyclines. Ultrasound Med Biol 2000;26:1099-108.

50. Nagueh SF, Appleton CP, Gillebert TC, Marino PN, Oh JK, Smiseth OA, et al. Recommendations for the evaluation of left ventricular diastolic function by echocardiography. Eur J Echocardiogr 2009;10:165-93.

51. Mason JW, Bristow MR, Billingham ME, Daniels JR. Invasive and non invasive methods of assessing Adriamycin cardiotoxic effects in man: superiority of histiopathologic assessment using endomyocardial biopsy. Cancer Treat Rep 1978;62:857-64.

52. Tanindi A, Demirci U, Tacoy G, Buyukberber S, Alsancak Y, Coskun U, et al. Assessment of right ventricular functions during cancer chemotherapy. Eur J Echocardiogr 2011;12:834-40.

53. Rudski LG, Lai WW, Afilalo I, Hua L, Handschumacher MD, Chandrasekaran K, et al. Guidelines for the echocardiographic assess ment of the right heart in adults: a report from the American Society of Echocardiography endorsed by the European Association of Echocardiography, a registered branch of the European Society of Cardiology, and the Canadian Society of Echocardiography. J Am Soc Echocardiogr 2010;23:685-713: quiz 786-8. 
54. Montani D, Bergot E, Gunther S, Savale L, Bergeron A, Bourdin A, et al. Pulmonary arterial hypertension in patients treated by dasatinib. Circulation 2012;125:2128-37.

55. Bansal RC. Infective endocarditis. Med Clin North Am 1995;79: 1205-40.

56. Roberts WC. The congenitally bicuspid aortic valve. A study of 85 autopsy cases. Am J Cardiol 1970;26:72-83.

57. Freed LA, Levy D, Levine RA, Larson MG, Evans JC, Fuller DL, et al Prevalence and clinical outcome of mitral-valve prolapse. N Engl J Med 1999;341:1-7.

58. Lancellotti P, Nkomo VT, Badano LP, Bergler J, Bogaert J, Davin L, et al. Expert consensus for multi-modality imaging evaluation of cardiovascular complications of radiotherapy in adults: a report from the European Association of Cardiovascular Imaging and the American Society of Echocardiography. Eur Heart J Cardiovasc Imaging 2013;14:721-40.

59. Edoute Y, Haim N, Rinkevich D, Brenner B, Reisner SA. Cardiac valvular vegetations in cancer patients: a prospective echocardiographic study of 200 patients. Am J Med 1997; 102:252-8.

60. Eiken PW, Edwards WD, Tazelaar HD, McBane RD, Zehr KJ. Surgical pathology of nonbacterial thrombotic endocarditis in 30 patients, 1985-2000. Mayo Clin Proc 2001;76:1204-12.

61. Hamza A, Tunick PA, Kronzon I. Echocardiographic manifestations of complications of radiation therapy. Echocardiography 2009;26:724-8.

62. Heidenreich PA, Kapoor JR. Radiation induced heart disease: systemic disorders in heart disease. Heart 2009;95:252-8.

63. Heidenreich PA, Hancock SL, Lee BK, Mariscal CS, Schnittger I. Asymptomatic cardiac disease following mediastinal irradiation. J Am Coll Cardiol 2003;42:743-9.

64. Tomlinson D, Mermel LA, Ethier MC, Matlow A, Gillmeister B, Sung L. Defining bloodstream infections related to central venous catheters in patients with cancer: a systematic review. Clin Infect Dis 2011;53: 697-710

65. Baumgartner H, Hung J, Bermejo J, Chambers JB, Evangelista A, Griffin BP, et al. Echocardiographic assessment of valve stenosis: EAE/ ASE recommendations for clinical practice. I Am Soc Echocardiogr 2009;22:1-23. quiz 101-2.

66. Lancellotti P, Tribouilloy C, Hagendorff A, Popescu BA, Edvardsen T, Pierard LA, et al. Recommendations for the echocardiographic assess ment of native valvular regurgitation: an executive summary from the European Association of Cardiovascular Imaging. Eur Heart J Cardiovasc Imaging 2013;14:611-44.

67. Cosyns B, Garbi M, Separovic I, Pasquet A, Lancellotti P. Education Committee of the European Association of Cardiovascular Imaging Associa tion (EACVI). Update of the Echocardiography Core Syllabus of the European Association of Cardiovascular Imaging (EACVI). Eur Heart I Cardiovasc Imaging 2013; 14:837-9.

68. Zoghbi WA, Enriquez-Sarano M, Foster E, Grayburn PA, Kraft CD, Levine RA, et al. Recommendations for evaluation of the severity of native valvular regurgitation with two-dimensional and Doppler echocardiography. J Am Soc Echocardiogr 2003;16:777-802.

69. Mugge A, Daniel WG, Frank G, Lichtlen PR. Echocardiography in infective endocarditis: reassessment of prognostic implications of vegetation size determined by the transthoracic and the transesophageal approach. J Am Coll Cardiol 1989;14:631-8.

70. Klein AL, Abbara S, Agler DA, Appleton CP, Asher CR, Hoit B, et al. American society of echocardiography clinical recommendations for multimodality cardiovascular imaging of patients with pericardial disease endorsed by the society for cardiovascular magnetic resonance and society of cardiovascular computed tomography. J Am Soc Echocardiogr 2013;26:965-1012. e15.

71. Bonow RO, Carabello BA, Chatterjee K, de Leon AC Jr., Faxon DP, Freed MD, et al. 2008 focused update incorporated into the ACC/ AHA 2006 guidelines for the management of patients with valvular heart disease: a report of the American College of Cardiology/American Heart Association Task Force on Practice Guidelines (Writing Committee to revise the 1998 guidelines for the management of patients with valvular heart disease). Endorsed by the Society of Cardiovascular Anesthesiolo- gists, Society for Cardiovascular Angiography and Interventions, and Society of Thoracic Surgeons. J Am Coll Cardiol 2008;52:e1-142.

72. Joint Task Force on the Management of Valvular Heart Disease of the European Society of Cardiology (ESC), European Association for Cardio-Thoracic Surgery (EACTS)Vahanian A, Alfieri O, Andreotti F, Antunes MJ, et al. Guidelines on the management of valvular heart disease (version 2012). Eur Heart I 2012;33:2451-96.

73. Morton DL, Glancy DL, Joseph WL, Adkins PC. Management of patients with radiation-induced pericarditis with effusion: a note on the development of aortic regurgitation in two of them. Chest 1973;64:291-7.

74. Gaya AM, Ashford RF. Cardiac complications of radiation therapy. Clin Oncol (R Coll Radiol) 2005;17:153-9.

75. Krupicka J, Markova J, Pohlreich D, Kozak T, Linkova H, Diehl V, et al. Echocardiographic evaluation of acute cardiotoxicity in the treatment of Hodgkin disease according to the German Hodgkin's Lymphoma Study Group. Leuk Lymphoma 2002;43:2325-9.

76. Tohda S, Kobayashi H, Suzuki T, Koyama T, Kamiyama T, Nakamura Y, et al. Acute pericarditis caused by daunorubicin in acute myelocytic leukemia. Rinsho Ketsueki 1988;29:874-8.

77. Casey DJ, Kim AY, Olszewski AJ. Progressive pericardial effusion during chemotherapy for advanced Hodgkin lymphoma. Am J Hematol 2012; 87:521-4

78. Dazzi H, Kaufmann K, Follath F. Anthracycline-induced acute cardiotoxicity in adults treated for leukaemia. Analysis of the clinico-pathological aspects of documented acute anthracycline-induced cardiotoxicity in patients treated for acute leukaemia at the University Hospital of Zurich Switzerland, between 1990 and 1996. Ann Oncol 2001;12:963-6.

79. Katayama M, Imai Y, Hashimoto H, Kurata M, Nagai K, Tamita K, et al. Fulminant fatal cardiotoxicity following cyclophosphamide therapy. Cardiol 2009;54:330-4.

80. Santos GW, Sensenbrenner LL, Burke PJ, Colvin M, Owens AH Jr., Bias WB, et al. Marrow transplanation in man following cyclophosphamide. Transplant Proc 1971;3:400-4.

81. Gottdiener JS, Appelbaum FR, Ferrans VI, Deisseroth A, Ziegler J. Cardiotoxicity associated with high-dose cyclophosphamide therapy. Arch Intern Med 1981;141:758-63.

82. Goldberg MA, Antin JH, Guinan EC, Rappeport JM. Cyclophosphamide cardiotoxicity: an analysis of dosing as a risk factor. Blood 1986;68 1114-8.

83. Yamamoto R, Kanda Y, Matsuyama T, Oshima K, Nannya Y, Suguro M, et al. Myopericarditis caused by cyclophosphamide used to mobilize pe ripheral blood stem cells in a myeloma patient with renal failure. Bone Marrow Transplant 2000;26:685-8

84. Braverman AC, Antin JH, Plappert MT, Cook EF, Lee RT. Cyclophospha mide cardiotoxicity in bone marrow transplantation: a prospective evaluation of new dosing regimens. J Clin Oncol 1991;9:1215-23.

85. Gahler A, Hitz F, Hess U, Cerny T. Acute pericarditis and pleural effusion complicating cytarabine chemotherapy. Onkologie 2003;26:348-50.

86. Reykdal S, Sham R, Kouides P. Cytarabine-induced pericarditis: a case report and review of the literature of the cardio-pulmonary complica tions of cytarabine therapy. Leuk Res 1995; 19:141-4.

87. Yamada T, Tsurumi H, Hara T, Sawada M, Oyama M, Moriwaki H. Cytar abine-induced pericarditis. Rinsho Ketsueki 1998;39:1115-20.

88. Hermans C, Straetmans N, Michaux JL, Ferrant A. Pericarditis induced by high-dose cytosine arabinoside chemotherapy. Ann Hematol 1997;75 55-7.

89. Vaickus L, Letendre L. Pericarditis induced by high-dose cytarabine ther apy. Arch Intern Med 1984;144:1868-9.

90. Barton JC, Jones SC, Lamberth WC, Reymann MT, Scott VC. Cardiac tamponade associated with imatinib mesylate therapy of chronic myelogenous leukemia. Am J Hematol 2002;71:139-40.

91. Breccia M, D'Elia GM, D'Andrea M, Latagliata R, Alimena G. Pleuralpericardic effusion as uncommon complication in CML patients treated with Imatinib. Eur J Haematol 2005;74:89-90.

92. Breccia M, Alimena G. Pleural/pericardic effusions during dasatinib treatment: incidence, management and risk factors associated to their devel opment. Expert Opin Drug Saf 2010;9:713-21. 
93. Krauth MT, Herndlhofer S, Schmook MT, Mitterbauer-Hohendanner G, Schlogl E, Valent P. Extensive pleural and pericardial effusion in chronic myeloid leukemia during treatment with dasatinib at $100 \mathrm{mg}$ or $50 \mathrm{mg}$ daily. Haematologica 2011;96:163-6.

94. Rauw J, Ahmed S, Petrella T. Pericardial effusion and tamponade following interferon alpha treatment for locally advanced melanoma. Med Oncol 2012;29:1304-7.

95. Cervera Miguel JI, Vallalta M, Iranzo E, Navarro Ibanez V. Pericardial effusion associated with interferon therapy. Med Clin (Barc) 2004;122 636-7.

96. Velasco J, Orinuela I, Sanjuan AZ, Ortiz de Zarate Z. Pericardial effusion associated to interferon in an immunocompetent patient. Enferm Infecc Microbiol Clin 2010;28:749-50.

97. Wisniewski B, Denis J, Fischer D, Labayle D. Pericarditis secondary to interferon alpha in chronic hepatitis C. Gastroenterol Clin Biol 2004, 28:315-6.

98. Popescu C, Arama V, Gliga S. Acute pericarditis due to pegylated interferon alpha therapy for chronic HCV hepatitis - case report. BMC Gas troenterol 2011;11:30-230. X-11-30.

99. Tallman MS, Andersen JW, Schiffer CA, Appelbaum FR, Feusner JH Ogden A, et al. All-trans-retinoic acid in acute promyelocytic leukemia. N Engl J Med 1997;337:1021-8.

100. Frankel SR, Eardley A, Lauwers G, Weiss M, Warrell RP Jr. The "retinoic acid syndrome" in acute promyelocytic leukemia. Ann Intern Med 1992 117:292-6.

101. Terpstra W, de Maat CE. Pericardial fibrosis following busulfan treatment Neth J Med 1989;35:249-52.

102. Forbat LN, Hancock BW, Gershlick AH. Methotrexate-induced pericarditis and pericardial effusion; first reported case. Postgrad Med J 1995;71: 244-5.

103. Savoia F, Gaddoni G, Casadio C, Patrizi A, Spadola G, Bassi P, et al. A case of aseptic pleuropericarditis in a patient with chronic plaque psoriasis under methotrexate therapy. Dermatol Online J 2010;16:13.

104. Mohyuddin T, Elyan M, Kushner I. Pericarditis: a rare complication of methotrexate therapy. Clin Rheumatol 2007;26:2157-8.

105. Palungwachira $P$, Palungwachira $P$, Laohathai P. Methotrexate induced pericarditis and pericardial effusion in psoriatic patient. J Med Assoc Thai 1998;81:141-5.

106. Huang SY, Chang CS, Tang JL, Tien HF, Kuo TL, Huang SF, et al. Acute and chronic arsenic poisoning associated with treatment of acute promyelocytic leukaemia. Br J Haematol 1998;103:1092-5.

107. Ueda K, Nagai S, Miyashita SI, Kaise T, Ichikawa M, Kumano K, et al. Arsenic-induced pericardial and pleural effusion without acute promye locytic leukemia differentiation syndrome. Leuk Res 2010;34:e25-6.

108. Calik AN, Celiker E, Velibey Y, Cagdas M, Guzelburc O. Initial dose effect of 5-fluorouracil: rapidly improving severe, acute toxic myopericar ditis. Am J Emerg Med 2012;30:257.e1-3.

109. Vincenzi B, Santini D, Frezza AM, Rocci L, Tonini G. Docetaxel induced pericardial effusion. J Exp Clin Cancer Res 2007;26:417-20.

110. Maisch B, Seferovic PM, Ristic AD, Erbel R, Rienmuller R, Adler Y, et al Guidelines on the diagnosis and management of pericardial diseases executive summary; The Task force on the diagnosis and management of pericardial diseases of the European society of cardiology. Eur Heart ] 2004;25:587-610.

111. Appleton CP, Hatle LK, Popp RL. Cardiac tamponade and pericardial effusion: respiratory variation in transvalvular flow velocities studied by Doppler echocardiography. J Am Coll Cardiol 1988;11:1020-30.

112. Pepi M, Muratori M. Echocardiography in the diagnosis and management of pericardial disease. J Cardiovasc Med 2006;7:533-44.

113. Wann S, Passen E. Echocardiography in pericardial disease. J Am Soc Echocardiogr 2008;21:7-13.

114. Applefeld MM, Cole JF, Pollock SH, Sutton FJ, Slawson RG, Singleton RT, et al. The late appearance of chronic pericardial disease in patients treated by radiotherapy for Hodgkin's disease. Ann Intern Med 1981;94:338-41.

115. Kane GC, Edie RN, Mannion JD. Delayed appearance of effusiveconstrictive pericarditis after radiation for Hodgkin lymphoma. Ann Intern Med 1996;124:534-5.
116. Tulleken JE, Kooiman CG, van der Werf TS, Zijlstra JG, de Vries EG. Constrictive pericarditis after high-dose chemotherapy. Lancet 1997; 350:1601.

117. Oki T, Tabata T, Yamada H, Abe M, Onose Y, Wakatsuki T, et al. Right and left ventricular wall motion velocities as diagnostic indicators of constrictive pericarditis. Am J Cardiol 1998;81:465-70.

118. Sengupta PP, Mohan JC, Mehta V, Arora R, Pandian NG, Khandheria BK. Accuracy and pitfalls of early diastolic motion of the mitral annulus for diagnosing constrictive pericarditis by tissue Doppler imaging. Am J Cardiol 2004;93:886-90.

119. Sohn DW, Kim YJ, Kim HS, Kim KB, Park YB, Choi YS. Unique features of early diastolic mitral annulus velocity in constrictive pericarditis. J Am Soc Echocardiogr 2004;17:222-6.

120. Badano LP, Boccalini F, Muraru D, Bianco LD, Peluso D, Bellu R, et al Current clinical applications of transthoracic three-dimensional echocardiography. J Cardiovasc Ultrasound 2012;20:1-22.

121. Armstrong GT, Plana JC, Zhang N, Srivastava D, Green DM, Ness KK, et al. Screening adult survivors of childhood cancer for cardiomyopathy: comparison of echocardiography and cardiac magnetic resonance imaging. J Clin Oncol 2012;30:2876-84.

122. Jenkins C, Moir S, Chan J, Rakhit D, Haluska B, Marwick TH. Left ventric ular volume measurement with echocardiography: a comparison of left ventricular opacification, three-dimensional echocardiography, or both with magnetic resonance imaging. Eur Heart J 2009;30:98-106.

123. King DL, Harrison MR, King DL Jr., Gopal AS, Kwan OL, DeMaria AN Ultrasound beam orientation during standard two-dimensional imaging: assessment by three-dimensional echocardiography. J Am Soc Echocar diogr 1992;5:569-76.

124. Cannesson M, Tanabe M, Suffoletto MS, McNamara DM, Madan S, Lacomis JM, et al. A novel two-dimensional echocardiographic image analysis system using artificial intelligence-learned pattern recognition for rapid automated ejection fraction. J Am Coll Cardiol 2007;49: 217-26.

125. Muraru D, Badano LP, Piccoli G, Gianfagna P, Del Mestre L, Ermacora D, et al. Validation of a novel automated border-detection algorithm for rapid and accurate quantitation of left ventricular volumes based on three-dimensional echocardiography. Eur J Echocardiogr 2010;11 359-68.

126. Mor-Avi V, Lang RM. Is echocardiography reliable for monitoring the adverse cardiac effects of chemotherapy? J Am Coll Cardiol 2013;61:85-7.

127. Tsang W, Kenny C, Adhya S, Kapetanakis S, Weinert L, Lang RM, et al. Interinstitutional measurements of left ventricular volumes, speckletracking strain, and dyssynchrony using three-dimensional echocardiog raphy. J Am Soc Echocardiogr 2013;26:1253-7.

128. Yu EH, Sloggett CE, Iwanochko RM, Rakowski H, Siu SC. Feasibility and accuracy of left ventricular volumes and ejection fraction determination by fundamental, tissue harmonic, and intravenous contrast imaging in difficult-to-image patients. J Am Soc Echocardiogr 2000;13:216-24.

129. Mulvagh SL, Rakowski H, Vannan MA, Abdelmoneim SS, Becher H Bierig SM, et al. American Society of Echocardiography Consensus Statement on the Clinical Applications of Ultrasonic Contrast Agents in Echocardiography. J Am Soc Echocardiogr 2008;21:1179-201 : quiz 1281.

130. Senior R, Becher $H$, Monaghan M, Agati L, Zamorano J, Vanoverschelde JL, et al. Contrast echocardiography: evidence-based recommendations by European Association of Echocardiography. Eur J Echocardiogr 2009; 10:194-212.

131. Douglas PS, Carr JJ, Cerqueira MD, Cummings JE, Gerber TC, Mukherjee D, et al. Developing an action plan for patient radiation safety in adult cardiovascular medicine: proceedings from the Duke University Clinical Research Institute/American College of Cardiology Foundation/ American Heart Association Think Tank held on February 28, 2011. J Am Coll Cardiol 2012;59:1833-47.

132. Yeh ETH, Bickford CL. Cardiovascular Complications of Cancer Therapy: Incidence, Pathogenesis, Diagnosis, and Management. J Am Coll Cardiol 2009;53:2231-47.

133. Jarfelt M, Kujacic V, Holmgren D, Bjarnason R, Lannering B. Exercise echocardiography reveals subclinical cardiac dysfunction in young adult 
survivors of childhood acute lymphoblastic leukemia. Pediatr Blood Cancer 2007;49:835-40.

134. De Wolf D, Suys B, Maurus R, Benoit Y, Verhaaren H, Matthijs D, et al. Dobutamine stress echocardiography in the evaluation of late anthracycline cardiotoxicity in childhood cancer survivors. Pediatr Res 1996;39: 504-12.

135. De Wolf D, Suys B, Verhaaren H, Matthys D, Taeymans Y. Low-dose dobutamine stress echocardiography in children and young adults. Am I Cardiol 1998;81:895-901.

136. Cottin Y, L'huillier I, Casasnovas O, Geoffroy C, Caillot D, Zeller M, et al. Dobutamine stress echocardiography identifies anthracycline cardiotoxicity. Eur J Echocardiogr 2000;1:180-3.

137. Lanzarini L, Bossi G, Laudisa ML, Klersy C, Arico M. Lack of clinically significant cardiac dysfunction during intermediate dobutamine doses in long-term childhood cancer survivors exposed to anthracyclines. Am Heart J 2000; 140:315-23.

138. Elbl L, Hrstkova H, Chaloupka V, Novotny J, Michalek J. The evaluation of left ventricular function in childhood cancer survivors by pharmacological stress echocardiography. Neoplasma 2003;50:191-7.

139. Hamada H, Ohkubo T, Maeda M, Ogawa S. Evaluation of cardiac reserved function by high-dose dobutamine-stress echocardiography in asymptomatic anthracycline-treated survivors of childhood cancer. Pediatr Int 2006;48:313-20.

140. Civelli M, Cardinale D, Martinoni A, Lamantia G, Colombo N, Colombo A, et al. Early reduction in left ventricular contractile reserve detected by dobutamine stress echo predicts high-dose chemotherapyinduced cardiac toxicity. Int I Cardiol 2006;111:120-6.

141. Grosu A, Bombardini T, Senni M, Duino V, Gori M, Picano E. End-systolic pressure/volume relationship during dobutamine stress echo: a prognostically useful non-invasive index of left ventricular contractility. Eur Heart J 2005;26:2404-12.

142. Tan-Chiu E, Yothers G, Romond E, Geyer CE Jr., Ewer M, Keefe D, et al. Assessment of cardiac dysfunction in a randomized trial comparing doxorubicin and cyclophosphamide followed by paclitaxel, with or without trastuzumab as adjuvant therapy in node-positive, human epidermal growth factor receptor 2-overexpressing breast cancer: NSABP B-31. J Clin Oncol 2005;23:7811-9.

143. Cardinale D, Colombo A, Lamantia G, Colombo N, Civelli M, De Giacomi G, et al. Anthracycline-induced cardiomyopathy: clinical relevance and response to pharmacologic therapy. J Am Coll Cardiol 2010;55:213-20.

144. Stoddard MF, Seeger J, Liddell NE, Hadley TJ, Sullivan DM, Kupersmith J. Prolongation of isovolumetric relaxation time as assessed by Doppler echocardiography predicts doxorubicin-induced systolic dysfunction in humans. J Am Coll Cardiol 1992;20:62-9.

145. Dorup I, Levitt G, Sullivan I, Sorensen K. Prospective longitudinal assessment of late anthracycline cardiotoxicity after childhood cancer: the role of diastolic function. Heart 2004;90:1214-6.

146. Eidem BW, Sapp BG, Suarez CR, Cetta F. Usefulness of the myocardial performance index for early detection of anthracycline-induced cardiotoxicity in children. Am J Cardiol $2001 ; 87: 1120-2$. A9.

147. Ishii M, Tsutsumi T, Himeno W, Eto G, Furui J, Hashino K, et al. Sequential evaluation of left ventricular myocardial performance in children after anthracycline therapy. Am J Cardiol 2000;86:1279-81. A9.

148. Rohde LE, Baldi A, Weber C, Geib G, Mazzotti NG, Fiorentini M, et al. Tei index in adult patients submitted to adriamycin chemotherapy: failure to predict early systolic dysfunction. Diagnosis of adriamycin cardiotoxicity. Int J Cardiovasc Imaging 2007;23:185-91.

149. Pellicori P, Calicchia A, Lococo F, Cimino G, Torromeo C. Subclinical an thracycline cardiotoxicity in patients with acute promyelocytic leukemia in long-term remission after the AIDA protocol. Congest Heart Fail 2012; 18:217-21.

150. Ho E, Brown A, Barrett P, Morgan RB, King G, Kennedy MJ, et al. Subclinical anthracycline- and trastuzumab-induced cardiotoxicity in the long-term follow-up of asymptomatic breast cancer survivors: a speckle tracking echocardiographic study. Heart 2010;96:701-7.
151. Nagy AC, Tolnay E, Nagykalnai T, Forster T. Cardiotoxicity of anthracycline in young breast cancer female patients: the possibility of detection of early cardiotoxicity by TDI. Neoplasma 2006;53:511-7.

152. Nagy AC, Cserep Z, Tolnay E, Nagykalnai T, Forster T. Early diagnosis of chemotherapy-induced cardiomyopathy: a prospective tissue Doppler imaging study. Pathol Oncol Res 2008;14:69-77.

153. Sawaya H, Sebag IA, Plana JC, Januzzi JL, Ky B, Cohen V, et al. Early detection and prediction of cardiotoxicity in chemotherapy-treated patients. Am J Cardiol 2011;107:1375-80.

154. Ganame J, Claus P, Uyttebroeck A, Renard M, D'hooge J, Bijnens B, et al. Myocardial dysfunction late after low-dose anthracycline treatment in asymptomatic pediatric patients. J Am Soc Echocardiogr 2007;20 $1351-8$.

155. Negishi K, Negishi T, Hare JL, Haluska BA, Plana JC, Marwick TH. Independent and incremental value of deformation indices for prediction of trastuzumab-induced cardiotoxicity. J Am Soc Echocardiogr 2013;26: 493-8.

156. Fallah-Rad N, Walker JR, Wassef A, Lytwyn M, Bohonis S, Fang T, et al The utility of cardiac biomarkers, tissue velocity and strain imaging, and cardiac magnetic resonance imaging in predicting early left ventricular dysfunction in patients with human epidermal growth factor receptor II-positive breast cancer treated with adjuvant trastuzumab therapy. I Am Coll Cardiol 2011;57:2263-70.

157. Thavendiranathan P, Poulin F, Lim KD, Plana JC, Woo A, Marwick TH Use of Myocardial Strain Imaging by Echocardiography for the Early Detection of Cardiotoxicity in Patients During and After Cancer Chemotherapy: A Systematic Review. J Am Coll Cardiol 2014;63: 2751-68.

158. Jurcut R, Wildiers H, Ganame J, D'hooge J, De Backer J, Denys H, et al Strain rate imaging detects early cardiac effects of pegylated liposomal Doxorubicin as adjuvant therapy in elderly patients with breast cancer J Am Soc Echocardiogr 2008;21:1283-9.

159. Poterucha JT, Kutty S, Lindquist RK, Li L, Eidem BW. Changes in left ventricular longitudinal strain with anthracycline chemotherapy in adolescents precede subsequent decreased left ventricular ejection fraction. I Am Soc Echocardiogr 2012;25:733-40.

160. Sawaya H, Sebag IA, Plana JC, Januzzi JL, Ky B, Tan TC, et al. Assessment of echocardiography and biomarkers for the extended prediction of cardiotoxicity in patients treated with anthracyclines, taxanes, and trastuzumab. Circ Cardiovasc Imaging 2012;5:596-603.

161. Stoodley PW, Richards DA, Hui R, Boyd A, Harnett PR, Meikle SR, et al. Two-dimensional myocardial strain imaging detects changes in left ventricular systolic function immediately after anthracycline chemotherapy. Eur J Echocardiogr 2011;12:945-52.

162. Hare JL, Brown JK, Leano R, Jenkins C, Woodward N, Marwick TH. Use of myocardial deformation imaging to detect preclinical myocardial dysfunction before conventional measures in patients undergoing breast cancer treatment with trastuzumab. Am Heart J 2009;158:294-301.

163. Cheung YF, Hong WJ, Chan GC, Wong SJ, Ha SY. Left ventricular myocardial deformation and mechanical dyssynchrony in children with normal ventricular shortening fraction after anthracycline therapy. Heart 2010;96:1137-41.

164. Tsai HR, Gjesdal O, Wethal T, Haugaa KH, Fossa A, Fossa SD, et al. Left ventricular function assessed by two-dimensional speckle tracking echocardiography in long-term survivors of Hodgkin's lymphoma treated by mediastinal radiotherapy with or without anthracycline therapy. Am J Cardiol 2011;107:472-7.

165. Kocabay G, Muraru D, Peluso D, Cucchini U, Mihaila S, Padayattil-Jose S, et al. Normal left 1 ventricular mechanics by two-dimensional speckle tracking echocardiography. Reference values in healthy adults. Rev Esp Cardiol 2014.

166. Takigiku K, Takeuchi M, Izumi C, Yuda S, Sakata K, Ohte N, et al. Normal range of left ventricular 2-dimensional strain: Japanese Ultrasound Speckle Tracking of the Left Ventricle (JUSTICE) study. Circ J 2012;76: 2623-32. 
167. Kuznetsova T, Herbots L, Richart T, D'hooge J, Thijs L, Fagard RH, et al Left ventricular strain and strain rate in a general population. Eur Heart ] 2008;29:2014-23.

168. Cheng S, Larson MG, McCabe EL, Osypiuk E, Lehman BT, Stanchev P, et al. Reproducibility of Speckle-Tracking-Based Strain Measures of Left Ventricular Function in a Community-Based Study. J Am Soc Echocar diogr 2013;26:1258-12662.

169. Risum N, Ali S, Olsen NT, Jons C, Khouri MG, Lauridsen TK, et al. Variability of global left ventricular deformation analysis using vendor dependent and independent two-dimensional speckle-tracking software in adults. J Am Soc Echocardiogr 2012;25:1195-203.

170. A Unique Collaboration to Advance Strain Imaging. Journal of the American Society of Echocardiography 2013;26:A21-2.

171. Cardinale D, Sandri MT. Role of biomarkers in chemotherapy-induced cardiotoxicity. Prog Cardiovasc Dis 2010;53:121-9.

172. Reichlin T, Hochholzer W, Bassetti S, Steuer S, Stelzig C, Hartwiger S, et al. Early diagnosis of myocardial infarction with sensitive cardiac troponin assays. N Engl J Med 2009;361:858-67.

173. Wright RS, Anderson JL, Adams CD, Bridges CR, Casey DE Jr. Ettinger SM, et al. 2011 ACCF/AHA focused update incorporated into the ACC/AHA 2007 Guidelines for the Management of Patients with Unstable Angina/Non-ST-Elevation Myocardial Infarction: a report of the American College of Cardiology Foundation/American Heart Association Task Force on Practice Guidelines developed in collaboration with the American Academy of Family Physicians, Society for Cardiovascular Angiography and Interventions, and the Society of Thoracic Surgeons. J Am Coll Cardiol 2011;57:e215-367.

174. Cardinale D, Sandri MT, Colombo A, Colombo N, Boeri M, Lamantia G, et al. Prognostic value of troponin I in cardiac risk stratification of cancer patients undergoing high-dose chemotherapy. Circulation 2004;109: 2749-54.

175. Auner HW, Tinchon C, Linkesch W, Tiran A, Quehenberger F, Link H, et al. Prolonged monitoring of troponin T for the detection of anthracy cline cardiotoxicity in adults with hematological malignancies. Ann Hematol 2003;82:218-22.

176. Specchia G, Buquicchio C, Pansini N, Di Serio F, Liso V, Pastore D, et al. Monitoring of cardiac function on the basis of serum troponin I levels in patients with acute leukemia treated with anthracyclines. J Lab Clin Med 2005:145:212-20.

177. Kilickap S, Barista I, Akgul E, Aytemir K, Aksoyek S, Aksoy S, et al. cTnT can be a useful marker for early detection of anthracycline cardiotoxicity. Ann Oncol 2005; 16:798-804.

178. Cardinale D, Colombo A, Torrisi R, Sandri MT, Civelli M, Salvatici M, et al. Trastuzumab-induced cardiotoxicity: clinical and prognostic impli cations of troponin I evaluation. J Clin Oncol 2010;28:3910-6.

179. Morris PG, Chen C, Steingart R, Fleisher M, Lin N, Moy B, et al. Troponin I and C-reactive protein are commonly detected in patients with breast cancer treated with dose-dense chemotherapy incorporating trastuzumab and lapatinib. Clin Cancer Res 2011;17:3490-9.

180. Schmidinger M, Zielinski CC, Vogl UM, Bojic A, Bojic M, Schukro C, et al. Cardiac toxicity of sunitinib and sorafenib in patients with metastatic renal cell carcinoma. J Clin Oncol 2008;26:5204-12.

181. Ederhy S, Massard C, Dufaitre G, Balheda R, Meuleman C, Rocca CG, et al. Frequency and management of troponin I elevation in patients treated with molecular targeted therapies in phase I trials. Invest New Drugs 2012;30:611-5.

182. Lenihan DJ, Massey MR, Baysinger KB, Adorno CL, Warneke CL, Steinert D, et al. Superior Detection of Cardiotoxicity during Chemotherapy Using Biomarkers. J Card Fail 2007;13:S151.

183. Romano S, Fratini S, Ricevuto E, Procaccini V, Stifano G, Mancini M, et al. Serial measurements of NT-proBNP are predictive of not-high-dose anthracycline cardiotoxicity in breast cancer patients. Br J Cancer 2011 105:1663-8.

184. Dodos F, Halbsguth T, Erdmann E, Hoppe UC. Usefulness of myocardial performance index and biochemical markers for early detection of anthracycline-induced cardiotoxicity in adults. Clin Res Cardiol 2008; 97:318-26
185. Knobloch K, Tepe J, Lichtinghagen R, Luck HJ, Vogt PM. Monitoring of cardiotoxicity during immunotherapy with Herceptin using simultaneous continuous wave Doppler depending on $\mathrm{N}$-terminal pro-brain natriuretic peptide. Clin Med 2007;7:88-9. author reply 89.

186. Knobloch K, Tepe J, Rossner D, Lichtinghagen R, Luck HJ, Busch $\mathrm{KH}$, et al. Combined NT-pro-BNP and CW-Doppler ultrasound cardiac output monitoring (USCOM) in epirubicin and liposomal doxorubicin therapy. Int J Cardiol 2008;128:316-25.

187. Nousiainen T, Jantunen E, Vanninen E, Remes J, Vuolteenaho O, Hartikainen J. Natriuretic peptides as markers of cardiotoxicity during doxorubicin treatment for non-Hodgkin's lymphoma. Eur J Haematol 1999;62:135-41.

188. Fish M, Lenihan DJ. Effectiveness of using biomarkers to detect and identify cardiotoxicity and describe treatment (PREDICT). 2013;(Accessed 2014 Mar 11) http://clinicaltrials.gov/ct2/show/NCT01311843.

189. Kalam K, Marwick TH. Role of cardioprotective therapy for prevention of cardiotoxicity with chemotherapy: A systematic review and metaanalysis. Eur J Cancer 2013;49:2900-9.

190. Lipshultz SE, Rifai N, Dalton VM, Levy DE, Silverman LB, Lipsitz SR, et al. The effect of dexrazoxane on myocardial injury in doxorubicintreated children with acute lymphoblastic leukemia. N Engl J Med 2004;351:145-53.

191. van Dalen EC, Caron HN, Dickinson HO, Kremer LC. Cardioprotective interventions for cancer patients receiving anthracyclines. Cochrane Database Syst Rev 2011;CD003917.

192. Seicean S, Seicean A, Plana JC, Budd GT, Marwick TH. Effect of statin therapy on the risk for incident heart failure in patients with breast cancer receiving anthracycline chemotherapy: an observational clinical cohort study. J Am Coll Cardiol 2012;60:2384-90.

193. Acar Z, Kale A, Turgut M, Demircan S, Durna K, Demir S, et al. Efficiency of atorvastatin in the protection of anthracycline-induced cardiomyopathy. J Am Coll Cardiol 2011;58:988-9.

194. Silber JH, Cnaan A, Clark BJ, Paridon SM, Chin AJ, Rychik J, et al. Enalapril to prevent cardiac function decline in long-term survivors of pedi atric cancer exposed to anthracyclines. J Clin Oncol 2004;22:820-8.

195. Blaes AH, Gaillard P, Peterson BA, Yee D, Virnig B. Angiotensin converting enzyme inhibitors may be protective against cardiac complications following anthracycline chemotherapy. Breast Cancer Res Treat 2010; 122:585-90.

196. Seicean S, Seicean A, Alan N, Plana IC, Budd GT, Marwick TH. Cardioprotective Effect of Beta-Adrenoceptor Blockade in Breast Cancer Pa tients Undergoing Chemotherapy: A Follow-Up Study of Heart Failure. Circ Heart Fail 2013;6:420-6.

197. Kalay N, Basar E, Ozdogru I, Er O, Cetinkaya Y, Dogan A, et al. Protective effects of carvedilol against anthracycline-induced cardiomyopathy. J Am Coll Cardiol 2006;48:2258-62.

198. Nakamae H, Tsumura K, Terada Y, Nakane T, Nakamae M, Ohta K, et al. Notable effects of angiotensin II receptor blocker, valsartan, on acute cardiotoxic changes after standard chemotherapy with cyclophosphamide, doxorubicin, vincristine, and prednisolone. Cancer 2005; 104:2492-8.

199. Cadeddu C, Piras A, Mantovani G, Deidda M, Dessi M, Madeddu C, et al. Protective effects of the angiotensin II receptor blocker telmisartan on epirubicin-induced inflammation, oxidative stress, and early ventricular impairment. Am Heart J 2010;160:487.e1-7.

200. Negishi T, Negishi K, Agler D, Plana JC, Haluska B, Marwick T. Cardioprotective effect of beta-blockade during chemotherapy for breat cancer J Am Coll Cardiol 2012;59:E1248.

201. Powe DG, Entschladen F. Targeted therapies: Using beta-blockers to inhibit breast cancer progression. Nat Rev Clin Oncol 2011;8:511-2.

202. Gottdiener JS, Mathisen DJ, Borer JS, Bonow RO, Myers CE, Barr LH, et al. Doxorubicin cardiotoxicity: assessment of late left ventricular dysfunction by radionuclide cineangiography. Ann Intern Med 1981 94:430-5.

203. Choi BW, Berger HJ, Schwartz PE, Alexander J, Wackers FJ, Gottschalk A, et al. Serial radionuclide assessment of doxorubicin cardiotoxicity in can cer patients with abnormal baseline resting left ventricular performance. Am Heart J 1983;106:638-43. 
204. Palmeri ST, Bonow RO, Myers CE, Seipp C, Jenkins J, Green MV, et al Prospective evaluation of doxorubicin cardiotoxicity by rest and exercise radionuclide angiography. Am J Cardiol 1986;58:607-13.

205. Pinder MC, Duan Z, Goodwin JS, Hortobagyi GN, Giordano SH Congestive heart failure in older women treated with adjuvant anthracy cline chemotherapy for breast cancer. J Clin Oncol 2007;25:3808-15.

206. Bellenger NG, Burgess MI, Ray SG, Lahiri A, Coats AJ, Cleland JG, et al Comparison of left ventricular ejection fraction and volumes in heart failure by echocardiography, radionuclide ventriculography and cardiovas cular magnetic resonance; are they interchangeable? Eur Heart J 2000; $21: 1387-96$.

207. Naik MM, Diamond GA, Pai T, Soffer A, Siegel RJ. Correspondence of left ventricular ejection fraction determinations from two-dimensional echocardiography, radionuclide angiography and contrast cineangiography. J Am Coll Cardiol 1995;25:937-42.

208. Mogelvang I, Stokholm KH, Saunamaki K, Reimer A, Stubgaard M, Thomsen C, et al. Assessment of left ventricular volumes by magnetic resonance in comparison with radionuclide angiography, contrast angiography and echocardiography. Eur Heart J 1992;13:1677-83.

209. Jiji RS, Kramer CM, Salerno M. Non-invasive imaging and monitoring cardiotoxicity of cancer therapeutic drugs. J Nucl Cardiol 2012;19:377-88.

210. van Royen N, Jaffe CC, Krumholz HM, Johnson KM, Lynch PJ, Natale D, et al. Comparison and reproducibility of visual echocardiographic and quantitative radionuclide left ventricular ejection fractions. Am J Cardiol 1996;77:843-50.

211. Abbasi SA, Ertel A, Shah RV, Dandekar V, Chung J, Bhat G, et al. Impact of cardiovascular magnetic resonance on management and clinical decision-making in heart failure patients. J Cardiovasc Magn Reson 2013;15:89-429 X-15-89.

212. Greenwood JP, Maredia N, Younger JF, Brown JM, Nixon J, Everett CC, et al. Cardiovascular magnetic resonance and single-photon emission computed tomography for diagnosis of coronary heart disease (CEMARC): a prospective trial. Lancet 2012;379:453-60.

213. Klein C, Nekolla SG, Bengel FM, Momose M, Sammer A, Haas F, et al. Assessment of myocardial viability with contrast-enhanced magnetic resonance imaging: comparison with positron emission tomography. Circulation 2002;105:162-7.

214. Neilan TG, Coelho-Filho OR, Pena-Herrera D, Shah RV, Jerosch-Herold M, Francis SA, et al. Left ventricular mass in patients with a cardiomyopathy af ter treatment with anthracyclines. Am I Cardiol 2012;110:1679-86.

215. Smith G, Kotwinski P, Carpenter JP, Hugh M, Pennell D. Cardiovascular magnetic resonance imaging in early anthracycline cardiotoxicity. J Cardiovasc Magn Reson 2009; 11:P18.

216. Pennell DJ, Sechtem UP, Higgins CB, Manning WJ, Pohost GM, Rademakers FE, et al. Clinical indications for cardiovascular magnetic resonance (CMR): Consensus Panel report. J Cardiovasc Magn Reson 2004;6:727-65.

217. Kawel N, Turkbey EB, Carr IJ, Eng J, Gomes AS, Hundley WG, et al. Normal left ventricular myocardial thickness for middle-aged and older subjects with steady-state free precession cardiac magnetic resonance: the multiethnic study of atherosclerosis. Circ Cardiovasc Imaging 2012;5:500-8.

218. The clinical role of magnetic resonance in cardiovascular disease. Task Force of the European Society of Cardiology, in collaboration with the Association of European Paediatric Cardiologists. Eur Heart J 1998; 19:19-39.

219. Bellenger NG, Davies LC, Francis JM, Coats AJ, Pennell DJ. Reduction in sample size for studies of remodeling in heart failure by the use of cardiovascular magnetic resonance. J Cardiovasc Magn Reson 2000;2:271-8.

220. Grothues F, Smith GC, Moon JC, Bellenger NG, Collins P, Klein HU, et al. Comparison of interstudy reproducibility of cardiovascular mag netic resonance with two-dimensional echocardiography in normal subjects and in patients with heart failure or left ventricular hypertrophy. Am J Cardiol 2002;90:29-34.

221. Armstrong AC, Gidding S, Gjesdal O, Wu C, Bluemke DA, Lima JA. LV mass assessed by echocardiography and CMR, cardiovascular outcomes, and medical practice. JACC Cardiovasc Imaging 2012;5:837-48.
222. Vogel-Claussen J, Finn JP, Gomes AS, Hundley GW, Jerosch-Herold M, Pearson G, et al. Left ventricular papillary muscle mass: relationship to left ventricular mass and volumes by magnetic resonance imaging. ] Comput Assist Tomogr 2006;30:426-32

223. Alfakih K, Bloomer T, Bainbridge S, Bainbridge G, Ridgway J, Williams G, et al. A comparison of left ventricular mass between two-dimensional echocardiography, using fundamental and tissue harmonic imaging, and cardiac MRI in patients with hypertension. Eur J Radiol 2004;52:103-9.

224. Missouris CG, Forbat SM, Singer DR, Markandu ND, Underwood R MacGregor GA. Echocardiography overestimates left ventricular mass: a comparative study with magnetic resonance imaging in patients with hypertension. J Hypertens 1996;14:1005-10.

225. Goldman M, Matthews R, Meng H, Bilfinger T, Kort S. Evaluation of cardiac involvement with mediastinal lymphoma: the role of innovative integrated cardiovascular imaging. Echocardiography 2012;29: E189-92.

226. Kim RJ, Wu E, Rafael A, Chen EL, Parker MA, Simonetti O, et al. The use of contrast-enhanced magnetic resonance imaging to identify reversible myocardial dysfunction. N Engl J Med 2000;343:1445-53.

227. Perez-Rodriguez J, Lai S, Ehst BD, Fine DM, Bluemke DA. Nephrogenic systemic fibrosis: incidence, associations, and effect of risk factor assessment-report of 33 cases. Radiology 2009;250:371-7.

228. Iles L, Pfluger H, Phrommintikul A, Cherayath J, Aksit P, Gupta SN, et al. Evaluation of diffuse myocardial fibrosis in heart failure with cardiac magnetic resonance contrast-enhanced T1 mapping. J Am Coll Cardiol 2008; $52: 1574-80$

229. Ugander M, Oki AJ, Hsu LY, Kellman P, Greiser A, Aletras AH, et al. Extracellular volume imaging by magnetic resonance imaging provides insights into overt and sub-clinical myocardial pathology. Eur Heart J 2012;33:1268-78.

230. Tham E, Chow K, Spavor M, Pagano JJ, Haykowsky M, Thompson RJ Degree of diffuse fibrosis measured by MRI correlates with LV remodelling in childhood cancer survivors after anthracycline chemotherapy. I Cardiovasc Magn Reson 2011;13:P276.

231. Neilan TG, Coelho-Filho OR, Shah RV, Feng JH, Pena-Herrera D, Mandry D, et al. Myocardial extracellular volume by cardiac magnetic resonance imaging in patients treated with anthracycline-based chemotherapy. Am J Cardiol 2013;111:717-22.

232. Korinek I, Kjaergaard I, Sengupta PP, Yoshifuku S, McMahon EM, Cha SS, et al. High spatial resolution speckle tracking improves accuracy of 2-dimensional strain measurements: an update on a new method in functional echocardiography. I Am Soc Echocardiogr 2007;20: 165-70.

233. Drafts BC, Twomley KM, D'Agostino R Jr., Lawrence J, Avis N, Ellis LR, et al. Low to moderate dose anthracycline-based chemotherapy is associated with early noninvasive imaging evidence of subclinical cardiovas cular disease. JACC Cardiovasc Imaging 2013;6:877-85.

234. Mornos C, Petrescu L. Early detection of anthracycline-mediated cardiotoxicity: the value of considering both global longitudinal left ventricular strain and twist. Can J Physiol Pharmacol 2013;91:601-7.

235. Baratta S, Damiano M, Marchese M, Trucco I, Rizzo M, Bernok F, et al. Serum Markers, Conventional Doppler Echocardiography and Twodimensional Systolic Strain in the Diagnosis of Chemotherapy-Induced Myocardial Toxicity. Rev Argent Cardiol 2013;81:151-8.

236. Mavinkurve-Groothuis AM, Marcus KA, Pourier M, Loonen J, Feuth T, Hoogerbrugge PM, et al. Myocardial 2D strain echocardiography and cardiac biomarkers in children during and shortly after anthracycline therapy for acute lymphoblastic leukaemia (ALL): a prospective study. Eur Heart J Cardiovasc Imaging 2013;14:562-9.

237. Stanton T, Leano R, Marwick TH. Prediction of all-cause mortality from global longitudinal speckle strain: comparison with ejection fraction and wall motion scoring. Circ Cardiovasc Imaging 2009;2:356-64.

238. Cho GY, Marwick TH, Kim HS, Kim MK, Hong KS, Oh DJ. Global 2 dimensional strain as a new prognosticator in patients with heart failure J Am Coll Cardiol 2009;54:618-24. 